\title{
Terrestrische und semiterrestrische Ökosysteme
}

Udo Schickhoff, Annette Eschenbach

6.1 Die Naturräume der Metropolregion Hamburg - 111

6.2 Diversität der Böden in der Metropolregion Hamburg - 112

6.2.1 Die natürlichen Böden der MRH - 112

6.2.2 Urbane Böden im Hamburger Stadtgebiet - 112

6.3 Auswirkungen des Klimawandels auf Bodenökosysteme und deren Funktionen - 114

6.3.1 Einleitung - 114

6.3.2 Potenzielle Auswirkungen des Klimawandels auf den Bodenwasserhaushalt - 116

6.3.3 Potenzielle Auswirkungen des Klimawandels auf die Erosionsgefährdung - 118

6.3.4 Potenzielle Auswirkungen des Klimawandels auf die Gefährdung der Bodenverdichtung - 119

6.3.5 Potenzielle Auswirkungen des Klimawandels auf Bodenorganismen und Bodenbiodiversität - 120

6.3.6 Potenzielle Auswirkungen des Klimawandels auf die organische Substanz - 121

6.3.7 Potenzielle Auswirkungen des Klimawandels auf die Abkühlungsfunktion - 122

6.4 Auswirkungen des Klimawandels auf Arten, Lebensgemeinschaften und Ökosysteme - 122

6.4.1 Phänologie - 123

6.4.2 Ökophysiologie, Primärproduktion und Kohlenstoffspeicherung - 124

6.4.3 Biotische Interaktionen - 126

6.4.4 Arealerweiterungen und Arealverluste - 127

6.4.5 Biologische Invasionen - 129 
6.5 Auswirkungen des Klimawandels auf terrestrische und semiterrestrische Ökosysteme in der MRH - 129

6.5.1 Wälder - 129

6.5.2 Moore - 131

6.5.3 Ästuare und Küstenökosysteme - 132

6.5.4 Heiden - 134

6.5.5 Grünland - 134

6.5.6 Urbane Ökosysteme - 135

6.6 Zusammenfassung: Auswirkungen

des Klimawandels auf terrestrische

und semiterrestrische Ökosysteme in der MRH - 137

Literatur - 138 


\subsection{Die Naturräume der Metropolregion Hamburg}

Die Metropolregion Hamburg (MRH) erstreckt sich auf einer Gesamtfläche von ca. $26.000 \mathrm{~km}^{2}$ über insgesamt 19 (Land-) Kreise/kreisfreie Städte in den Bundesländern Hamburg, Schleswig-Holstein, Mecklenburg-Vorpommern und Niedersachsen. Entsprechend vielgestaltig sind die naturräumlichen Verhältnisse, die im Hinblick auf die Landschaftsentwicklung maßgeblich durch die quartären Vereisungen geprägt sind. Das Klima der MRH lässt sich in ein stärker ozeanisch geprägtes in Küstennähe und in ein weniger ozeanisch geprägtes der südöstlichen Teilgebiete differenzieren. Die Zunahme kontinentaler Klimaeinflüsse entlang eines von Nordwest nach Südost verlaufenden Gradienten kommt $u$. a. in einer um $0,4^{\circ} \mathrm{C}$ ansteigenden Jahresmitteltemperatur und einer von $831 \mathrm{~mm} /$ Jahr (Station Cuxhaven) auf $557 \mathrm{~mm} / \mathrm{Jahr}$ (Station Lüchow) zurückgehenden Niederschlagsmenge zum Ausdruck ( Abschn. 2.2.3).

Wie fast das gesamte Norddeutsche Tiefland sind auch die Naturräume der MRH ein Produkt des jüngeren Eiszeitalters, in dem die aus Norden vorstoßenden Eismassen der Saale- (310.000 bis 128.000 Jahre vor heute) und der Weichseleiszeit (115.000 bis 11.700 Jahre vor heute) Material zum Aufbau transportiert und abgelagert haben und das Relief geformt wurde. Lediglich Nordseemarschen, Flussauen und Moore sind in der Postglazialzeit hinzugekommen (Behre 2008). An den Fronten der weit nach Norddeutschland vordringenden Gletscher bildeten sich Endmoränen, denen Schwemmfächer aus Schmelzwassersanden (Sander) oder Flugsanddecken sowie breite Urstromtäler vorgelagert waren, die als Abflussbahnen für die Schmelzwassermengen fungierten. Im rückwärtigen Bereich der Endmoränen hinterließen die Gletscher nach ihrem endgültigen Abtauen die aus mitgeführtem Material bestehende flächenhaft verbreitete Grundmoräne.

Relief und oberflächennaher Untergrund der MRH lassen sich postglazial räumlich-genetisch in die größeren Einheiten Altmoränenlandschaft, Jungmoränenlandschaft und Urstromtal der Elbe gliedern (• Abb. 6.1), die eine unterschiedliche landschaftsgeschichtliche Entwicklung sowohl hinsichtlich der ursprünglichen Anlage als auch in Bezug auf die nachträgliche Überformung und Überprägung aufweisen (Benda 1995; Schipull 1999). Das Glazial- und Glazifluvialrelief der Altmoränenlandschaft, die weite Teile der Geest beiderseits des Elbtals einnimmt, wurde in der Saaleeiszeit angelegt und während der Weichseleiszeit durch Solifluktion, Kryoturbation und äolische Prozesse intensiv periglazial umgestaltet. Im Holozän erfolgte eine nur geringe Weiterentwicklung durch Verwitterung, Boden- und Moorbildung sowie fluviale Aktivität. Die den Nordosten der Region einnehmende Jungmoränenlandschaft ist in der Weichseleiszeit entstanden. Eine nachträgliche periglaziale Überprägung fehlt hier nahezu vollständig, was in abweichenden Relief- und Bodenmerkmalen ( Abschn. 6.2.1) zum Ausdruck kommt. Über das Urstromtal der Elbe wurden die gewaltigen Schmelzwassermengen abgeführt. Die im Spätglazial eingeschnittene Talsohle wurde im Holozän durch Akkumulationsprozesse überformt, die vom Anstieg des Meeresspiegels und damit verbundenem

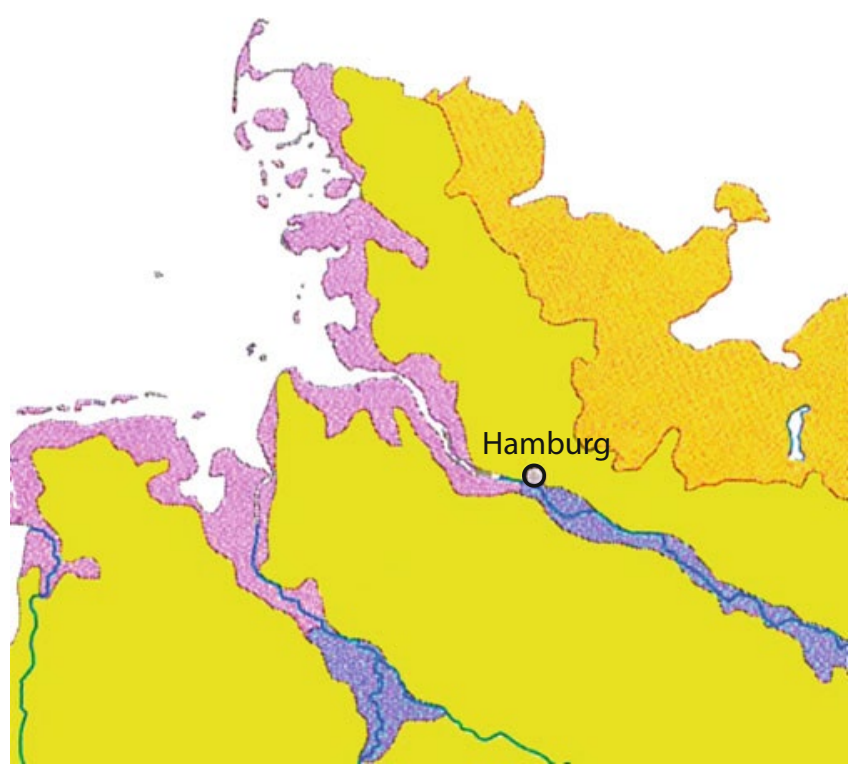

- Abb. 6.1 Die Naturräume der MRH mit der Grobgliederung in die Landschaftsräume der Jungmoräne (braun), der Altmoräne ( $\mathrm{gel}$ b), der großen Flussniederungen (blau) sowie der Marschen der Ästuare und der Nordseeküste (violett). (AG Boden 2005)

Vordringen gezeitengesteuerter perimariner Prozesse in das Elbeästuar ausgingen (Schipull 1999).

Diese im Pleistozän angelegten Landschaftseinheiten werden durch die küstennahen Gebiete der Nordsee ergänzt (vgl. - Abb. 6.1), die als holozäne Entwicklung durch Trans- und Regression gekennzeichnet werden. Auch die Vernässung von küstennahen Niederungen und die Entstehung von Geestrandmooren geht auf den holozänen Meeresspiegelanstieg zurück (Benda 1995; Jensen et al. 2011).

Die nacheiszeitliche Landschaft ist durch den Einfluss des Menschen, insbesondere durch Waldrodungen, umfangreiche Entwässerungsmaßnahmen und Eindeichungen von Fluss- und Küstenmarschen, gravierend verändert worden. Die potenziell natürliche Vegetation sind weithin von Rotbuchen (Fagus sylvatica) dominierte Wälder, d. h., ohne anthropogene Eingriffe würden große Flächenanteile der Alt- und Jungmoränenlandschaften von Buchenwäldern eingenommen (Jensen et al. 2014). In abflusslosen Senken und in Gebieten mit hoch anstehendem Grundwasser wären Hoch- und Niedermoore kennzeichnend, während Auwälder die großen Flusstäler prägen würden. Entlang der Küsten und in den äußeren Bereichen des Elbeästuars würden Salzmarschen dominieren, die bei abnehmendem Salzgehalt stromaufwärts in Brack- und Süßwassermarschen sowie Tide-Auwälder übergehen würden (Jensen et al. 2014; Jensen und Schoenberg 2015). Naturnahe Lebensräume sind heute aufgrund der lang andauernden und vielfältigen Tätigkeiten des wirtschaftenden Menschen auf kleine Restflächen reduziert. Gleichzeitig sind Lebensräume der Kulturlandschaft wie Heiden oder Feuchtgrünland entstanden, die von der Aufrechterhaltung landwirtschaftlicher Flächennutzung abhängig sind. Im Fokus der Betrachtungen zu den Auswirkungen des Klimawandels in Abschn. 6.5 stehen sowohl die naturnahen Lebensräume der MRH (Wälder, Ästuare und Küstenökosysteme, Moore) als auch jene der Kulturlandschaft (Heiden, Feuchtgrünland) und der urbanen Räume. 


\subsection{Diversität der Böden in der Metropolregion Hamburg}

Böden bilden die Schnittstelle zwischen Lithosphäre, Hydrosphäre, Biosphäre und Atmosphäre. Organismen, Relief, Ausgangsmaterial, Klima, Zeit und seit einigen Jahrhunderten vermehrt auch der Mensch beeinflussen die Bodenbildung, die Bodeneigenschaften und die daraus abgeleiteten Funktionen von Böden. Durch das standortspezifisch ausgeprägte Zusammenspiel dieser Faktoren entstehen weltweit viele Hunderte unterschiedlicher Bodentypen. Bodentypen unterscheiden sich in ihren Horizontkombinationen und ihren Eigenschaften und in den in ihnen ablaufenden Prozessen. Anhand dieser werden sie, je nach System (z. B. World Reference Base for Soil Resources, IUSS Working Group 2006) oder für die in Deutschland gültige Klassifikation nach der bodenkundlichen Kartieranleitung (AG Boden 2005) angesprochen und klassifiziert. In der MRH kommen über 30 verschiedene Leitböden vor. Ihre verschiedenen Eigenschaften und Funktionen müssen im Hinblick auf die Auswirkungen des Klimawandels differenziert betrachtet werden.

\subsubsection{Die natürlichen Böden der MRH}

Die wesentlichen Leitböden und Bodengesellschaften der MRH sind in 0 Abb. 6.2 ausgewiesen. Ihre Entwicklung und Ausprägung hängt maßgeblich von den im Quartär und Holozän ausgeprägten Landschaftsräumen mit ihren charakteristischen Ausgangsmaterialien ab. Die Darstellung der wichtigsten Böden und Bodenregionen erfolgt hier auf der Basis von LANU (2006); AG Boden (2005); Schlichting (1960); Scheffer und Schachtschabel (2010) sowie Miehlich (2010). Im ersten „Klimabericht für die Metropolregion Hamburg“ (1. HKB, Jensen et al. 2011) findet sich eine detailliertere Beschreibung der Böden für den damals enger gefassten Bereich der Metropolregion. Zur MRH sind die folgenden markanten Bodenregionen zu zählen:

- die Bodenregionen des östlichen Hügellands in der Jungmoränenlandschaft,

- die Bodenregion der Niederen Geest als Übergang zwischen Jung- und Altmoränenlandschaft,

- die Bodenregion der Hohen Geest in der Altmoränenlandschaft,

- die Bodenregionen des Küstenholozän und

- die Bodenregion der überregionalen Flusslandschaften.

Die Jungmoränenlandschaft in der MRH ist durch eine kuppige Grundmoränenlandschaft mit abflusslosen Hohlformen geprägt. Oberflächennah ist Geschiebemergel und in entkalkter Form Geschiebelehm das am weitesten verbreitete Ausgangsmaterial. Daneben kommen Geschiebesande, Schmelzwassersande und in Talauen holozäne Flusssedimente sowie Flugsandflächen und Torfbildungen vor. Dominierende Bodentypen sind Parabraunerden mit Übergängen zu Pseudogleyen, wenn ein Einfluss von Stauwasser vorhanden ist. Die kuppigen Bereiche der Endmoränen sind durch Braunerden und Parabraunerden gekennzeichnet, in Senken und Unterhanglagen treten Kolluvien, Niedermoore und Gleye auf. Auf sandigen Ausgangssubstraten sind vorwiegend Braunerden, Podsol-Braunerden und vereinzelt auch Humus-Podsole ausgebildet.

Die Niedere Geest, auch Vorgeest oder Sandergeest genannt, bildet den Übergang zwischen der Jung- und der Altmoränenlandschaft mit den Schmelzwasserablagerungen der Weichselvereisung. Zum Teil sind die Sanderflächen durch Flugsanddecken überlagert. Auf den Sanderflächen haben sich nährstoff- und tonarme Böden entwickelt, namentlich Braunerden und Podsole sowie deren Übergangsformen. In Niederungsbereichen finden sich in Abhängigkeit vom Wasserhaushalt Gleye und Gley-Podsole sowie an feuchteren Standorten Anmoorgleye und Niedermoore.

Die Hohe Geest bzw. Altmoränenlandschaft ist durch Endmoränen, Grundmoränen und Sander der Saalevereisung geprägt. Das Relief wurde durch Periglazialprozesse wie Solifluktion und Ausblasung stark eingeebnet. Auf den Geschiebesanden, Geschiebedecksanden und Geschiebelehmen als Ausgangsmaterialien der Bodenbildung dominieren Podsole und Braunerden mit ihren Übergangsformen. Bei oberflächennahem Stauwassereinfluss treten Pseudogleye auf, in den Niederungen auch Hochund Niedermoore sowie Gleye, Gley-Podsole und Anmoorgleye.

Im Küstenholozän haben sich infolge von Meeresspiegeländerungen (Trans- und Regression) feinkörnige Meeres- und Flusssedimente im Bereich der heutigen Marschgebiete an der Nordseeküste und im Elbeästuar abgelagert. An der Nordsee wurden aufgrund der Gezeiten vorwiegend schluffige bis tonige Feinsedimente abgelagert. Auf den Sedimenten entwickelt sich nach der Entsalzung die Kalkmarsch, und aus dieser bildet sich mit zunehmender Kalkauswaschung die Kleimarsch. Der postglaziale Meeresspiegelanstieg verursachte zudem die Vernässung von Niederungen in Küstennähe und die Bildung von Mooren (Jensen und Schoenberg 2015). Im Elbtal sind auf den holozänen Ablagerungen Flussrohmarschen und Flusskleimarschen mit Übergängen zu Organomarschen ausgebildet.

Auf den Sedimenten der überregionalen Flusslandschaften, d. h. im nicht tidebeeinflussten Bereich des Elbeurstromtals östlich des Wehres von Geesthacht und im äußersten Süden der MRH im Tal der Aller, sind grundwasserbeeinflusste Auenböden ausgeprägt. Diese werden periodisch oder episodisch überflutet und sind durch wechselnde Grundwasserstände charakterisiert. Als Bodentypen kommen Vega-Gleye und Auengleye vor, auf den Dünensanden des Elbtals auch Regosole und Gley-Regosole, vergesellschaftet mit Niedermooren.

Diese natürlichen Bodenformen sind in der MRH z. T. stark durch den Menschen überprägt. Im Rahmen der Heidebauernwirtschaft entstanden beispielsweise Plaggenesche und ausgedehnte Heideflächen mit vorwiegend Podsolen. Auf vernässten Standorten wurden durch Entwässerung und Drainage eine landwirtschaftliche Nutzung ermöglicht und die Böden dadurch tiefgehend verändert. Im Stadtgebiet Hamburgs tritt der anthropogene Einfluss besonders deutlich hervor.

\subsubsection{Urbane Böden im Hamburger Stadtgebiet}

Im Hamburger Stadtgebiet ist aufgrund der naturräumlich bedingten engen Verzahnung der unterschiedlichen Ausgangsma- 


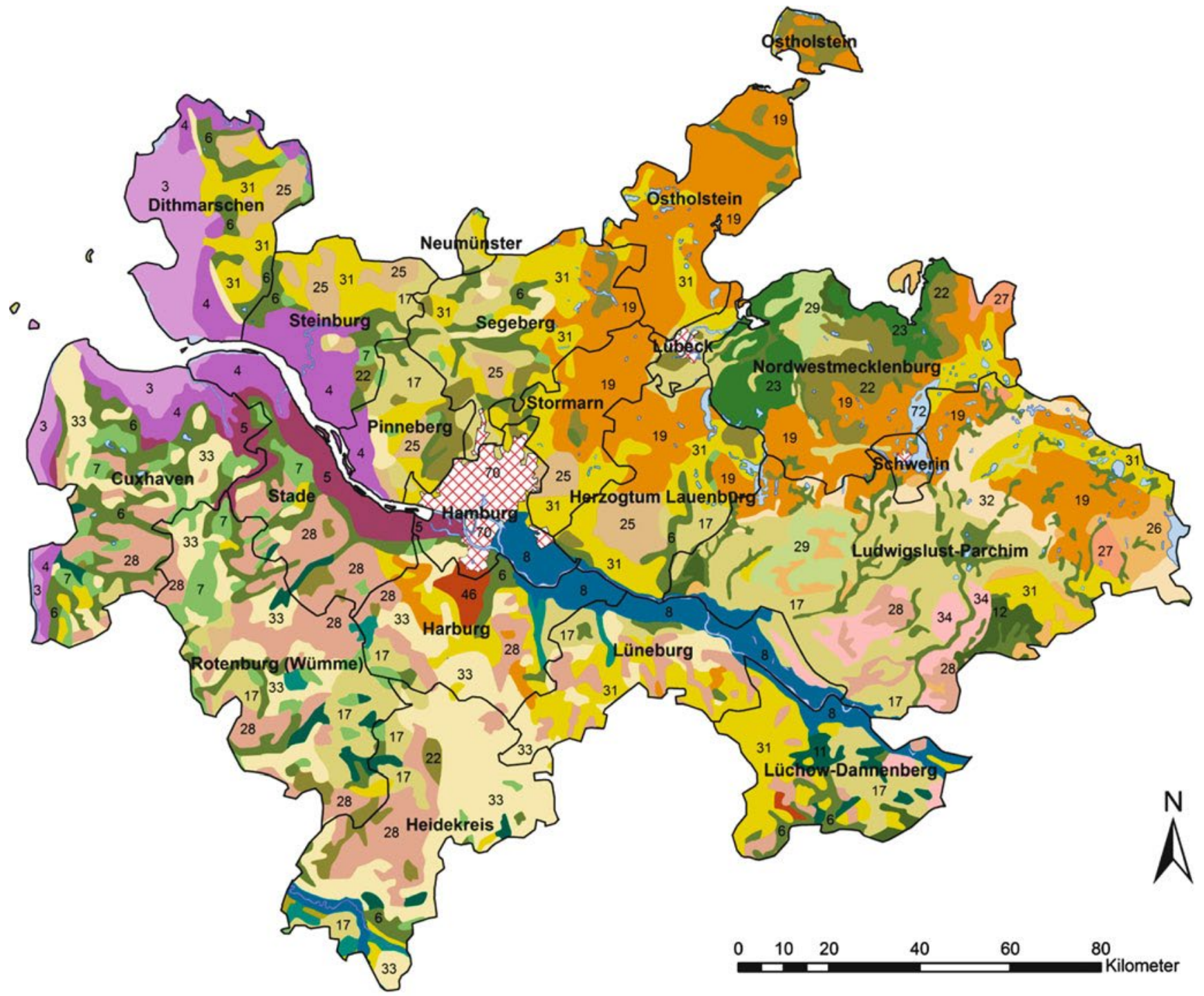

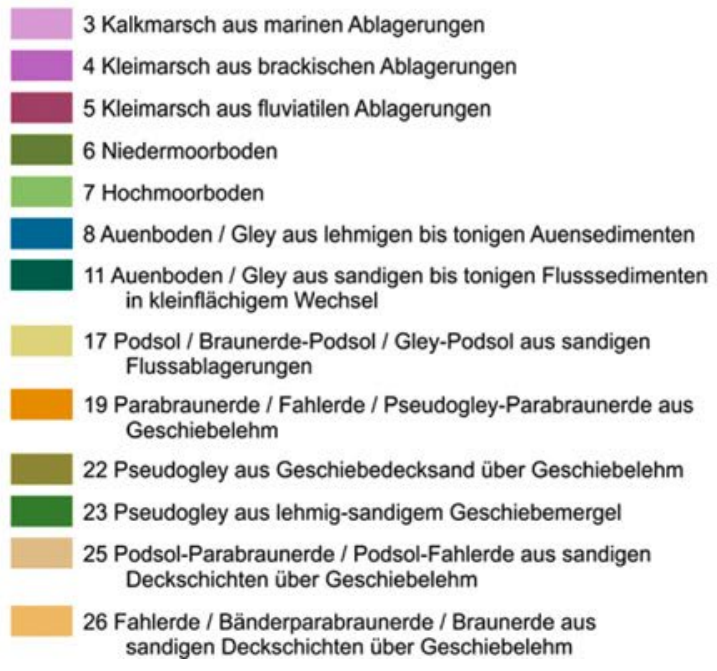

27 Pararendzina / Regosol / Bänderparabraunerde im engräumigen Wechsel aus sandigen bis lehmigen Bildungen der Endmoränen

28 Podsolierte Pseudogley-Braunerde / Pseudogley-Fahlerde aus Geschiebedecksand über Geschiebelehm

29 Braunerde-Pseudogley / Podsol-Pseudogley aus sandigen Deckschichten über Geschiebelehm

31 Braunerde-Podsol / Podsol-Braunerde aus trockenen, nährstoffarmen Sanden

32 Braunerde / Bänderparabraunerde aus nährstoffreichen Sanden

33 Eisenhumuspodsol / Podsol-Regosol aus trockenen, nährstoffarmen Sanden

34 Regosol / Lockersyrosem aus trockenen, nährstoffarmen Sanden

46 Parabraunerde / Fahlerde / Braunerde aus Sandlöss über Sand oder Lehm

70 Versiegelte Flächen in größeren Städten

72 Gewässer

- Abb. 6.2 Typische Leitböden in der MRH. Leicht generalisierte Darstellung unter Verwendung von Daten des Bundesamtes für Kartographie und Geodäsie (2011) und der BÜK 1000 nach BGR (2013). (Eigene Darstellung Eschenbach) 
terialien - im Hamburger Stadtgebiet sind alle der genannten Bodenregionen der MRH ausgeprägt - und der kleinräumigen Unterschiede im Relief und Wasserhaushalt eine hohe Diversität von Böden vorhanden. Im Stadtgebiet sind die natürlichen Bodenformengesellschaften durch die anthropogene Nutzung stark überprägt. Die Böden im stark besiedelten Bereich sind insbesondere durch Abtrag, Auftrag und Eintrag von Stoffen sowie von Durchmischung und Versiegelung betroffen. Die häufig verwendete unpräzise Bezeichnung „Stadtböden“ erfasst diesen Zusammenhang nur unzureichend. Im urbanen Raum werden generell folgende Böden unterschieden:

- Böden mit natürlicher Bodenentwicklung (naturnahe Böden),

- Böden anthropogener Aufträge natürlicher oder technogener Substrate bzw. Mischungen,

- versiegelte Böden.

Der Anteil von tiefgründig gestörten und teilweise versiegelten Böden und der Böden auf Aufschüttungen im Hamburger Stadtgebiet wird in $\bullet$ Abb. 6.3 deutlich.

Eine Auswertung von über 1700 Bohrungen in der Stadt Hamburg ergab, dass etwa $90 \%$ dieser untersuchten Böden meist sandige Aufträge unterschiedlicher Mächtigkeit und ca. $30 \%$ der Böden erhebliche Mengen technogener Substrate enthalten (Miehlich 2015); dies ist auch für andere Städte charakteristisch (Greinert 2015). Als technogene Substrate der Bodenbildung sind besonders ausgeprägt Bauschutt, Schlacken, Müll sowie Aschen (Henninger 2011; Endlicher 2012). In der Stadt Hamburg sind aktuell nahezu 60 \% der Fläche als Siedlungs- und Verkehrsfläche genutzt (Jahr 2014, Metropolregion Hamburg o.J.), etwa $38 \%$ der Böden des Stadtgebietes sind versiegelt. Auch in den letzten Jahren hat der Grad der Versiegelung in der Stadt Hamburg zugenommen: Im Zeitraum 2000-2014 ist die versiegelte Fläche im Mittel um 100 ha pro Jahr gestiegen (Arbeitskreis Umweltökonomische Gesamtrechnungen der Länder 2015). Bei versiegelten Standorten ist neben anderen Bodenfunktionen auch der Wasser- und Gashaushalt stark beeinträchtigt. In Abhängigkeit der Versiegelungsmaterialien, der Vollständigkeit der Versiegelung und dem Alter der Versiegelung können die Niederschläge nur zu einem deutlich geringeren Anteil in den Boden eindringen als auf unversiegelten und nicht verdichteten Standorten (Wessolek et al. 2010).

\subsection{Auswirkungen des Klimawandels auf Bodenökosysteme und deren Funktionen}

\subsubsection{Einleitung}

Böden spielen eine zentrale Rolle im Erd- und Klimageschehen. Der Boden als natürliche und nicht erneuerbare Ressource bildet die Lebensgrundlage für Menschen, Tiere und Pflanzen und hat wichtige Produktions- und Regelungsfunktionen für terrestrische Ökosysteme. Die Bodenfunktionen sind in Deutschland seit 1998 über das Bundesbodenschutzgesetz unter Schutz gestellt (BBodSchG 1998). Zu den Regelungsfunktionen gehören u. a. der Ab- und Umbau der organischen Substanzen, der Abbau von Schadstoffen, die Mobilisierung von Nähr-, aber auch von Schadstoffen sowie die Regulierung des Wasser- und Lufthaushalts. Der Boden trägt über die landwirtschaftliche Nutzungsfunktion zur Sicherung der Ernährung bei. Die Bodenorganismen spielen eine zentrale Rolle bei der Aufrechterhaltung und Kontrolle dieser Funktionen und der zugrunde liegenden Prozesse.

Von den erwarteten Klimaänderungen sind Böden mit ihren Eigenschaften und Prozessen sowohl direkt als auch indirekt betroffen: direkt z. B. durch die Einwirkungen auf den Wasser- und Wärmehaushalt der Böden, indirekt beispielsweise über die Aktivität der Bodenorganismen, die Veränderung der Primärproduktion der Pflanzen und die Streunachlieferung sowie durch die damit verknüpften Einwirkungen auf den Stoff- und Nährstoffhaushalt. Andererseits wirken sich klimabedingte Änderungen von Bodeneigenschaften sowie menschliche Eingriffe wiederum auf das Klima aus, z. B. durch Freisetzung oder Festlegung von Treibhausgasen im Boden oder durch veränderte Verdunstungsprozesse an der Grenzschicht Boden-Vegetation-Atmosphäre.

Das Klima beeinflusst viele Bodenprozesse und ist - neben dem Ausgangsgestein, dem Relief, den Organismen, dem Menschen und der Zeit - ein wesentlicher Faktor der Bodengenese. Komplexe Wechselbeziehungen bestehen mit den angrenzenden bzw. verwobenen Ökosystemkomponenten wie den in und auf dem Boden lebenden Organismengemeinschaften und der Hydrosphäre. Des Weiteren besteht ein deutlicher Einfluss der jeweiligen anthropogenen Landnutzung auf die Bodeneigenschaften. Bei einer veränderten bodenschonenden Landnutzung und Bewirtschaftung besteht somit z. T. ein großes Anpassungspotenzial. Bedingt durch diese vielfältigen Interaktionen und durch die zugleich große Unsicherheit der projizierten Veränderungen der Klimaparameter basieren Projektionen zu den Auswirkungen des erwarteten Klimawandels auf das System Boden bisher z. T. auf Annahmen und sind zeitlich und räumlich noch wenig aufgelöst (Varallyay 2010).

Beim Einwirken von äußeren Faktoren auf den Boden ergeben sich nach Varallyay $(1990,2010)$ unterschiedliche Zeitskalen der Veränderung von Bodeneigenschaften und -merkmalen. Kurzfristige Veränderungen - in einer Zeitspanne innerhalb eines Jahres bis zu einer Dekade - sind beim Wärmehaushalt, der Bodenfeuchte und dem Bodenwasserhaushalt, der Zusammensetzung und Aktivität des Bodenlebens, der Qualität und Quantität von Streu und Pflanzenrückständen sowie $\mathrm{pH}$ - ̈̈nderungen, Kationenaustauschkapazität, Basensättigung und der Zusammensetzung der Bodenlösung möglich. Langsamer - in einer Zeitspanne von mehreren Dekaden - reagieren die $\mathrm{Zu}$ sammensetzung und der Gehalt der organischen Bodensubstanz (SOM), die Aggregatform und Aggregatstabilität, Porengrößenverteilung, Wasserhaltekapazität und beispielsweise die Infiltrationskapazität. Bodenhorizonte, Bodenfarbe, Bodentextur und Gründigkeit weisen erst nach mehreren Jahrhunderten merkbare Veränderungen auf (Varallyay 1990). Bei direkten anthropogenen Eingriffen, z. B. durch Verdichtung, können jedoch auch kurzfristige Änderungen im System Boden verursacht werden.

Zumeist werden die möglichen Auswirkungen des Klimawandels über Modellierungen und Simulationen abgeleitet (Ker- 


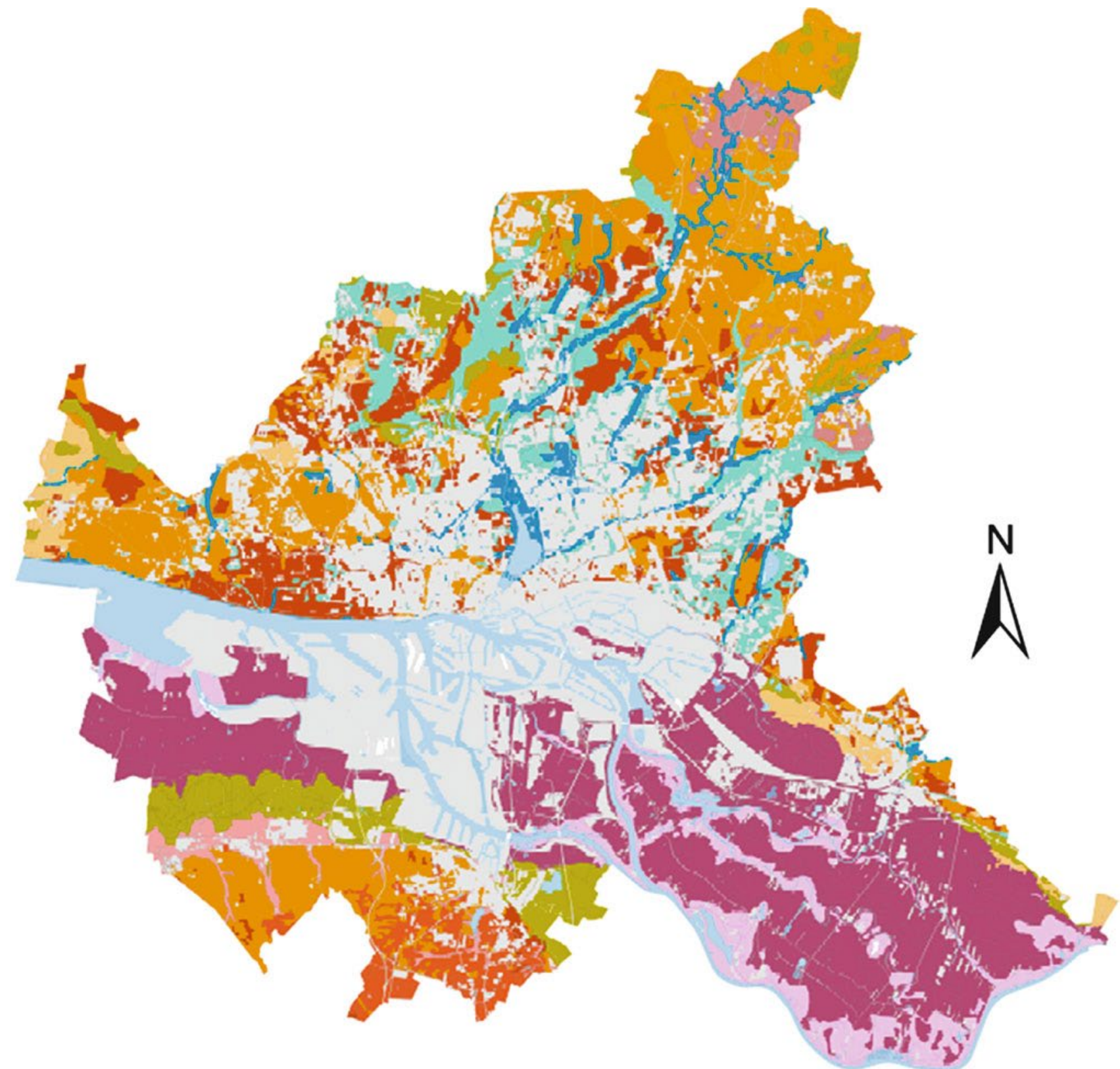

Pseudogleye, Braunerden, Parabraunerden und Podsole aus Geschiebedecksand über saalezeitticher Grundmoräne

Braunerden und Podsole aus saalezeitlichen Schmelzwassersanden Pseudogleye und Parabraunerden aus Geschiebedecksand über weichselzeitlichem Geschiebelehm der Grundmoräne

Braunerden, Podsole und Gleye aus weichselzeitlichen Schmelzwassersanden

In Senken Anmoorgleye, Podsole und Niedermoore aus Sand/Torf;

In höher gelegenen Flächen Pseudogleye und Braunerden aus weichselzeitl. Sanden über saalezeitl. Grundmorăne

In Trockentälern der Harbuger Berge: Kolluvisole. Im Elbtal Podsole und Gleye aus weichselzeitlich umgelagerten Sanden

Parabraunerden und Braunerden aus weichselzeitlichem Sandlöss
Podsole und Regosole aus weichselzeitlichen und holozänen Flugsanden

Gleye, Vegen und Niedermoore aus holozänen Fluss-, Bach und Seeablagerungen

Flusswatt, Flussstrand, Flussrohmarsch und Flusskleimarsch aus holozänen, perimarinen Sanden und Lehmen

Flusskleimarschen, Organomarschen aus holozänen, perimarinen Lehmen und Tonen

Moore

Tiefgründig gestörte und teilweise versiegelte Böden Aufschüttungen, nicht kartiert

- Abb. 6.3 Im Stadtgebiet Hamburg verbreitete Bodenformengesellschaften und tiefgründig gestörte und versiegelte Böden. (Verändert nach FHH 2012) 
sebaum und Nendel 2014; Trnka et al. 2013; Jones et al. 2009), die ebenfalls mit $z$. T. erheblichen Unsicherheiten behaftet sind (Asseng et al. 2013).

Die projektierten Veränderungen der Klimaparameter sind regional unterschiedlich ausgeprägt und treffen auf eine große regionale Diversität der Böden, mit unterschiedlicher Vulnerabilität gegenüber Änderungen (Lal 2010; Kimble et al. 1998). Daher sind die erwarteten Auswirkungen in einzelnen Regionen sehr unterschiedlich, und eine differenzierte Betrachtung von regionalen Ausprägungen und Mustern sowohl des Klimawandels als auch der möglichen Bodenveränderungen in Abhängigkeit der jeweiligen Standortbedingungen ist erforderlich (• Tab. 6.1).

\subsubsection{Potenzielle Auswirkungen des Klimawandels auf den Bodenwasserhaushalt}

Der Bodenwasserhaushalt wird direkt durch die Klimaparameter Niederschlag und Temperatur beeinflusst, die über Wassernachlieferung und Verdunstung den pflanzenverfügbaren Wasservorrat im Boden steuern. Bei steigenden Temperaturen nimmt die Verdunstung generell zu. Die tatsächliche Evapotranspiration unterscheidet sich aber deutlich von der potenziellen, die im Wesentlichen über die Klimaparameter errechnet wird. Bei der tatsächlichen Evapotranspiration werden der vorhandene Bodenwasservorrat und die Wassernachlieferung, die z. B. durch kapillaren Aufstieg aus oberflächennahen Stau- oder Grundwasser generiert werden kann, berücksichtigt.

Durch eine für möglich gehaltene Temperaturerhöhung und gleichzeitige Abnahme der Sommerniederschläge sowie eine Zunahme der Trockentage ( Abschn. 2.4) kann es während der Vegetationsperiode zu einer raschen Reduzierung des Bodenwasserspeichers kommen. Wird der Speicher des pflanzenverfügbaren Bodenwassers zu stark vermindert und liegt dieser unter einem Mindestwert von ca. 30-40\% nutzbarer Feldkapazität (nFK) im effektiven Wurzelraum (Heidt 2009; Schmelmer und Urban 2014), treten langfristig Implikationen für die Vegetation ein, wie z. B. vermindertes Pflanzenwachstum, Trockenschäden an Pflanzen und auf landwirtschaftlichen Nutzflächen reduzierte Ernteerträge (Olde Venterink et al. 2002; Asseng et al. 2013). Die pflanzenverfügbaren Bodenwassermengen im effektiven Wurzelraum variieren in Abhängigkeit von standortspezifischen Bodeneigenschaften - wie Bodenart, Lagerungsdichte, Humusgehalt, Substanzvolumen, um nur einige zu nennen - stark.

Heidt (2009) hat die Auswirkungen des Klimawandels auf die Wasservorräte in landwirtschaftlich genutzten Böden in Nordostniedersachsen anhand von Simulationen auf Basis der Regionalisierung von IPCC-Szenarien untersucht. Die klimatische Wasserbilanz in der Hauptvegetationsperiode wird sich gemäß dieser Simulationen in der Region, die in großen Teilen Bereiche der MRH abdeckt, von ca. $-45 \mathrm{~mm} / \mathrm{v}$ (Millimeter pro Vegetationsperiode) in den Referenzjahren 1961-1990 auf ca. -190 mm/v für den Zeitraum 2071-2100 verringern. Innerhalb des Untersuchungsraumes wird dieser Simulation zufolge die klimatische Wasserbilanz dabei im Südosten (Bereich LüchowDannenberg) mit erwarteten Wasserbilanzdefiziten zwischen
-250 und -200 mm/v bis zum Jahr 2021 am negativsten ausgebildet sein.

Die Auswirkungen einer möglichen Abnahme der Sommerniederschläge und einer Verschiebung der Niederschlagsperioden sind je nach Bodeneigenschaften verschieden: Marschen, feuchte Gleye, feuchte Pseudogleye und Moore werden Heidt (2009) zufolge nicht oder nur unwesentlich von zu geringen pflanzenverfügbaren Bodenwassermengen betroffen sein. Eine gute Wasserspeicherfähigkeit der Marschen und Elbmarschböden, kombiniert mit zumeist nur geringen Grundwasserflurabständen, wird eine gute Wasserversorgung und -nachlieferung ermöglichen. Die Auenböden der Elbe können jedoch auch von einer für möglich gehaltenen Zunahme der Sommertrockenheit betroffen sein. Nach Simulationen von Scharnke et al. (2014) wird eine Abnahme des pflanzenverfügbaren Bodenwassers für möglich erachtet, sodass sich Trockenstress für Pflanzen vor allem in den Monaten Juli bis November deutlich ausprägen könnte. Die Überschwemmungsgebiete der Elbe sind unter gegebenen Klimabedingungen und auch unter projizierten künftigen Klimabedingungen durch sehr variable Feuchtezustände charakterisiert. Diese dynamischen hydrologischen Bedingungen mit den auentypischen Gradienten sind aber eine Grundvoraussetzung zum Erhalt dieser dynamischen Landschaftsstrukturen (Schwartz et al. 2000; Scharnke et al. 2014).

An der Westküste Schleswig-Holsteins und in den südwestlichen Geestgebieten wird keine das Pflanzenwachstum beeinträchtigende Abnahme der nutzbaren Feldkapazität erwartet, da ein generell höheres Niveau der Niederschlagssumme vorhanden ist und auch weiterhin projiziert wird (Böhm 2008). Auch im östlichen Hügelland wird die Veränderung der Wasserverfügbarkeit der Böden, die auf Geschiebelehmen und Geschiebemergeln ausgebildet sind, als gering bewertet.

Demgegenüber sind Böden mit nur geringem Wasserspeichervermögen und geringer Wasserleitfähigkeit besonders trockenheitsgefährdet. In der MRH sind dies Braunerde-Podsole, Gley-Podsole und Podsole, Pseudogley-Podsole sowie PodsolBraunerden. Auf den sandigen Böden mit geringer nutzbarer Feldkapazität vor allem im Bereich der Niederen Geest sowie der Flugsanddecken oder glazifluviatilen Ablagerungen werden die erwarteten Klimaänderungen aber die Wasserverfügbarkeit einschränken. Diese Böden werden nur geringe Mengen der Winter- und Frühjahrsniederschläge bis in die Vegetationsperiode hinein speichern können. Für das Gebiet der Lüneburger Heide haben Schmelmer und Urban (2014) auf Basis von Bodenwasserhaushaltssimulationen für sandige Ackerböden der Region eine Zunahme der Tage mit trockenheitsbedingtem Wasserstress um 67-69\% simuliert. Die Trockenphasen werden sich diesen Untersuchungen zufolge weiter in das Frühjahr und den Herbst ausdehnen.

Das für möglich erachtete sommerliche Wasserbilanzdefizit kann zu einer verminderten Sickerwasserrate im Sommer und somit zu einer Abnahme der Sickerwasserspende führen. Für die jährliche Sickerwassermenge wird in der Lüneburger Heide eine Änderung zwischen $+1,3$ und $-19 \%$ erwartet; die Spannbreite verdeutlicht den Einfluss der jeweiligen Bodeneigenschaften (Schmelmer und Urban 2014). Höhere winterliche Niederschläge steigern dagegen die Sickerwasserrate. Allerdings findet 
- Tab. 6.1 Potenzielle Auswirkungen von für möglich gehaltenen Klimaänderungen auf Böden in der MRH

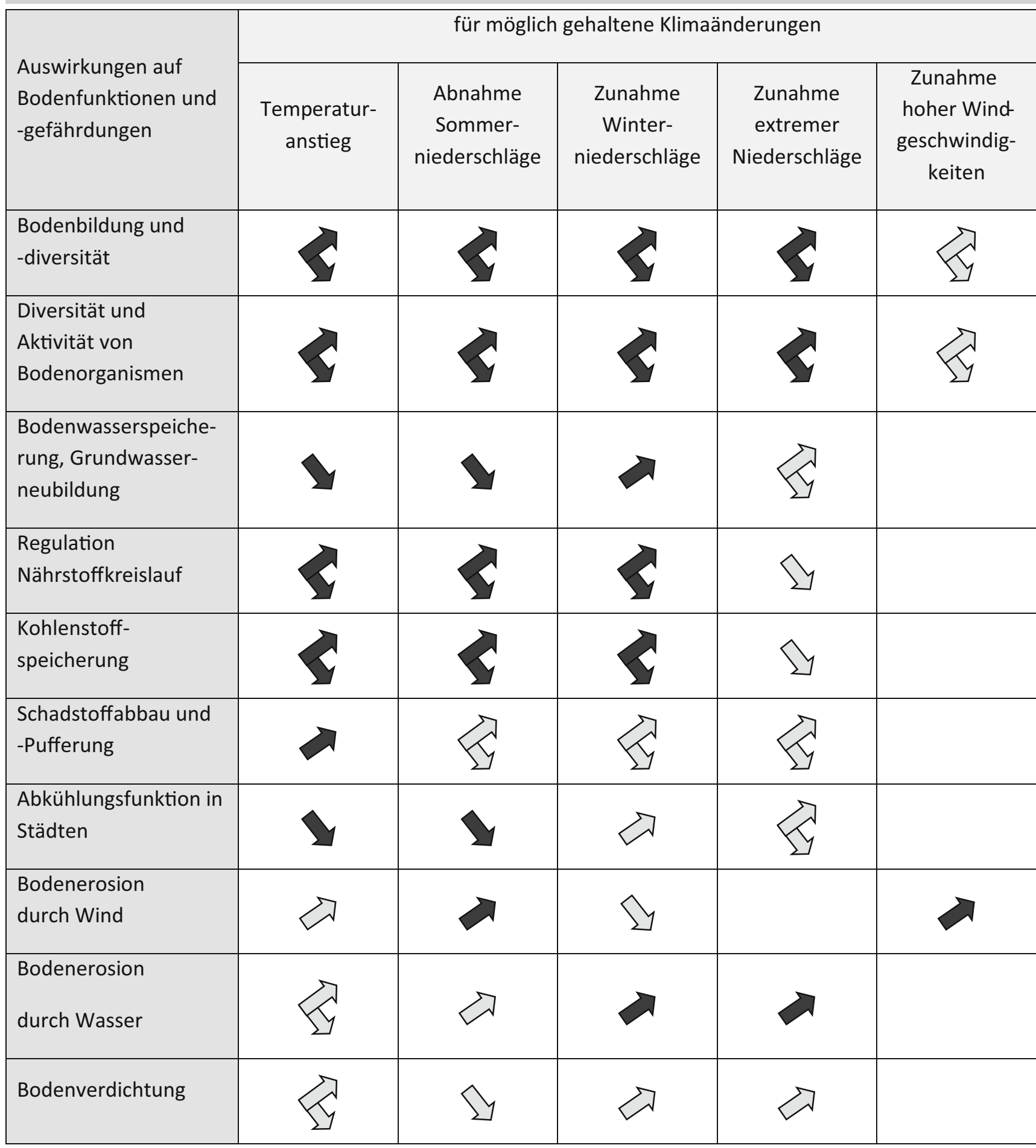

\section{Zunahme möglich}

Abnahme möglich

in Abhängigkeit von Standortbedingungen Zu- oder Abnahme möglich durch indirekte Wirkungen Zunahme möglich

durch indirekte Wirkungen Abnahme möglich

durch indirekte Wirkungen in Abhängigkeit von Standortbedingungen Zu- oder Abnahme möglich 
in der betrachteten Region die Grundwasserneubildung unter den gegebenen Klimabedingungen im Wesentlichen im Winter statt, während die Niederschläge im Sommer meist vollständig verdunsten bzw. der Wasserversorgung und Transpiration der Vegetation dienen. In der Folge des Klimawandels werden durch die projizierten zunehmenden Winterniederschläge und die für möglich gehaltene Verschiebung der sommerlichen Niederschläge in spätere Phasen der Vegetationsperiode (Heidt 2009) in weiten Teilen der MRH höhere Grundwasserneubildungsraten zu erwarten sein. Vor allem auf den sandigen und gut wasserdurchlässigen Geeststandorten kann es zu erhöhter Grundwasserneubildung kommen. Auf den Böden geringer Durchlässigkeit in den Marschen und dem Östlichen Hügelland wird diese mögliche erhöhte Niederschlagswasserzufuhr in den Wintermonaten als für den Bodenwasser- und Lufthaushalt ungünstig einzuschätzen sein, da zeitweilige Vernässungen und Stauwasserbildung zunehmen werden, mit Implikationen für Verdichtung und Erosion. Nur in den Regionen, in denen gemäß dieser Simulationen eine nur geringe Zunahme der Winterniederschläge einer deutlichen Abnahme der Sommerniederschläge gegenübersteht, ist auch mit einem Rückgang der Grundwasserneubildung im Jahresverlauf zu rechnen. Insgesamt wird der Grundwasserspiegel höheren Schwankungen unterliegen (Heidt 2009).

In einem direkten Zusammenhang mit dem Bodenwasser- sowie dem Temperaturhaushalt steht der Stoffhaushalt des Bodens mit seinen Umwandlungs- und Verlagerungsprozessen. Durch erwartete höhere Winterniederschläge und erhöhte Niederschlagsintensitäten kann es zu einer vermehrten Verlagerung von Stoffen, auch Schadstoffen, mit dem Sickerwasser kommen. Durch kurzfristige Änderungen u. a. der Redoxbedingungen und der mikrobiellen Aktivität können Freisetzungen und Mobilisierungsprozessen stattfinden, die eine Änderung des $\mathrm{pH}$ und der Nähr- und Schadstoffgehalte in der Bodenlösung bedingen.

Regional ist durch eine projektierte winterliche Niederschlagszunahme und vermehrte Sickerwasserbildung mit einer erhöhten winterlichen Nitratverlagerung und -auswaschung zu rechnen. Ein potenziell hohes Verlagerungsrisiko besteht in den Böden der Geestgebiete mit hohen bis sehr hohen Sandanteilen. In den Gebieten mit mittlerer bis geringerer Wasserleitfähigkeit, in den Marschen und den Böden der Jungmoränenlandschaft, ist bei lehmigen bis tonigen Böden das Verlagerungsrisiko geringer zu bewerten. Bei Steigerung der Niederschläge und geringem Pflanzenentzug kann allerdings auch hier der Austrag erhöht werden, wie Dahl (2001) für Salzmarschen zeigte. Auch Taylor et al. (2004) verweisen auf eine erhöhte Stickstoffauswaschung als Effekt eines veränderten Niederschlagsregimes, bedingt durch beeinträchtigte Leistungen von Bodenorganismen.

Die bisherigen Untersuchungen zu den Auswirkungen des Klimawandels - auch der sommerlichen Trockenperioden - auf Sickerwasserchemie und Stoffverlagerungen zeichnen noch kein einheitliches Bild. Der Gehalt und potenziell durch Klimawandel erhöhte Abbau der organischen Substanz des Bodens beeinflusst die Mobilität von pflanzenverfügbaren Nähr- und Schadstoffen; ebenso sind die Mikroorganismen maßgeblicher Treiber für die Stofflüsse zwischen den (Boden-)Kompartimenten (Scholes und Scholes 2013).
Für die z. T. in hohem Maße mit Schadstoffen belasteten Auenböden in den Überflutungsbereichen der Elbe ergeben sich im Zuge des Klimawandels durch veränderte Überschwemmungsbedingungen und ein verändertes Bodenfeuchteregime Beeinflussungen. Durch zunehmende Hochwasser können einerseits weitere Sedimentablagerungen eines im Vergleich zur Vergangenheit weniger belasteten Sedimentes zu einem Verdünnungseffekt oder andererseits durch Remobilisierung von hoch belasteten Sedimenten oder Altlasten zu einer erhöhten Schadstoffbelastung der Überflutungsbereiche führen. Längere Zeiten von reduzierenden Bedingungen könnten darüber hinaus zu einer Mobilisierung von Schwermetallen und Arsen beitragen (Krüger und Urban 2014). Es besteht Forschungsbedarf, um mögliche Interaktionen zwischen dem Verhalten organischer und anorganischer Schadstoffe, einer möglichen Temperaturerhöhung und längeren Überflutungsphasen bzw. veränderten Redoxbedingungen detaillierter zu erfassen.

Im stark besiedelten Bereich sollte aufgrund der beschriebenen möglichen Auswirkungen der Klimaänderungen auf den Bodenwasser- und Stoffhaushalt mit den Konsequenzen für langfristig angelegte Maßnahmen zur Sanierung schädlicher Bodenveränderungen und Altlasten gerechnet werden. Dies betrifft insbesondere Sanierungsmaßnahmen, die auf dem Konzept des Monitored Natural Attenuation (MNA) basieren, bei dem auf die natürlicherweise im Boden ablaufenden Prozesse zur Verringerung der Schadstoffverfügbarkeit vertraut wird. $\mathrm{Zu}$ den Auswirkungen des Klimawandels auf Schadstoffabbau, -festlegung und -bioverfügbarkeit besteht allerdings noch erheblicher Forschungsbedarf.

Durch einen im Zuge des Klimawandels bedingten Meeresspiegelanstieg (vgl. z. B. Gönnert et al. 2009 sowie Schlünzen und Linde (2014) für die MRH) ist in einigen Gebieten mit episodischen Überflutungen salzhaltigen oder brackischen Wassers zu rechnen. In Teilen der MRH wird durch wasserwirtschaftliche Maßnahmen der Tide- bzw. Grundwasserstand reguliert (z. B. Elbinsel Wilhelmsburg, Schlünzen und Linde 2014). An den Küsten der MRH schützen Deiche die eingedeichten Böden der Marschen weitgehend vor weiteren Überspülungen. In den küstennahen Niederungen kann der Meeresspiegelanstieg zu einem veränderten Bodenwasserhaushalt führen (Huang et al. 2013; Morris et al. 2002), auch wenn die Akkretionsraten in der MRH ausreichend groß sind, um einen moderaten Meeresspiegelanstieg zu kompensieren ( Abschn. 6.5.3). Die Folge können veränderte Stickstoffmineralisationsraten mit einer erhöhten Nitratauswaschung (Dahl 2001) und veränderte Kohlenstoffumsatzprozesse mit erhöhten Treibhausgasfreisetzungen (z. B. Pfeiffer 1998; Blume und Müller-Thomsen 2007) sein.

\subsubsection{Potenzielle Auswirkungen des Klimawandels auf die Erosionsgefährdung}

Das Risiko der Bodenerosion ist aufgrund kleinräumig variierender Einflussfaktoren (Niederschlag, Windgeschwindigkeit, Topographie, Bodenstruktur und -eigenschaften sowie die Bewirtschaftung durch den Menschen) lokal sehr verschieden. 
Die projektierte Zunahme der winterlichen Niederschläge und die in regionalen Simulationen abgeleitete Zunahme der Starkregenereignisse ( Abschn. 2.4) können zu einem häufigeren und erhöhten Oberflächenabfluss und somit bei Relief zu erhöhter Gefährdung durch wasserbedingte Bodenerosion führen (Jones et al. 2009). Der mögliche Anstieg der Winterniederschläge führt primär zu einer erhöhten Infiltration, d. h. einem Eindringen des Wassers in den Boden, bis die Wasseraufnahmekapazität des Bodens erschöpft ist. Die Infiltration hängt neben der zur Verfügung stehenden Wassermenge maßgeblich vom Bodenwassergehalt zu Beginn der Infiltration, von der Beschaffenheit der Bodenoberfläche (Verschlämmung und Aggregatstabilität), von der Benetzbarkeit der Bodenteilchen (Hydrophobizität) und vom Vorhandensein sekundärer Grobporen (Trocknungsrisse, Wurmgänge etc.) ab. Bei der Abschätzung der Bodenerosion durch Wasser ist besonders zu berücksichtigen, dass die Starkniederschläge bei Fortführung der bisherigen (konventionellen) Bewirtschaftung auf im Winterhalbjahr nur schwach von Vegetation bedeckte oder unbewachsene Bodenoberflächen treffen können, was die Verschlämmung und damit den Oberflächenabfluss und das Erosionsrisiko erhöht.

Ein erhöhtes Erosionsrisiko ist aber auch durch die für möglich erachteten geringeren Sommerniederschläge gegeben, da durch abnehmende Bodenwassergehalte und längere Trockenperioden die Hydrophobizität humoser Oberböden steigt, was zu einer Verminderung der Infiltration führen kann. Stärkere Verschlämmungen, erhöhter Oberflächenabfluss bei Starkregenereignissen und Erosionserscheinungen wären die Folge. Bei tonreichen Böden wirken dem allerdings die möglicherweise ausgebildeten Trockenrisse entgegen, die ein schnelles Eindringen und Abtransportieren des Wassers in tiefere Bodenschichten ermöglichen. Weitere durch den Klimawandel ausgelöste Bodenveränderungen können die Erosionsanfälligkeit der Böden negativ beeinflussen: Durch einen möglichen Humusabbau (s. u.) und die projektierte geringe Anzahl von Frosttagen verschlechtern sich die Bodenstruktur und Gefügestabilität, die Verschlämmungsneigung nimmt zu und somit auch die Erodierbarkeit der Böden.

In der MRH werden insbesondere Böden des östlichen Hügellandes sowie in geringerem Umfang auch die der südwestlichen Hohen Geest durch wasserbedingte Erosion gefährdet sein. An den ackerbaulich genutzten Hängen des östlichen Hügellandes betrifft dies besonders die lehmigen Parabraunerden und in der Hohen Geest die feinsandigen Braunerden (Böhm 2008). Weniger bis gar nicht werden die Böden der Marschen und der Niederen Geest betroffen sein, und zwar aufgrund des geringeren Gefälles bzw. wegen hoher Grobsandanteile.

$\mathrm{Zu}$ beachten ist, dass durch eine klimawandelbedingte Verlängerung der Vegetationsperiode ( Abschn. 6.2.2) auch eine Abnahme der Erodierbarkeit der Standorte möglich ist, da bereits früher im Jahr eine bodenbedeckende Vegetation ausgebildet sein kann (Engel und Müller 2009). Diese möglichen Effekte des Klimawandels müssten vor allem im Zusammenhang mit Änderungen der landwirtschaftlichen Nutzung und Bewirtschaftung genauer untersucht werden, da durch Änderungen der Bodennutzung ein deutliches Adaptationspotenzial an den Klimawandel vorhanden ist.
Als Folge eines möglicherweise erhöhten Oberflächenabflusses nimmt die Wahrscheinlichkeit von lokalen und regionalen Hochwasserereignissen zu. Die Gefahr von Hochwasser und Überschwemmungen kann entlang von natürlichen, aber auch von stark menschlich überprägten Flussläufen und in urbanen Regionen auftreten.

Windbedingte Bodenerosion tritt dort auf, wo hohe Windgeschwindigkeiten auf Böden geringer Vegetationsbedeckung mit geringer Oberbodenfeuchte und feinsand- und schluffhaltiger Bodentextur oder trockene, vererdete Moore und Anmoore treffen. In der MRH ist unter gegebenen Klimabedingungen mit einem Maximum der windbedingten Erosionsgefährdung in den Monaten April und Mai zu rechnen (Hassenpflug 2005). Als Folge des Klimawandels ist durch die möglicherweise geringeren Sommerniederschläge und eine erhöhte Verdunstung mit einer schnelleren und stärkeren Austrocknung der Oberböden zu rechnen. Dies beeinflusst die Erodierbarkeit der Böden maßgeblich, sodass dann bei Beibehaltung oder sogar möglicherweise erhöhten Windgeschwindigkeiten in weiten Teilen der MRH von einer Zunahme der Bodenerosion durch Wind auszugehen wäre. Allerdings spielt der Bedeckungsgrad durch Vegetation eine große Rolle, weshalb sich Veränderungen der Vegetationsperiode oder der Bewirtschaftung deutlich auswirken können.

Als winderosionsgefährdet gelten in der MRH besonders die sandigen und trockenen Geeststandorte sowie die Niedermoorböden in den Niederungen der Geestlandschaften, falls sie sich unter Ackernutzung befinden, sowie die sich südlich anschließenden Gebiete der Norddeutschen Tiefebene. Die Auen und Marschenböden weisen, außer möglicherweise den sehr stark sandig ausgeprägten Kalkmarschen, kein erhöhtes Erosionsrisiko auf. Es ist nach Untersuchungen von Engel und Müller (2009) davon auszugehen, dass das zukünftige Erosionsrisiko besonders auf den unter heutigen Bedingungen als mittel erosionsgefährdet eingestuften Standorten zunehmen wird.

Auswirkungen erhöhter Erosion sind der Verlust von nährstoffreichem und auch kohlenstoffhaltigem Oberbodenmaterial. Dieser Verlust hat negative Implikationen für die Bodenfruchtbarkeit, Wasserspeicherfähigkeit und Gefügestabilität. Durch Verlust an Bodenmaterial wird zudem langfristig die Gründigkeit der Bodenprofile abnehmen.

Ziel des Bodenschutzes - insbesondere unter den Bedingungen des Klimawandels - sollte es sein, das Ausmaß der Bodenerosion durch eine angepasste Landnutzung und Bodenbewirtschaftung ( Abschn. 6.2.3) zu minimieren.

\subsubsection{Potenzielle Auswirkungen des Klimawandels auf die Gefährdung der Bodenverdichtung}

Bodenverdichtung ist ein standortspezifisches, bodenfeuchteabhängiges und bewirtschaftungsbedingtes Problem auf landwirtschaftlich genutzten Standorten, das sich unter den Bedingungen des Klimawandels verschärfen könnte. Bei der landwirtschaftlichen Bodenbearbeitung kann es zu dauerhaften Schäden durch Bodenverdichtung kommen, wenn die Tragfähigkeit der Böden bei der Bearbeitung bzw. Befahrung mit landwirtschaftlichen Ge- 
räten überschritten wird. Die Stabilität des Bodengefüges hängt von der Bodentextur, dem Gehalt an organischer Substanz und der mikrobiellen Aktivität ab und wird ganz wesentlich durch hohe Bodenwassergehalte herabgesetzt. Durch eine für möglich gehaltene Zunahme der Winterniederschläge kann somit auch die Gefahr einer Bodenverdichtung zunehmen. Die Stabilität des Bodengefüges kann darüber hinaus durch eine mögliche Abnahme der Frosttage reduziert werden.

In der MRH sind insbesondere die ackerbaulich genutzten Böden der Marschen, der Auen und der Jungmoränenlandschaft mit hohen Ton-, Schluff- oder Lehmanteilen von zunehmender Verdichtung betroffen. Die überwiegend sandigen Böden der Geest, die vielfach als Grünland genutzt werden, weisen dagegen eine geringere Verdichtungsanfälligkeit auf. Infolge des Klimawandels zunehmend hoch anstehendes Grundwasser oder Stauwasser kann jedoch auch hier die Verdichtungsanfälligkeit erhöhen.

Längere Feuchtephasen, gerade im Zusammenhang mit einem früheren Beginn der Vegetationsperiode, wie diese für möglich gehalten werden, können das Risiko einer Bodenbearbeitung unter nicht optimalen Bedingungen erhöhen. Die für die Region projektierte Verlängerung der Vegetationsperiode um bis zu 25 Tage (Chmielewski 2007; A Abschn. 6.4.1) mit erhöhten Nutzungspotenzialen bis hin zu zwei Ernten kann das Verdichtungsrisiko durch mehrfache Bearbeitung im Jahresablauf zusätzlich erhöhen. Durch eine an die Bodeneigenschaften und die Witterung angepasste Bodenbearbeitung kann allerdings auch zukünftig eine mögliche Bodenverdichtung landwirtschaftlicher Nutzflächen weitgehend vermieden werden ( Abschn. 6.2.2).

\subsubsection{Potenzielle Auswirkungen des Klimawandels auf Bodenorganismen und Bodenbiodiversität}

Die im Boden lebenden Organismen weisen eine außerordentlich hohe Diversität und Individuenzahl auf. Die Biodiversität der im Boden lebenden Organismen ist wesentlich höher als diejenige der auf dem Boden lebenden Organismen (Wall und Virginia 2000; Theuerl und Buscot 2010; Hüttl et al. 2012; Wall et al. 2008). Die Bodenmikroorganismen und die Bodenfauna sind an den Transformationsprozessen der Pedogenese, an der Entwicklung der Bodenstruktur und Aggregatstabilität maßgeblich beteiligt und beeinflussen so den Wasser- und Lufthaushalt. Wichtigste Funktion ist der Abbau der organischen Substanz und die Humifizierung, also die Umwandlung und der Aufbau des Bodenhumus. Der Bodenkohlenstoffhaushalt (s. u.) wird von der Aktivität der Organismen gesteuert. Bodenorganismen sind auch für die Nährstoffbereitstellung im Boden verantwortlich und maßgeblich für die Stoffflüsse und die Freisetzung klimarelevanter Spurengase.

Standortspezifische klimarelevante Faktoren wie Bodenfeuchtigkeit und Bodentemperatur haben einen Einfluss auf das Vorkommen, den Artenreichtum, die Populationsdynamik und die Leistung der Bodenorganismen und somit auf die Nahrungsnetzstruktur im Boden (Kardol et al. 2011; Briones et al. 2009; Carrera et al. 2009). Es besteht ein direkter Zusammenhang zwischen der Lufttemperatur und der Bodentemperatur. Die
Bodentemperatur ist allerdings über die unterschiedliche Wärmeleitfähigkeit und -kapazität unterschiedlich feuchter Böden eng an den Bodenwasserhaushalt geknüpft. Generell begünstigt eine Erhöhung der Bodentemperatur die biologische Aktivität im Boden (Kimble et al. 1998).

Ein multifaktorielles Experiment zum Einfluss klimawandelrelevanter Parameter auf die Bodenrespiration an einem der MRH durchaus vergleichbaren Heidestandort in Dänemark zeigt deutlich die Relevanz sich überlagernder Effekte (Selsted et al. 2012). Eine Erhöhung der $\mathrm{CO}_{2}$-Konzentration um $130 \mathrm{ppm}$ führte zu einer um ca. 38 \% erhöhten Bodenatmung, die simulierte Sommertrockenheit führte zu einer Abnahme der Bodenatmung um $14 \%$, während eine um $0,4{ }^{\circ} \mathrm{C}$ erhöhte Temperatur hier keinen signifikanten Effekt zeigte. Die Kombination von Sommertrockenheit und erhöhter Temperatur resultierte jedoch in einer ca. 50-prozentigen Reduktion der Bodenatmung, und diese war wiederum eng mit der Bodenfeuchte korreliert.

Die Aussagen zu der Auswirkung von möglicherweise auftretenden höheren Sommertemperaturen auf die Abundanz und die Aktivität der Bodenfauna sind bisher widersprüchlich. In Abhängigkeit der Standortbedingungen profitieren einigen Untersuchungen zufolge einige Arten der Bodenfauna von höheren Sommertemperaturen, etwa durch erhöhtes Populationswachstum, schnellere Reproduktion und erhöhte Biomasse, z. B. Regenwürmer (Uvarov et al. 2011) oder Enchytraeiden (Carrera et al. 2009; Briones et al. 2009). Eine durch die Temperatursteigerung erhöhte Organismenaktivität führte nach Carrera et al. (2009) zu einem verstärkten Umsatz von C-Vorräten im Boden. Andererseits ist nach Eggleton et al. (2009) und Russel et al. (2014) durch eine für möglich gehaltene sommerliche Trockenheit eine starke Abnahme der Biodiversität und Aktivität der Bodenorganismen zu erwarten. Ein weltweit durchgeführtes Dekompositionsexperiment zeigte die große Bedeutung des Faktors Klima für den Abbau der organischen Substanz: Das Klima erklärt 70 \% der Abbaurate (Wall et al. 2008). Die Aktivität der Bodenfauna wurde in dieser Studie durch Trockenheit und höhere Temperaturen meist gehemmt, diese Hemmung ist allerdings regionenspezifisch unterschiedlich ausgeprägt (Wall et al. 2008).

Ein weiterer Effekt des Klimawandels ist durch die projektierten erhöhten $\mathrm{CO}_{2}$-Konzentrationen in der Atmosphäre und die daraus folgende Erhöhung des C/N-Verhältnisses im Pflanzengewebe und in der Streu zu erwarten. Damit würde sich die Nahrungsressource für Bodenorganismen verschlechtern. Studien zeigen auf, dass die organische Substanz mit erhöhten C/N-Verhältnissen einem langsameren Abbau unterliegt (Marhan et al. 2010; Coûteaux und Bolger 2000).

Dorendorf et al. (2015) konnten diesen Effekt des C/N-Verhältnisses auf den Abbau von Streu unterschiedlicher Herkunft (urban und periurban) nicht bestätigen, jedoch spielten hier weitere Faktoren wie die chemische Zusammensetzung (z. B. der Ligningehalt) eine Rolle für die Abbaugeschwindigkeit.

Es besteht noch erheblicher Forschungsbedarf zu den Auswirkungen der Klimaveränderungen - insbesondere in ihrer Kombination - auf die Biodiversität im Boden und zu den ökologischen Folgen einer klimabedingten Veränderung der Abundanz und Aktivität von Bodenmikroorganismen und der Bodenfauna. 


\subsubsection{Potenzielle Auswirkungen des Klimawandels auf die organische Substanz}

Böden spielen als Kohlenstoffspeicher, als Senke und Quelle von Treibhausgasen eine essenzielle Rolle im Klimageschehen. Sie sind nach den Ozeanen der zweitgrößte Speicher für Kohlenstoff. In ihnen ist nach dem IPCC-Report 2013 mit weltweit ca. 1500-2400 Pg C bis zu viermal so viel Kohlenstoff gespeichert wie in der Atmosphäre ( $589 \mathrm{PgC}$ ) und etwa drei- bis fünfmal so viel wie in der Vegetation (350-550 PgC) (Ciais et al. 2013). Durch Kohlenstofffestlegung, auch als C-Sequestrierung bezeichnet, leistet der Boden einen Beitrag zur Minderung der Treibhausgase in der Atmosphäre und wirkt somit dem Klimawandel entgegen. Steigt allerdings die Freisetzungsrate durch Humusabbau, wirkt sich dies verstärkend auf den Klimawandel aus. Eine Veränderung des Humushaushaltes, auch um nur geringe Prozentanteile, hat daher gravierende Folgen (Schils et al. 2008; LABO 2010).

Der Gehalt der organischen Substanz des Bodens hängt von einer Reihe von interagierenden Faktoren ab. Zentral sind Bodentyp und Textur, die mikrobielle Aktivität sowie die der Bodentiere, das Klima, die Quantität und Qualität der oberund unterirdisch gelieferten pflanzlichen Rückstände und Ausscheidungen und somit die Vegetation mit Bedeckungsgrad und Zusammensetzung sowie die Landnutzung. Bodentemperatur und Bodenfeuchte als Steuergrößen der biologischen Umsatzprozesse sind wichtige Standorteigenschaften, die den Abbau oder die Anreicherung von organischer Substanz im Boden regeln.

Eine Erhöhung der Bodentemperatur führt durch erhöhte Mineralisationsprozesse zu einem erhöhten Abbau der organischen Substanz (z. B. Carrera et al. 2009). Allerdings kann dieser Faktor nicht getrennt von anderen gekoppelten Einflüssen und Feedbackreaktionen wie veränderter Nährstoffnachlieferung, erhöhter Biomasseproduktion durch höhere Temperaturen oder auch höhere atmosphärische $\mathrm{CO}_{2}$-Konzentrationen und somit einem erhöhten C-Input in Böden gesehen werden (Trumbore und Czimczik 2008; Davidson und Janssens 2006). Neben der Reduktion des Humusgehaltes durch Temperaturerhöhung ist an einigen Standorten auch eine Humusanreicherung als gegenläufiger Prozess denkbar. Der Abbau der organischen Substanz kann entweder durch zu trockene Bodenbedingungen (Reduktion der Sommerniederschläge und Zunahme der Trockentage, Wan et al. 2007; Poll et al. 2013) oder durch zu feuchte, wassergesättigte Bodenbedingungen (zunehmende Winterniederschläge) mit einer Abnahme der Abbauraten - bei gleichzeitig erhöhtem anaeroben C-Umsatz mit erhöhter Methanbildung - gehemmt werden (Scheffer und Schachtschabel 2010).

$\mathrm{Ob}$ und in welchem Maße der Klimawandel zu einem vermehrten Humusabbau oder zu einer Humusanreicherung führen kann, hängt davon ab, inwieweit der erwartete zusätzliche Eintrag an Biomasse die erhöhten Abbauraten ausgleichen kann. Die Zusammenhänge sind so komplex, dass die regional ausgeprägten Effekte der zu erwartenden Änderungen bislang nicht gesichert vorhergesagt werden können (Trumbore und Czimczik 2008). Nach wie vor sind die Aussagen zu den Auswirkungen des Klimawandels auf den im Boden gespeicherten Kohlenstoff uneinheitlich und mit hohen Unsicherheiten behaftet (Davidson und Janssens 2006; Tang und Riley 2014; Morales et al. 2007; Knorr et al. 2005; Varallyay 2010; Schils et al. 2008; Subke und Bahn 2010). Zum einen sind die Prozesse und Interaktionen des Bodenkohlenstoffhaushaltes noch nicht vollständig verstanden, zum anderen wirken sich regional ausgeprägte Klimabedingungen und deren Änderungen sowie Bodeneigenschaften und Bewirtschaftungsmaßnahmen z. T. gegenläufig und in komplexer Weise interagierend aus.

Hoch- und Niedermoore weisen die höchste Empfindlichkeit gegenüber dem Abbau der organischen Substanz auf. Eine Entwässerung und Austrocknung erhöht den Humusabbau in Mooren erheblich (z. B. Wessolek et al. 2003; Erwin 2009; Drösler et al. 2009) und lässt Moore zu Quellen von Treibhausgasen werden, während intakte Moore eine Senke darstellen (Erwin 2009). Vanselow-Algan (2014) hat durch ein Regenausschlussexperiment die Auswirkungen zunehmender Sommertrockenheit auf die Treibhausgasemissionen $\left(\mathrm{CO}_{2^{-}}, \mathrm{CH}_{4^{-}}\right.$und $\mathrm{N}_{2} \mathrm{O}$-Flüsse) in dem nordwestlich von Hamburg gelegenen Himmelmoor untersucht. In der von Torfmoosen und Heide dominierten Untersuchungsfläche nahmen die Treibhausgasemissionen bei Sommertrockenheit zu, während sie sich bei der von Pfeifengras bewachsenen Fläche durch eine deutliche Reduzierung der $\mathrm{CH}_{4}$-Emissionen verringerte. Die Untersuchungen zeigten darüber hinaus einen deutlich positiven Effekt der Renaturierung von Teilflächen des Moores auf die Treibhausgasemissionen. Die entwässerte Torfabbaufläche zeigte deutlich höhere Emissionen als die renaturierten Bereiche, die jedoch nach wie vor eine Quelle für Treibhausgase darstellten (Vanselow-Algan et al. 2015).

Insgesamt wird in der Fachdiskussion davon ausgegangen, dass veränderte Bodennutzungen wesentlich schneller als der Klimawandel zu Veränderungen der Humusgehalte in Böden führen (Lal 2014). Höper und Schäfer (2012) vergleichen die Kohlenstofffreisetzung aus Böden bei unterschiedlichen Bewirtschaftungsmaßnahmen und zeigen deutlich eine relevante Abnahme des Kohlenstoffpools durch Entwässerung von Mooren nachfolgender Bewirtschaftung und durch Grünlandumbruch von hydromorphen Böden.

Der Humusgehalt ist für viele Bodeneigenschaften und -funktionen ausschlaggebend und steuert maßgeblich die Bodenfruchtbarkeit (Lal 2010; Kimble et al. 1998; Scheffer und Schachtschabel 2010). Er steuert und beeinflusst z. B. die Wasserspeicherung und nutzbare Feldkapazität, die Nährstoffkreisläufe und Nährstoffnachlieferung, das Filter- und Puffervermögen des Bodens, die biologische Aktivität sowie die Speicherung von klimarelevanten Treibhausgasen und trägt zur Verbesserung des Bodengefüges bei. Böden mit ihrer organischen Substanz vermögen also über diese Eigenschaften und Funktionen Auswirkungen des Klimawandels z. B. durch erhöhte Wasserspeicherfähigkeit zu mildern bzw. diesen entgegenzuwirken. Die Steuerung des Kohlenstoffhaushaltes und Erhöhung des Humusgehaltes ist eine der wichtigsten Größen zur Sicherung der Ressource Boden und deren Anpassung an den Klimawandel (Lal 2014; Willand et al. 2014; Umweltbundesamt (2011)). 


\subsubsection{Potenzielle Auswirkungen des Klimawandels auf die Abkühlungsfunktion}

Eine weitere im besiedelten Raum wichtige Bodenfunktion, die durch den Klimawandel beeinflusst werden könnte, ist die Abkühlungsfunktion der Böden in der Stadt. Nicht versiegelte Böden nehmen am Wasserhaushalt teil und können durch Evapotranspiration, bei der flüssiges Wasser aus dem Bodenwasserspeicher unter Energieverbrauch in Wasserdampf umgewandelt wird, den Wärmehaushalt und damit das lokale Klima beeinflussen (Goldbach und Kuttler 2012). Durch Evapotranspiration wird die Umwandlung der eingestrahlten Energie in fühlbare Wärme reduziert und diese in Form von latenter Wärme abgegeben. Diese Verdunstungsleistung und Umwandlung von Energie in latente Wärme wird durch die Wasserverfügbarkeit und -nachlieferung im Boden gesteuert (Goldbach und Kuttler 2012). In Städten beeinträchtigen die Versiegelung des Bodens mit verringerter Infiltration und erhöhtem Oberflächenabfluss sowie die Grundwasserabsenkung und auch die weit verbreiteten urbanen Böden mit oft geringen nutzbaren Feldkapazitäten diese natürliche Klimafunktion (Wessolek et al. 2010; Jansson et al. 2007; Damm et al. 2012).

In Modellberechnungen wurde der Bereich des Grundwasserflurabstands von 2-5 m als kritische Zone identifiziert, da hier eine enge Korrelation zwischen dem Grundwasserflurabstand und der latenten Wärme gefunden wurde (Maxwell und Kollet 2008). Für Stadtböden in Hamburg mit unterschiedlichen Grundwasserflurabständen und mit sehr heterogener Bodenzusammensetzung zeigte sich, dass zwischen 11 und $17 \%$ der maximalen Temperaturunterschiede der Luft durch die unterschiedlichen Oberbodenwassergehalte erklärt werden können (Wiesner et al. 2014). Für Nordrhein-Westfalen wurde kürzlich ein Leitpfaden zur Einbringung der Kühlleistung von Böden in stadtklimatische Konzepte vorgelegt und die ökonomische Relevanz dieser Bodenfunktion dargestellt (LANUV 2015). Es ist davon auszugehen, dass sich die möglicherweise zu erwartende Verringerung der Sommerniederschläge und die Temperaturerhöhung ungünstig auf die Kühlfunktion auswirken werden. Das Problem der städtischen Überwärmung in den Sommermonaten wird durch die zu erwartende Klimaerwärmung voraussichtlich weiter verstärkt (Damm et al. 2012); es kann also eine unerwünschte positive Rückkopplung vermutet werden. Es besteht Forschungsbedarf, um diese Effekte des Klimawandels in der Stadt differenzierter betrachten zu können und gleichzeitig die Leistung von stark gestörten Böden und von künstlich konstruierten urbanen Böden und Pflanzengemeinschaften, die mit zunehmender Urbanisierung eine immer größere Rolle spielen werden, zu erfassen. Berechnungen weisen darauf hin, dass die gestörten neuen Bodenlandschaften in der Regel deutlich geringere potenzielle Kühlleistungen erzielen als der natürlicherweise ausgeprägte Boden (Willand et al. 2014).

\subsection{Auswirkungen des Klimawandels auf Arten, Lebensgemeinschaften und Ökosysteme}

Der robuste Erwärmungstrend, den wir mit Fortschreiten der Industrialisierung seit einigen Jahrzehnten weltweit beobachten, ist ungebrochen und wird sich wegen der Trägheit des Klimas auch im weiteren Verlauf des 21. Jahrhunderts fortsetzen. Der Anstieg der globalen Mitteltemperaturen geht mit Veränderungen der Niederschlagsmuster und einer Zunahme bislang als extrem geltender Witterungsereignisse einher. Der global gemittelte Temperaturanstieg zwischen 1880 und 2012 betrug $0,85^{\circ} \mathrm{C}$, in Deutschland sogar $1,3^{\circ} \mathrm{C}$, und in Hamburg ist die Mitteltemperatur seit 1881 um gut $1{ }^{\circ} \mathrm{C}$ angestiegen (IPCC 2014; Trusilova und Riecke 2015). Ohne umfangreiche Maßnahmen zur Vermeidung der Emission von Treibhausgasen ist bis zum Jahr $2100 \mathrm{im}$ globalen Mittel ein Temperaturanstieg von $3-5^{\circ} \mathrm{C}$ gegenüber dem ersten Jahrzehnt des 20. Jahrhunderts zu erwarten (IPCC 2014). Der in den letzten Dekaden ermittelte rasche Temperaturanstieg ist erdgeschichtlich nicht extrem, gilt jedoch für die Jahrtausende mit menschlicher Zivilisation als bisher einmalig und ist gegenüber paläoklimatischen Veränderungen zum ersten Mal überwiegend durch anthropogene Aktivitäten verursacht.

Die Frage nach der Entwicklung der belebten Umwelt unter den Bedingungen des Klimawandels gehört zu den aktuellen Kernfragen der Erdsystemwissenschaften. Die Bedeutung der Vegetation in den globalen biogeochemischen Stoffkreisläufen (vor allem Kohlenstoff, Wasser) oder deren Rolle als strukturelle und funktionale Komponente in Ökosystemen führt die Dringlichkeit vor Augen, ein besseres Verständnis der ökosystemaren Auswirkungen des Klimawandels zu entwickeln. Dass Klimaänderungen in der Erdgeschichte in der Regel tief greifende Konsequenzen für Ökosysteme gehabt haben, lehren uns Pollenanalysen und andere paläoökologische Untersuchungen (z. B. Giesecke et al. 2014; Jackson und Blois 2015). Die Wälder Nordund Mitteleuropas wurden beispielsweise während der Eiszeiten mehrfach massiv zurückgedrängt und mussten sich in den Warmzeiten jeweils neu etablieren, was zu großen Artenverlusten führte. Die ökologische Anpassung an solche Klimaänderungen beanspruchte einen Zeitraum von Jahrtausenden. Allerdings lassen sich Erkenntnisse aus der Paläo-Vegetationsentwicklung aufgrund der unterschiedlichen ökologischen Rahmenbedingungen kaum auf die zukünftige Vegetationsdynamik übertragen. Es bestehen nach wie vor erhebliche Unsicherheiten bzgl. der konkreten Reaktion von Ökosystemen auf den Klimawandel. Die Kenntnisse über die Biosphäre mit ihren vielfältigen und hoch komplexen lebenden Systemen, die durch unterschiedlichste funktionelle Interaktionen und Prozesse gekennzeichnet sind, reichen bisher keinesfalls aus, um gesicherte Vorhersagen künftiger Entwicklungen in Ökosystemen treffen zu können (z. B. Luo et al. 2011; Bellard et al. 2012). Auch neuere Simulationsmodelle zur globalen Vegetationsentwicklung liefern allenfalls großräumige Übersichten zur Verschiebung von Vegetationszonen und zur Biomasseentwicklung. Aufgrund ihrer geringen räumlichen Auflösung und des hohen Komplexitätsgrades der Biosphäre können sie jedoch keine konkreten ökosystemaren Auswirkungen des Klimawandels prognostizieren. Wissensdefizite betreffen 
nahezu alle Konsequenzen sowohl für Artenzusammensetzung und Artenvielfalt als auch für Strukturen und Funktionalität von Ökosystemen, insbesondere jedoch die Auswirkungen auf den Stoffhaushalt, die Konkurrenzverhältnisse von Pflanzenarten und viele weitere biotische Interaktionen, die Wanderungsmöglichkeiten von Populationen und Arten sowie die zu erwartenden Verluste an Biodiversität.

Da die Geschwindigkeit des Klimawandels die Anpassungsfähigkeit vieler Arten überfordern wird, sind Verluste an Biodiversität unvermeidlich, zumindest auf globaler Ebene (vgl. Moritz und Agudo 2013; Warren et al. 2013). Jede Art reagiert individuell unterschiedlich auf klimatische Veränderungen (Anderson et al. 2012). Spezifische Ausbreitungsgeschwindigkeiten von sich neu etablierenden Arten sowie artspezifische Reaktionen z. B. auf verlängerte Wuchsperioden, die in unterschiedlichen Biomassezuwächsen zum Ausdruck kommen können, oder auf eine veränderte Spätfrostgefährdung werden einen Wandel der Konkurrenzverhältnisse und somit der Artabundanzen und Artdominanzen zur Folge haben. Biomverschiebungen werden daher nicht ohne grundlegende Änderungen von Artenzusammensetzung und Dominanzstrukturen der Lebensgemeinschaften erfolgen (z. B. Lurgi et al. 2012). Neuartige Biozönosen werden entstehen, deren Struktur und Funktion indes auch von anderen anthropogenen Einflüssen (Habitatkonversion und -fragmentierung, Ressourcenübernutzung, stoffliche Belastungen, Artenverschleppungen) stark bestimmt sein wird. Veränderte Dominanzverhältnisse, Konkurrenzbedingungen und Populationsdichten wirken sich zwangsläufig auf die funktionelle Vielfalt von Ökosystemen und damit auf die ökologische Funktionalität aus, die für die Bereitstellung ökologischer Serviceleistungen oder auch für die Resilienz gegenüber Störungen durch klimatische Veränderungen oder Extremereignisse entscheidend ist. Die Aufrechterhaltung von ökologischen Serviceleistungen wie sauberes Grundwasser, Bestäubung von Obstbäumen oder Hangstabilität ist für das Leben und auch das Wirtschaften des Menschen essenziell. Eine Beeinträchtigung der ökologischen Funktionalität und Stabilität von Ökosystemen durch den Verlust an Biodiversität hätte tief greifende Konsequenzen für Wirtschaft und Gesellschaft (Beierkuhnlein und Foken 2008).

$\mathrm{Zu}$ den Auswirkungen des Klimawandels auf Arten, Lebensgemeinschaften und Ökosysteme gibt es bisher kaum Studien, die sich konkret auf die MRH beziehen. Die in Mitteleuropa und darüber hinaus gewonnenen Erkenntnisse zu den Klimawandelfolgen können jedoch prinzipiell auf die MRH übertragen werden, auch wenn es regionale Abweichungen gibt. Auf diese wird bei der Bearbeitung ausgewählter Ökosysteme der MRH ( Abschn. 6.5.1, 6.5.2, 6.5.3, 6.5.4, 6.5.5, 6.5 .6) hingewiesen, die sowohl naturnahe Ökosysteme (Wälder, Ästuare und Küstenökosysteme, Moore) als auch solche der Kulturlandschaft (Heiden, Feuchtgrünland) und des Siedlungsraums umfasst. Der Behandlung spezieller Lebensraumtypen wird in den nächsten Abschnitten der Kenntnisstand zu generellen Effekten des Klimawandels auf Arten und Ökosysteme vorangestellt, um einen Verständnisrahmen für die weiteren Ausführungen zu schaffen. Dabei stehen Auswirkungen auf Pflanzen und Vegetation im Vordergrund.

\subsubsection{Phänologie}

Standardisierte Erfassungen des Deutschen Wetterdienstes, der Internationalen Phänologischen Gärten und anderer Institutionen dokumentieren seit einigen Jahrzehnten, dass sich phänologische Ereignisse in Reaktion auf den rezenten Klimawandel verschieben. Diese im Jahresablauf periodisch wiederkehrenden Ereignisse im Lebenszyklus von Organismen sind im temperaten Klima der feuchten Mittelbreiten maßgeblich von Temperatur und Photoperiode (Tages- und Nachtlänge) abhängig (Rabitsch und Herren 2013). Dazu gehören beispielsweise Blattaustrieb, Blattentfaltung, Knospung, Blüten- und Fruchtbildung, Reifestadien bei Getreide, Beginn und Ende des Winterschlafs, Vogelzugtermine, Wanderungen, Eiablage oder herbstliche Blattverfärbung und Blattfall. Charakteristische Eintrittszeiten der jahreszeitlich wiederkehrenden Entwicklungsstadien in der Pflanzen- und Tierwelt, auch als Phänophasen bezeichnet, verschieben sich in der Regel bei Änderungen der klimatischen Rahmenbedingungen, auch wenn die Phänologie einiger Arten, z. B. alpiner Pflanzenarten, eine gewisse Sensitivität gegenüber der Photoperiode zeigt (Keller und Körner 2003; Körner und Basler 2010).

Die Verschiebung phänologischer Ereignisse gilt als sensible Indikation der Reaktion von Organismen auf klimatische Trends. Zahlreiche Studien haben weltweit und bei verschiedensten Pflanzen- und Tierarten einen phänologischen Fingerabdruck des rezenten Klimawandels nachgewiesen, wobei besonders deutliche phänologische Verschiebungen in höheren Breiten aufgetreten sind (Walther et al. 2002; Parmesan und Yohe 2003; Root et al. 2003; Menzel et al. 2006a, 2006b; Amano et al. 2010; Cook et al. 2012; Ovaskainen et al. 2013; Peñuelas et al. 2013). Die rezente Klimaerwärmung hat in den letzten Jahrzehnten in der Nordhemisphäre zu einer Verschiebung phänologischer Ereignisse um einige Tage pro Dekade geführt (Rabitsch und Herren 2013; Settele et al. 2014). Davon sind insbesondere Ereignisse im zeitigen Frühjahr betroffen. Der Eintritt des phänologischen Frühlings hat sich in der Nordhemisphäre im Mittel um 3 Tage pro Dekade vorverlegt (Parmesan 2007), während die Verspätung der Herbstphasen geringer ausfällt (Menzel et al. 2006b). In den mittleren Breiten der Nordhalbkugel ergibt sich dadurch insgesamt eine Verlängerung der Vegetationsperiode um 14-24 Tage in den letzten 5-7 Jahrzehnten (vgl. Menzel 2013; Kolářová et al. 2014; Schuster et al. 2014), die mit anderen Proxydaten (z. B. Vegetationsindizes aus Satellitenbildern, Jahresgang des $\mathrm{CO}_{2}$-Gehaltes der Atmosphäre) und abiotischen Signalen (z. B. Auftauen und Zufrieren von Flüssen und Seen) sehr gut übereinstimmt (Tucker et al. 2001; Nemani et al. 2003).

In Mitteleuropa werden die deutlichsten phänologischen Änderungen bei Pflanzen im Frühling festgestellt. Eine signifikante Verfrühung der Pflanzenentwicklung ist sowohl für Wild- als auch für Kulturpflanzen vielfach nachgewiesen worden (Chmielewski und Rötzer 2001; Chmielewski et al. 2004; Menzel et al. 2006a; Estrella et al. 2007; Wittich und Liedtke 2015; Chmielewski 2016), wobei sich der Trend im Zeitraum 2000-2011 verlangsamt hat (Fu et al. 2014). Eine der längsten kontinuierlichen phänologischen Datenreihen Europas (seit 1808) dokumentiert das Öffnen der Blattknospen der Rosskastanie (Aesculus hippo- 
Blattausbruch der Rosskastanie in Genf 1808-2016



- Abb. 6.4 Das Öffnen der Blattknospen der Rosskastanie (Aesculus hippocastanum) in Genf im Zeitraum 1808-2016. Blaue Linie: Eintrittstermine, rote Linie: 20-jähriges gewichtetes Mittel. (Meteo-Schweiz)

castanum) in Genf ( $\bullet$ Abb. 6.4), das den deutlichen Trend $\mathrm{zu}$ früheren Eintrittsterminen ab etwa 1900 sowie eine abrupte Verfrühung seit Ende der 1980er-Jahre belegt. Diese Verschiebung wird in langen Datenreihen auch am Beispiel des Blühbeginns für viele Arten sehr deutlich. Der Blühbeginn der Obstgehölze in Deutschland hat sich in den letzten 55 Jahren für Süßkirsche, Birne, Sauerkirsche und Apfel um mindestens 15 Tage verfrüht (- Tab. 6.2). Im selben Zeitraum hat sich der Erntetermin für Gerste und Winterweizen um 16 bzw. 11 Tage vorverlegt (Prochnow et al. 2015). Für den Zeitraum 1959-1993 ist eine durchschnittliche Vorverlegung von Frühlingsereignissen um 6 Tage und eine Verspätung von Herbstereignissen um 4,8 Tage dokumentiert, was einer Verlängerung der Vegetationsperiode um etwa 11 Tage entspricht (Menzel und Fabian 1999; Sparks et al. 2011). Bei unveränderten klimatischen Trends könnte sich die Vegetationsperiode im Zeitraum 2071-2100 um mehr als einen Monat verlängert haben (Krause 2010). Auch für die MRH sind entsprechende phänologische Änderungen dokumentiert. So hat sich der Blühbeginn der Forsythie (Forsythia intermedia) seit 1945 um etwa 4 Wochen verfrüht (• Abb. 6.5; Rötzer et al. 2000; Jensen et al. 2011). In städtischen Ballungszentren setzen aufgrund des Effektes der städtischen Wärmeinsel phänologische Frühlingsereignisse oftmals früher ein als im Umland (vgl. Lu et al. 2006; Jochner et al. 2012).

\subsection{2 Ökophysiologie, Primärproduktion und Kohlenstoffspeicherung}

Die Frage nach den Auswirkungen der klimatischen Veränderungen auf die Fitness und Produktivität von Pflanzen ist in hohem Maße klimarelevant, da der terrestrischen Biosphäre eine zentrale Rolle im globalen Kohlenstoffkreislauf zukommt und Änderungen der Primärproduktion mit Änderungen in der Kohlenstoffspeicherung von Ökosystemen einhergehen. Die Photosyntheseleistung einer Pflanze hängt von Faktoren wie der Temperatur, der Wasserverfügbarkeit und der $\mathrm{CO}_{2}$-Konzentration in der Atmosphäre ab, die sich im Zuge des rezenten Klimawandels verändern. Änderungen der Wuchsbedingungen können sich wiederum indirekt auf die Wasser- und Nährstoffnutzungseffizienz auswirken; auch Stressreaktionen der Pflanzen sind oftmals klimasensitiv, z. B. die Reaktion auf zunehmende Sommertrockenheit. Je nach Konstellation der an einem Standort zusammenwirkenden Faktoren kann eine Pflanze in ihrer Biomasseproduktion, die generell durch das natürliche Angebot an $\mathrm{CO}_{2}$ limitiert ist, unterschiedlich auf eine Erhöhung der Temperatur und der $\mathrm{CO}_{2}$-Konzentration reagieren.

Theoretisch zu erwarten und empirisch belegt ist eine Steigerung der Primärproduktion durch ein erhöhtes $\mathrm{CO}_{2}$-Angebot und höhere Temperaturen, wobei das Ausmaß der Erwärmung eine Rolle spielt und der positive Effekt einer $\mathrm{CO}_{2}$-Anreicherung auf die Nettophotosynthese bei Leguminosen deutlicher festzustellen ist als bei Nichtleguminosen, bei Wildpflanzen deutlicher als bei Kulturpflanzen und bei Gehölzen deutlicher als bei krautigen Pflanzen (Wang et al. 2012). Die Unterschiede zwischen Leguminosen und Nichtleguminosen deuten darauf hin, dass die Effekte der sich wechselseitig beeinflussenden Faktoren Erwärmung und erhöhtes $\mathrm{CO}_{2}$-Angebot auch von der Stickstoffversorgung der Pflanzen beeinflusst werden. Aus den Ergebnissen zahlreicher experimenteller Untersuchungen (zusammengefasst in Ainsworth und Long 2005; Ainsworth und Rogers 2007; Leakey et al. 2009; Wang et al. 2012) lässt sich für C3-Pflanzen die mehr oder weniger einheitliche Tendenz ableiten, dass sich die Nettoprimärproduktion langfristig trotz reduzierter Assimilationskapazität erhöht, dass sowohl die Stickstoff- als auch die Wassernutzungseffizienz ansteigt und dass die produzierte organische Substanz ein höheres C/N-Verhältnis und einen höheren Kohlenhydratgehalt aufweist, was sich wiederum auf die Abbaurate der abgestorbenen Biomasse auswirken kann (vgl. Jensen et al. 2011). Bei C3-Pflanzen geht die effizientere Ausnutzung des Photosyntheseapparates unter erhöhter $\mathrm{CO}_{2}$-Konzentration mit einer Reduktion des Carboxylierungspotenzials und einer Verringerung der Kapazität des photosynthetischen Elektronentransports einher (Ainsworth und Rogers 2007). Geringere Gehalte des carboxylierenden Enzyms RuBisCO ziehen einen Rückgang des Stickstoffgehaltes der Blätter nach sich, der wiederum in einem erhöhten $\mathrm{C} / \mathrm{N}$-Verhältnis resultiert. Das Wachstum von C3-Pflanzen wird unter erhöhtem $\mathrm{CO}_{2}$-Angebot selbst bei defizitärer Wasserversorgung stimuliert (Xu et al. 2013). Die höhere Wassernutzungseffizienz (geringere Transpiration pro fixiertem $\mathrm{CO}_{2}$ ) geht auf die Reduktion der stomatären Leitfähigkeit unter erhöhten $\mathrm{CO}_{2}$-Konzentrationen zurück, die sich in entsprechenden Freilandexperimenten um durchschnittlich $20 \%$ verringerte (Ainsworth und Long 2005). Eine reduzierte Transpirationsleistung wirkt sich potenziell auf die Wasserbilanz ganzer Ökosysteme aus.

Aufgrund der $\mathrm{CO}_{2}$-Konzentrationsmechanismen des C4Photosyntheseweges ist bei den in subtropischen und tropischen Regionen verbreiteten C4-Pflanzen von geringeren Effekten einer $\mathrm{CO}_{2}$-Anreicherung auf Nettophotosynthese und Biomasseproduktion auszugehen (Wang et al. 2012). Bei C4-Pflanzen wird die Photosynthese bei erhöhter $\mathrm{CO}_{2}$-Konzentration nicht direkt stimuliert, die Assimilation von Kohlenstoff wird aber auf trockenen Standorten bzw. in Dürrezeiten, wenn die höhere Wassernutzungseffizienz wirksam wird, indirekt begünstigt (Leakey et al. 2009; Xu et al. 2013). Die Steigerung der Primärproduktion 
- Tab. 6.2 Mittlere Eintrittstermine und Trends im Blühbeginn von Obstgehölzen in Deutschland. (Chmielewski 2016)

\begin{tabular}{|c|c|c|c|c|c|}
\hline Obstart & $\mathbf{x}$ & Datum & s & T in 55 Jahren & Konfidenzintervall \pm Tage \\
\hline Süßkirsche & 113 & 23.04 . & 8,0 & $-14,9 * * *$ & 2,2 \\
\hline Birne & 117 & 27.04 . & 9,0 & $-19,1^{* * *}$ & 2,4 \\
\hline Sauerkirsche & 118 & 28.04. & 7,7 & $-16,1^{* * *}$ & 2,1 \\
\hline Apfel & 124 & 04.05 & 7,4 & $-14,5^{* * *}$ & 2,0 \\
\hline \multicolumn{6}{|c|}{$\begin{array}{l}\text { x: mittlerer Eintrittstermin in Tagen nach Jahresbeginn; s: Standardabweichung der Jahreswerte; T: Trend } 1961-2015 \text { mit } 95 \% \text {-Konfidenzintervall i } \\
\text { Tagen }\end{array}$} \\
\hline \multicolumn{6}{|c|}{ Trends signifikant mit einer Irrtumswahrscheinlichkeit ${ }^{* *} p>0,1 \%$} \\
\hline
\end{tabular}

\section{Forsythien-Kalender für den Standort "Hamburger Lombardsbrücke" 1945 bis 2016 notiert von Carl Wendorf (+ 1984) und Jens Iska-Holtz}

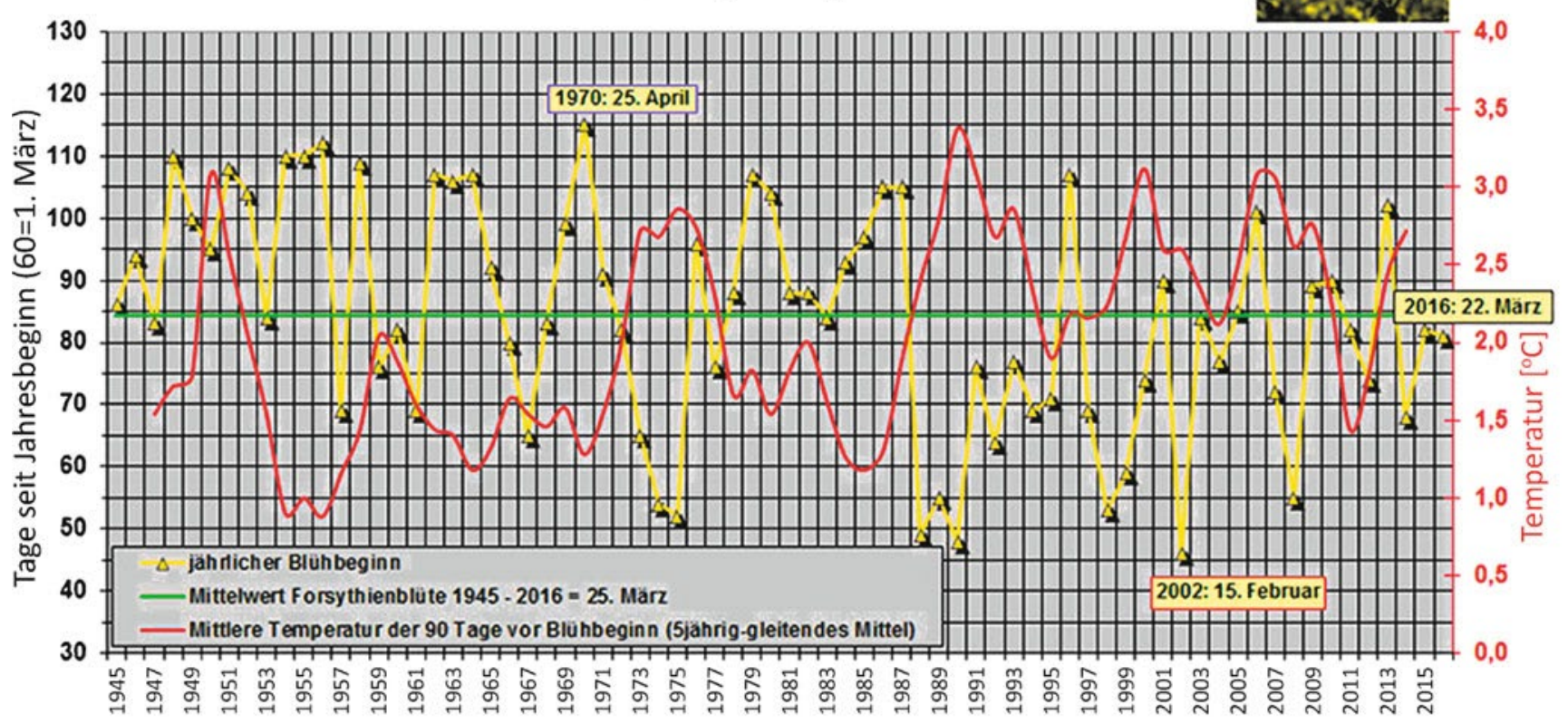

D Abb. 6.5 Forsythien-Kalender (Forsythia intermedia) für den Standort „Hamburger Lombardsbrücke“ 1945-2016. (Deutscher Wetterdienst)

fällt sowohl bei Wild- als auch bei Kulturpflanzen insgesamt geringer aus, als lange Zeit angenommen wurde. Auch ist zu berücksichtigen, dass erhebliche Unterschiede zwischen Ökosystemen, funktionalen Pflanzentypen (z. B. Bäume, Sträucher, Gräser) sowie auch zwischen Arten eines funktionalen Typs auftreten können, was das Ausmaß der Erhöhung der Nettoprimärproduktion betrifft.

In den letzten Jahrzehnten ist die Nettoprimärproduktion global leicht angestiegen. Im Zeitraum 1982-1999 betrug der Anstieg etwa $6 \%$ (Myneni et al. 1997; Zhou et al. 2001; Nemani et al. 2003), in der Dekade 2000-2009 setzte sich der Anstieg mit etwa $5 \%$ relativ zum vorindustriellen Level fort, sodass die terrestrische Vegetation erhebliche Mengen des vom wirtschaftenden Menschen freigesetzten Kohlenstoffs gebunden hat (Raupach et al. 2008; Le Quéré et al. 2009; Settele et al. 2014). Aus der Erhöhung der Nettoprimärproduktion lässt sich ableiten, dass die wachstumsfördernden Effekte von $\mathrm{CO}_{2}$-Anstieg (Kohlenstoffdüngung) und Klimawandel bisher überwiegen. Allerdings muss berücksichtigt werden, dass auch andere Faktoren wie Stickstoffdeposition, Aufforstung und Landmanagement den Biomassenzuwachs und die Kohlenstoffspeicherung positiv beeinflussen. In den Wäldern Mitteleuropas wurden in den letzten Jahrzehnten überwiegend Zuwachssteigerungen festgestellt, die temperaten Wälder sind eine bedeutende Senke für Kohlenstoff (Hasenauer et al. 1999; Karnosky et al. 2007). Dieser positive Zusammenhang könnte sich jedoch mit fortschreitendem Klimawandel in der zweiten Hälfte dieses Jahrhunderts umkehren, da andere Prozesse die Kohlenstoffspeicherung in der Biosphäre reduzieren können (Essl et al. 2013a). Die Intensivierung von Störungsregimen 

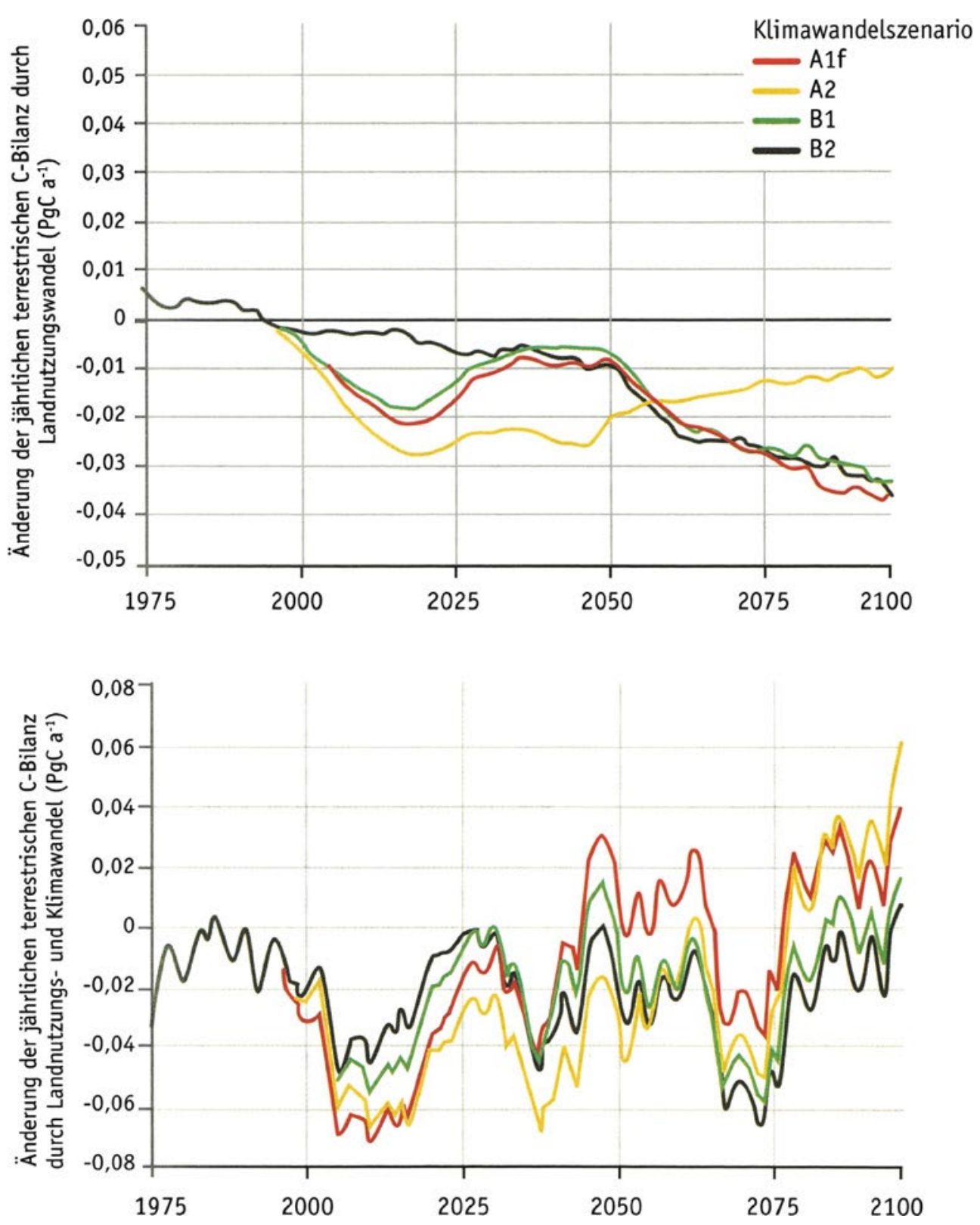

- Abb. 6.6 Änderung des globalen terrestrischen Kohlenstoffspeicherungspotenzials unter verschiedenen Klimawandelszenarien im 21. Jahrhundert. Negative Werte bedeuten eine zunehmende und positive Werte eine abnehmende Kohlenstoffsequestrierung der terrestrischen Biosphäre. (Essl et al. 2013a) (z. B. klimatische Extremereignisse, Insektenkalamitäten, Feuer) kann über die Mortalität von Wäldern zu einem Rückgang der Primärproduktion führen. Bezüglich der Steuerung der Kohlenstoffspeicherung in der terrestrischen Biosphäre kommt der Niederschlagssumme eine besondere Bedeutung $\mathrm{zu}$ (Beer et al. 2010). Vermehrter Trockenstress in den Sommermonaten, wie er für Mitteleuropa projiziert wird (z. B. Kovats et al. 2014), würde die Kohlenstoffspeicherung einschränken und könnte die Landflächen zu einer $\mathrm{CO}_{2}$-Quelle werden lassen. Gegenwärtige Modellberechnungen gehen in ihrer Mehrzahl von einem Rückgang der Netto-Kohlenstoffaufnahme der terrestrischen Ökosysteme im Verlauf des 21. Jahrhunderts aus; einige Modelle sagen mit weiterem Voranschreiten des Klimawandels den Wandel von terrestrischer Vegetation und Böden zu einer $\mathrm{CO}_{2}$-Quelle voraus ( $\bullet$ Abb. 6.6; Zaehle et al. 2007; Le Quéré et al. 2009; Settele et al. 2014).

\subsubsection{Biotische Interaktionen}

Die Auswirkungen des Klimawandels auf die funktionellen Beziehungen und Wechselwirkungen zwischen Organismen, die als biotische Interaktionen bezeichnet werden, sind immer noch weitgehend unklar. Das für Ökosysteme charakteristische enge Netzwerk gegenseitiger Abhängigkeiten und Beeinflussungen (z. B. Nahrungsnetze, Nahrungsketten, Pflanzenbestäubergemeinschaften) ermöglicht ein gewisses Maß an Selbstregulation und Resilienz gegenüber Umweltveränderungen. Die dynamische Stabilität und die Gewährleistung der Funktionsfähigkeit von Ökosystemen wären bei einem Verlust von funktionellen Beziehungen und ökologischer Komplexität beeinträchtigt (Beierkuhnlein und Jentsch 2005; Schmid et al. 2009; Hillebrand und Fitter 2013). Der Klimawandel wird sich zwangsläufig auf das auf verschiedensten Interaktionen basierende Beziehungsgeflecht in Ökosystemen aus- 
wirken. Arten weisen individuelle Kombinationen von Merkmalen, Nischenbedürfnissen und Reaktionstoleranzen auf und reagieren somit artspezifisch auf klimatische Änderungen. Aufgrund von Individualität und intraspezifischer Variabilität ändert sich die Wettbewerbsfähigkeit von Arten bei einer klimawandelbedingten Änderung des standörtlichen Beziehungsgefüges. Es kommt zu Änderungen von Artenzusammensetzung und Dominanzstrukturen, teilweise zum Ausfall von Arten. Dadurch entstehen veränderte Lebensgemeinschaften („novel communities“), die einstweilen durch das Fehlen von koevolvierten, d. h. lang etablierten biotischen Interaktionen charakterisiert sind (Schweiger et al. 2013). Neben einer weiteren Beeinflussung der Konkurrenzverhältnisse können davon so fundamentale ökologische Beziehungen wie Herbivorie, Bestäubung, Prädation oder Parasitismus betroffen sein, was potenziell in einer Beeinträchtigung von Ökosystemfunktionen und damit zusammenhängenden ökologischen Serviceleistungen resultiert (Tylianakis et al. 2008; Montoya und Raffaelli 2010; Schweiger et al. 2010).

Trotz des defizitären Kenntnisstandes ist inzwischen eine Vielzahl von klimawandelbedingten Änderungen in ökologischen Beziehungen belegt. Bekannt sind die Beispiele phänologischer Entkopplung, bei denen die zeitliche Abstimmung des Lebenszyklus z. B. von Herbivoren und ihren Nahrungspflanzen nicht mehr gegeben ist, weil Pflanzen früher austreiben als Tiere aktiv werden oder umgekehrt. Die zeitliche Entkopplung von interagierenden Arten kann gravierende Änderungen in Nahrungsnetzen über verschiedene trophische Ebenen hinweg zur Folge haben, die erst durch evolutive Anpassungen ausgeglichen werden können (van der Putten et al. 2004; van Asch und Visser 2007; Both et al. 2009). Aufgrund von Arealänderungen treten auch räumliche Entkopplungen zwischen Pflanzen und ihren Herbivoren auf, die neuartige Nahrungsbeziehungen zwischen Schädlingen und Wirtspflanzen entstehen lassen können. Wie Hódar und Zamora (2004) gezeigt haben, befällt der südeuropäische Pinien-Prozessionsspinner (Thaumetopoea pityocampa) nach seiner Arealausweitung nach Norden bzw. in größere Höhenlagen auch Arten wie die Waldkiefer (Pinus sylvestris), die nicht in dem bisherigen Verbreitungsgebiet vorkamen.

Der Klimawandel gilt nach Landnutzungsveränderungen als zweitwichtigste Ursache für den Rückgang von Bestäubern (Potts et al. 2010). Er wirkt sich in vielfältiger Weise und in der Regel negativ auf die Interaktionen zwischen Blütenpflanzen und Bestäubern aus (Hegland et al. 2009; Schweiger et al. 2010; Kjøhl et al. 2011). Da 60-80 \% der Wildpflanzen und etwa $35 \%$ der Feldfrüchte von Bestäubern abhängig sind (Kearns et al. 1998), stellt die Bestäubung eine fundamental wichtige ökologische Serviceleistung dar, die durch den massiven Rückgang von Bienenarten und anderen Bestäubern gefährdet ist (Burkle et al. 2013). Der Klimawandel führt über die Beeinflussung von Metabolismus, Phänologie, Verbreitung und Merkmalen von Pflanzen und Bestäubern zu Diskrepanzen in deren Interaktionen, die sich wiederum auf Reproduktionserfolg und Populationsdynamik auswirken (Schweiger et al. 2013). Für den verbreitet zu beobachtenden Rückgang von Honigbienen sind Faktoren wie Pestizideinsatz, Krankheiten und Stress bzw. deren Kombination relevanter als der Klimawandel, Letzterer erhöht jedoch inner- halb des Faktorenkomplexes die Sensitivität gegenüber anderen Einflüssen (Le Conte und Navajas 2008). In welchem Ausmaß die Ökosysteme der Zukunft durch klimawandelbedingte Änderungen von biotischen Interaktionen in Mitleidenschaft gezogen werden, kann gegenwärtig nur schwer abgeschätzt werden. Die Wechselwirkungen sind extrem vielschichtig und schwierig $\mathrm{zu}$ erfassen. Andererseits werden zuverlässige Abschätzungen der sich verändernden Bereitstellung von ökologischen Serviceleistungen zunehmend wichtiger, um potenziell erhebliche Konsequenzen für Gesellschaft und Wirtschaft abmildern zu können.

\subsubsection{Arealerweiterungen und Arealverluste}

Das Areal oder Verbreitungsgebiet einer Art hängt in seiner Größe und Lage vom Einfluss der Umweltbedingungen auf die Populationsdynamik der einzelnen Individuen (Überleben, Reproduktion, Ausbreitung) ab. Die äußere Grenze des potenziellen Areals ist großklimatisch bedingt. Selbst wenn ausreichend Zeit für die Ausbreitung zur Verfügung steht, gelangt eine Art aber niemals in alle Teile ihres potenziellen Areals, da Ausbreitungsschranken (Meere, Gebirge) und Ansiedlungshindernisse (z. B. ungeeignete Bodenverhältnisse, Konkurrenz, Prädation, Mangel an Symbionten, Wirten, Bestäubern) die Arealausfüllung einschränken. Das reale Areal, die räumliche Entsprechung der realisierten ökologischen Nische, ist daher in der Regel kleiner als das potenzielle Areal. Die Wettbewerbsfähigkeit, die durch Umweltbedingungen im Bereich der realen Arealgrenzen herabgesetzt wird, spielt oft eine entscheidende Rolle: In botanischen Gärten, in denen die Konkurrenz ausgeschaltet wird, lassen sich Arten noch weit jenseits der realen Arealgrenzen kultivieren. Da die Umweltbedingungen nie konstant bleiben, unterliegen die Areale stets einer gewissen Dynamik, die an den Arealrändern in progressiven oder regressiven Arealentwicklungen zum Ausdruck kommt. Arealänderungen sind begleitet von veränderter Abundanz von Arten, von Kolonisierungsprozessen sowie lokalen Aussterbeereignissen. Wenn von diesen Veränderungen dominante Arten wie Bäume, Schlüsselarten wie Bestäuber oder z. B. Arten, die als Vektoren für Krankheitserreger fungieren, betroffen sind, kann dies gravierende Auswirkungen auf ökologische Serviceleistungen haben (Zarnetske et al. 2012; Settele et al. 2014).

Im Zuge des Klimawandels werden zunehmend Veränderungen der Verbreitungsgebiete von Arten dokumentiert, wobei Arealerweiterungen gegenüber Arealverlusten sehr stark überrepräsentiert sind (Parmesan und Yohe 2003; Parmesan 2007; Chen et al. 2011). Thermophile Arten können bei sich verändernden bioklimatischen Voraussetzungen ihre polwärtigen Arealgrenzen bzw. ihre Höhengrenzen in Gebirgen im Rahmen komplexer Reaktionen auf neue Konstellationen von Umweltfaktoren (neben der Erwärmung insbesondere Veränderungen von Niederschlagsmustern, Landnutzung, biotischen Interaktionen, daneben viele weitere Faktoren) verschieben. Solche Arealexpansionen können rasch ablaufen und sind deutlich sichtbar, während Arealverkleinerungen an äquatorwärtigen Arealgrenzen oder unteren Grenzen in Gebirgen das Ergebnis längerfristiger populationsökologischer Veränderungsprozesse sind, die nur mit aufwendigem quantitati- 

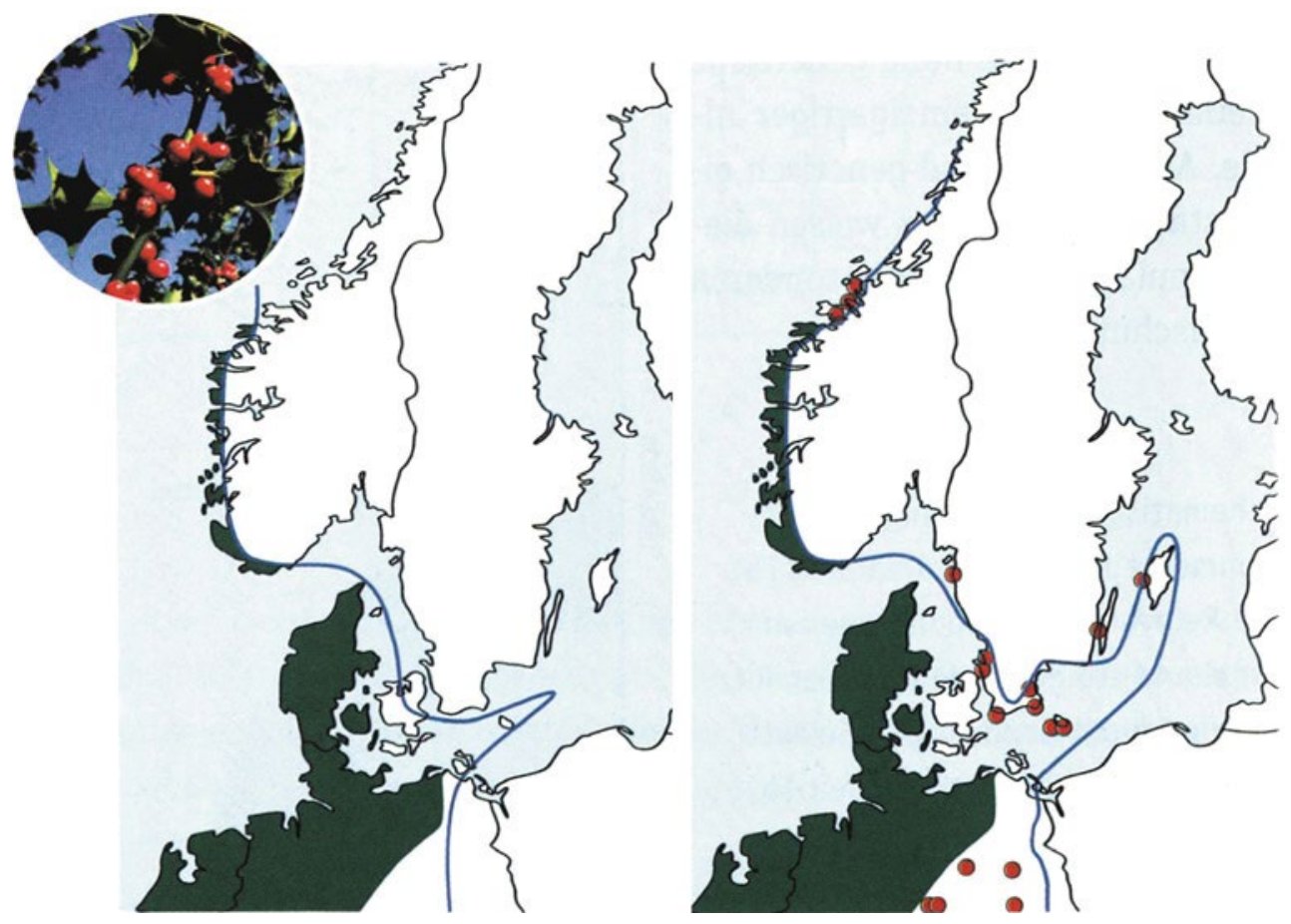

- Abb. 6.7 Verbreitung der Stechpalme (Ilex aquifolium) im nördlichen Mitteleuropa und Nordeuropa Mitte des 20. Jahrhunderts (links) und zu Beginn des 21. Jahrhunderts (rechts) mit entsprechenden Verläufen der $0{ }^{\circ} \mathrm{C}$-Januar-Isotherme (blaue Linie). (Rabitsch et al. 2013a)

vem Monitoring über längere Zeiträume nachzuweisen sind (vgl. Dullinger et al. 2012). Die Reaktion von Pflanzenarten auf günstiger werdende Klimabedingungen in Form einer Kolonisation von neuen Lebensräumen ist in der Regel kurzfristiger und viel deutlicher erkennbar als die Reaktion auf ungünstiger werdende klimatische Verhältnisse in Form lokalen Aussterbens (Doak und Morris 2010; Chen et al. 2011). So kann es zeitweilig zu einer $\mathrm{Zu}$ nahme der Artenzahlen durch in höhere Breiten oder Lagen einwandernde Arten kommen. Da die Populationen auf dem Rückzug befindlicher Arten kühlerer (Hoch-)Lagen langfristigen Aussterbeprozessen unterliegen („Aussterbeschuld“; Dullinger et al. 2012), werden sich die Artenzahlen wieder verringern, möglicherweise bis unter den Ausgangswert. Die Einflüsse sich verändernder Umweltbedingungen können ebenfalls zu Arealerweiterungen führen, die äquatorwärts bzw. bergabwärts gerichtet sind (Crimmins et al. 2011; McCain und Colwell 2011).

Globale Metaanalysen belegen zunehmende, durch den Klimawandel ausgelöste Arealerweiterungen zahlreicher Pflanzen- und Tierarten. Parmesan und Yohe (2003) ermittelten für 279 Arten eine mittlere polwärtige Arealverschiebung um 6,1 km/Dekade. Chen et al. (2011) stellten für verschiedene taxonomische Gruppen eine mittlere Arealverschiebung in höhere Breiten um 16,9 km/Dekade und in höhere Lagen in Gebirgen um 11 m/Dekade fest. Für Großbritannien wurde eine Arealverschiebung nach Norden um 12-25 km/Dekade für 275 Arten aus 16 verschiedenen Tiergruppen dokumentiert (Hickling et al. 2006). Im nördlichen Mitteleuropa ist eine auffällige Arealerweiterung nach Norden für die Stechpalme (Ilex aquifolium) belegt (• Abb. 6.7) (Walther et al. 2005; Berger et al. 2007). Dieser kälteempfindliche, in atlantisch beeinflussten Regionen Westeuropas vorkommende immergrüne kleine Baum hat sein Areal in den letzten Jahrzehnten in Anpassung an mildere Wintertemperaturen und weniger extreme Frostereignisse nach Norden und in Deutschland nach Osten ausgedehnt. Neben den horizontalen Arealausdehnungen ist für verschiedene Pflanzenund Tierarten auch ein Anstieg in der Höhenverbreitung nachgewiesen. In den Gipfellagen der meisten europäischen Gebirge hat die Anzahl der Gefäßpflanzen rezent deutlich zugenommen, lediglich in von stärkerer Sommertrockenheit betroffenen mediterranen Gebirgen geht die Artenzahl leicht zurück (Grabherr 2003; Pauli et al. 2007, 2012). Auch für Moose ist ein deutlicher Anstieg der Höhenverbreitung ( $24 \mathrm{~m} /$ Dekade) in den Alpen dokumentiert (Bergamini et al. 2009). Aufwärtswanderungen von Pflanzenarten gehen einher mit einer graduellen Transformation alpiner Pflanzengesellschaften durch erhöhte Abundanz thermophiler Arten auf Kosten kälteadaptierter Arten, die europaweit festgestellt wurde (Gottfried et al. 2012). In der Waldstufe europäischer Gebirge ist eine signifikante Höhenverschiebung des Optimalvorkommens von Pflanzenarten ermittelt worden, die im Mittel $29 \mathrm{~m} /$ Dekade im 20. Jahrhundert betrug (Lenoir et al. 2008).

Viele Arten werden unter mittleren bis hohen Raten der Klimaerwärmung (RCP4.5-, RCP6.0- und RCP8.5-Szenarien) im 21. Jahrhundert nicht in der Lage sein, in ihrer Ausbreitungs- und Wanderungsgeschwindigkeit mit der Verlagerung klimatisch geeigneter Lebensräume Schritt zu halten (Kühn et al. 2013; Settele et al. 2014). Dies gilt insbesondere für krautige Pflanzen und Bäume, die häufig eine geringe Ausbreitungsfähigkeit aufweisen. Modelle der potenziellen zukünftigen Verbreitung von 845 Pflanzenarten in Deutschland deuten darauf hin, dass sich die geeigneten Lebensräume für viele Arten verkleinern werden, insbesondere in Nordost- und Südwestdeutschland, während die Auswirkungen auf die Artenzahlen in Nordwestdeutschland mit der MRH geringer ausfallen (Pompe et al. 2008, 2011). Bei starkem Klimawandel $\left(+4^{\circ} \mathrm{C}\right.$ Szenario) könnten $20 \%$ der Pflanzenarten mehr als drei Viertel ihrer heute bioklimatisch geeigneten Gebiete bis zum Jahr 2080 verlieren, bei gemäßigtem Klimawandel $\left(+2{ }^{\circ} \mathrm{C}\right.$-Szenario) wären immerhin noch $7 \%$ der Arten betroffen (Kühn et al. 2013). 
- Tab. 6.3 Flächenanteile der Waldbäume (in \%) in Hamburg, Schleswig-Holstein und im west- und ostniedersächsischen Tiefland. (Jensen et al. 2011)

\begin{tabular}{|c|c|c|c|c|}
\hline & Hamburg & Schleswig-Holstein & Westniedersächsisches Tiefland & Ostniedersächsisches Tiefland \\
\hline Laubbäume & 56 & 61 & 46 & 27 \\
\hline Buche & 12 & 19 & 4 & 2 \\
\hline Eiche & 11 & 15 & 15 & 9 \\
\hline $\begin{array}{l}\text { Esche, Ahorn, Ulme, Hain- } \\
\text { buche, Kirsche }\end{array}$ & 7 & 8 & 2 & 1 \\
\hline Birke, Weide, Erle, Pappel & 26 & 19 & 25 & 15 \\
\hline Nadelbäume & 44 & 39 & 54 & 73 \\
\hline Kiefer, Lärche & 32 & 17 & 38 & 58 \\
\hline Fichte, Douglasie & 12 & 22 & 16 & 15 \\
\hline
\end{tabular}

\subsubsection{Biologische Invasionen}

In den letzten Jahrzehnten hat die absichtliche oder unabsichtliche Einbringung von Arten durch den Menschen in Gebiete, die sie natürlicherweise zuvor nicht erreicht haben, zugenommen (Kowarik 2010). Die Ausbreitung von invasiven Arten, d. h. von nichteinheimischen Arten, die sich nach Etablierung stark vermehren, hat zunehmend negative Auswirkungen auf ökologische Serviceleistungen und die Biodiversität und richtet hohe wirtschaftliche Schäden an (Nentwig 2010; Simberloff et al. 2013). Die meisten gebietsfremden Arten weisen Eigenschaften auf, die sie zu Gewinnern des Klimawandels machen. Sie sind häufig wärmeliebend, haben eine breite ökologische Amplitude und sind anpassungsfähig, sodass sie einen Konkurrenzvorteil gegenüber einheimischen Arten besitzen und vom Anstieg der Temperaturen und entsprechenden Lebensraumänderungen profitieren (Rabitsch et al. 2013b). Die Etablierung bisher unbeständig auftretender Neophyten und Neozoen und der Aufbau eigenständiger Populationen werden durch den Klimawandel ebenso begünstigt wie die beginnende Ausbreitung in höhere Lagen im Gebirge (Walther et al. 2009; Pauchard et al. 2009). Modellsimulationen legen eine zunehmende Habitateignung für verschiedene Neophyten in Mitteleuropa nahe (Kleinbauer et al. 2010).

Die Expansion von gebietsfremden Arten wird zu Artenverschiebungen und zur Neuorganisation von Lebensgemeinschaften beitragen und damit ökologische Interaktionen und ökologische Serviceleistungen verändern. In Mitteleuropa trägt der Klimawandel zum Vordringen immergrüner Gehölze in wintermilde Lagen bei, wie die Beispiele der Hanfpalme (Trachycarpus fortunei) und der Lorbeerkirsche (Prunus laurocerasus) verdeutlichen (Berger et al. 2007; Walther et al. 2007). Die Lorbeerkirsche zeigt in städtischen Regionen, z. B. im Ruhrgebiet, eine starke Ausbreitungstendenz (Hetzel 2012) und findet auch im wintermilden Hamburger Klima gute Bedingungen vor, sodass sie in siedlungsnahen Wäldern in Ausbreitung begriffen ist (Poppendieck et al. 2010). Als weitere Beispiele für großenteils klimawandelinduzierte rezente Ausbreitung lassen sich Kakteen der Gattung Opuntia, die in Deutschland und der Schweiz Populationen aufgebaut haben (Essl und Kobler 2009), oder der aus China stammende Blauglockenbaum (Paulownia tomentosa) anführen, der sich in warmen Tieflagen Deutschlands ausbreitet (Nehring et al. 2013). Auch die ungewöhnlich starke Ausbreitungstendenz des Walnussbaums (Juglans regia) in Hamburg und anderen Stadtregionen Mitteleuropas in den letzten 10-15 Jahren (Hetzel 2012) steht offenbar in Zusammenhang mit milderen Wintern und verlängerten Vegetationsperioden.

\subsection{Auswirkungen des Klimawandels auf terrestrische und semiterrestrische Ökosysteme in der MRH}

\subsubsection{Wälder}

Obwohl die Hamburger Stadtlandschaft gegenüber der ersten Hälfte des 20. Jahrhunderts heute wieder einen höheren Waldanteil aufweist, zählt sie zu den waldärmsten Verdichtungsräumen Deutschlands (Bertram und Poppendieck 2010). Die Waldflächen nehmen etwa 6,7 \% der gesamten Bodenfläche der Freien und Hansestadt Hamburg ein, während im angrenzenden niedersächsischen Tiefland und in Schleswig-Holstein (mit Ausnahme der westlich gelegenen Kreise) der Waldanteil meist deutlich höher liegt (Jensen et al. 2011). Das heutige Erscheinungsbild der Wälder ist das Ergebnis einer viele Jahrhunderte langen land- und forstwirtschaftlichen Nutzungsgeschichte, in deren Verlauf nicht nur die ursprüngliche Waldfläche sehr stark reduziert und fragmentiert wurde, sondern auch die Bestandsstrukturen (Bestandsdichte, Schichtung, Altersstrukturen, Alt- und Totholzanteile) und die Baumartenzusammensetzung grundlegenden Veränderungen unterworfen waren. Darauf geht der gegenüber natürlichen Verhältnissen deutlich überhöhte Anteil von Nadelbäumen in der MRH zurück, die im ostniedersächsischen Tiefland einen Flächenanteil von etwa $75 \%$ erreichen und auch im Stadtgebiet Hamburgs noch deutlich überrepräsentiert sind (• Tab. 6.3).

Die Rotbuche (Fagus sylvatica) ist aufgrund ihrer Vitalität und Konkurrenzkraft sowohl auf basischen als auch auf sauren Böden mit stark unterschiedlicher Nährstoffversorgung und 
aufgrund ihrer Toleranz gegenüber unterschiedlichen Bodenfeuchteverhältnissen die von Natur aus vorherrschende Baumart in Mitteleuropa (Ellenberg und Leuschner 2010). Buchenwälder bilden auch in der MRH die potenziell natürliche Vegetation auf oligo- bis eutrophen sowie mäßig trockenen bis mäßig feuchten Böden, d. h. über weite Bereiche der Trophie- und Feuchtegradienten. Eindrucksvolle Buchenhallenwälder sind auf kuppigen, trockenen und schon weitgehend entkalkten Moränen des Wohldorfer Waldes erhalten. Auf grundwassernahen Böden mit höherem Basengehalt gehen die Buchenwälder in EichenHainbuchen-Wälder und andere Laubmischwälder über, die in nassen Senken und Tälern von Erlen-Eschen-Wäldern und Erlen-Bruchwäldern sowie auf sehr nährstoffarmen Torfböden von Birken-Bruchwäldern abgelöst werden (vgl. Bertram und Poppendieck 2010). Auenwälder kommen noch in kleinen Fragmenten an der Alster und im Außendeichgebiet der Elbe vor.

Spezielle Untersuchungen zu den Auswirkungen des Klimawandels auf die Wälder der MRH liegen bisher nicht vor. Es gibt jedoch inzwischen zahlreiche Forschungsergebnisse zur Reaktion von Bäumen in den Wäldern Mitteleuropas, die sich auf die Stadt Hamburg und deren Umland übertragen lassen, auch wenn die vorliegenden Ergebnisse aufgrund der Komplexität der Zusammenhänge nicht immer eindeutig sind, was den nach wie vor hohen Forschungsbedarf unterstreicht. Den Waldökosystemen kommt aufgrund ihrer vielfältigen ökologischen, wirtschaftlichen und sozialen Funktionen eine besondere Bedeutung zu. Diese Multifunktionalität wird durch den sich rasch vollziehenden Klimawandel gefährdet, denn Bäume sind sehr langlebig und ortsfest, und Waldbestände sind daher gezwungen, sich in ihrer gesamten Lebensspanne an sehr unterschiedliche Umwelt- und Wachstumsbedingungen anzupassen. Der Klimawandel ändert die ökologischen Rahmenbedingungen für den Wald und ist somit auch eine bedeutende Herausforderung für die durch langfristige Planung und lange Produktionszeiträume gekennzeichnete Forstwirtschaft, die Anpassungsstrategien entwickeln muss, um ökologische und ökonomische Unsicherheiten und Risiken der Waldbewirtschaftung so gering wie möglich zu halten.

Veränderte Rahmenbedingungen und Risiken für den Wald ergeben sich insbesondere durch die ansteigenden Temperaturen, die biotische und abiotische Prozesse beschleunigen (z. B. Massenvermehrung von Schädlingen, Waldbrände), durch veränderte Niederschlagsmuster und durch die Zunahme von klimatischen Extremereignissen (Trockenperioden, Stürme, Überschwemmungen, Nassschneefälle). Rezent zeichnet sich die verschärfte Trockenheit zur Vegetationszeit als bedeutender Faktor ab, der Wachstum, Verjüngung und Mortalität der Bäume beeinflusst (Wohlgemuth et al. 2014). Veränderungen im Zuwachs der Bäume, der wesentlich von der Nährstoff- und Wasserversorgung der Standorte und den vorherrschenden Temperaturen abhängt, sind in Mitteleuropa zeitlich und räumlich differenziert. Für die letzten Dekaden des 20. Jahrhunderts ist in zahlreichen Arbeiten ein deutlicher Trend zur Zuwachssteigerung bei den meisten Baumarten dokumentiert worden, die sowohl den Höhen- als auch den Volumenzuwachs betreffen (Spiecker et al. 1996; Pretzsch 1999; Dittmar et al. 2003). Die teilweise beträchtlichen Zuwachsanstiege für alle Hauptbaumarten stehen offenbar in Zusammenhang mit verstärkter sommerlicher Erwärmung der Atmosphäre und des Bodens und der Ver- längerung der Vegetationszeit; daneben sind auch anhaltend hohe Stickstoffeinträge sowie der Rückgang der Schwefeleinträge zu berücksichtigen. Düngungseffekte infolge des steigenden $\mathrm{CO}_{2}-\mathrm{Ge}-$ haltes der Atmosphäre sind wahrscheinlich (Karnosky et al. 2007), experimentell bisher jedoch nicht nachgewiesen (Bader et al. 2013). Die bis zum Ende des 20. Jahrhunderts ermittelten hohen durchschnittlichen Holzzuwächse der Wälder sind im Zeitraum 20022008 zurückgegangen, insbesondere bei der Fichte (Picea abies) (Umweltbundesamt 2015). Die Produktivitätseinbußen werden vorrangig auf die heißen und trockenen Jahre 2003 und $2006 \mathrm{zu}-$ rückgeführt, die auch die Mortalität von Laub- und Nadelbäumen deutlich erhöht haben (Bréda et al. 2006). Auch im Folgezeitraum 2008-2012 sind die Holzzuwächse im bundesweiten Mittel weiter zurückgegangen, am stärksten bei der Kiefer (Pinus sylvestris), gefolgt von der Buche (Umweltbundesamt 2015). Es wird davon ausgegangen, dass die Zuwachsrückgänge vornehmlich aus verschärfter Wasserknappheit in ausgeprägteren und häufigeren Trockenperioden resultieren, die das Baumwachstum physiologisch durch „Verdursten“ infolge von Dampfbläschenbildung (Kavitation) sowie durch „Verhungern“ infolge von ungenügender Versorgung mit Kohlenhydraten („carbon starvation“) limitiert (vgl. Charru et al. 2010; Kint et al. 2012; Wohlgemuth et al. 2014). Verringertes Baumwachstum wirkt sich auf die Rolle temperater Wälder als bedeutende globale Kohlenstoffsenke negativ aus (Pan et al. 2011). Nachteilige Auswirkungen auf die Holzzuwächse sind zukünftig insbesondere auf Standorten zu erwarten, auf denen schon heute Hitze und Trockenheit das Wachstum begrenzen. Auf bisher wärmelimitierten Standorten dürfte es dagegen bei ausreichender Wasserversorgung zu Zuwachssteigerungen kommen.

Die klimatischen Toleranzgrenzen der Hauptbaumarten Mitteleuropas sind vergleichsweise groß; allerdings kann schon eine moderate Klimaerwärmung von $1-2{ }^{\circ} \mathrm{C}$ deutliche Verschiebungen in der Baumartenzusammensetzung hervorrufen (Essl et al. 2013b; Lexer et al. 2014). Die Klimaansprüche lassen sich als sog. Klimahüllen darstellen und zu heutigem bzw. wärmerem Klima in Beziehung setzen (- Abb. 6.8). Aus der klimatischen Amplitude, weiteren standörtlichen Toleranzgrenzen und der Anfälligkeit für Schadinsekten können zukünftige Wuchs- und Existenzbedingungen abgeleitet werden. Diese würden sich für die Fichte bei der erwarteten Erwärmung, bei verstärktem Auftreten von Trockenperioden und häufigeren Sturmereignissen auf vielen Standorten verschlechtern. Hinzu käme die destabilisierende Rolle der Wechselwirkung zwischen Trockenheit, Totholzangebot und Borkenkäferbefall (Müller-Kroehling et al. 2009; Bolte et al. 2010; Hickler et al. 2012; Falk und Hempelmann 2013). Von der erwarteten erheblichen Reduzierung der Fichtenanbaufläche dürfte die Buche profitieren, deren Vitalität und Produktivität jedoch ebenfalls durch vermehrte Trockenstressbedingungen beeinträchtigt werden (Kölling und Zimmermann 2014). Sie weist jedoch eine größere Plastizität auf und dürfte auf tiefgründigen Böden mittlerer bis guter Wasserspeicherkapazität die vorherrschende Baumart Mitteleuropas bleiben (Kölling et al. 2007; Manthey et al. 2007; Sutmöller et al. 2008). In die gleiche Richtung weisen Modellierungen der zukünftigen Verbreitung von Buchenwald-Lebensraumtypen, die für Deutschland nur geringfügige Änderungen bis Ende dieses Jahrhunderts projizieren (Bittner und Beierkuhnlein 2014). Eine verringerte ökologische Fitness und Konkurrenzkraft 
- Abb. 6.8 Klimahüllen aus Jahresniederschlag und Jahresmitteltemperatur für Lärche (a), Fichte (b), Flaumeiche (c) und Buche (d), dargestellt in Bezug zum heutigen Klima in Deutschland und zu einem $1,8^{\circ} \mathrm{C}$ wärmeren Klima. (Essl et al. 2013b) a

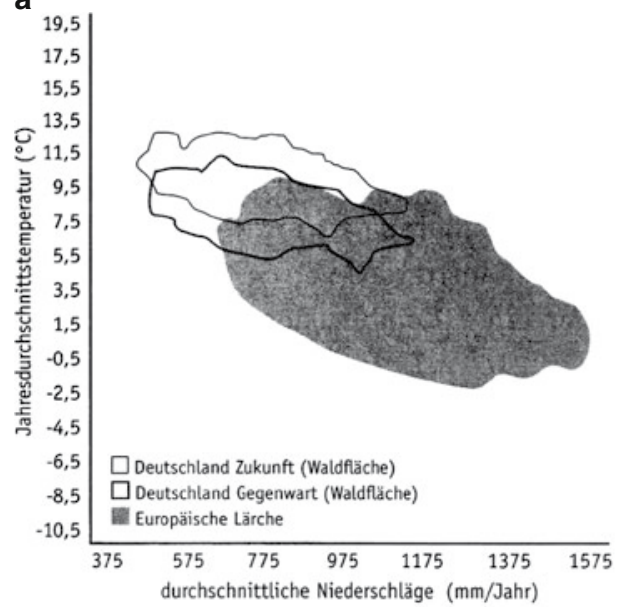

C

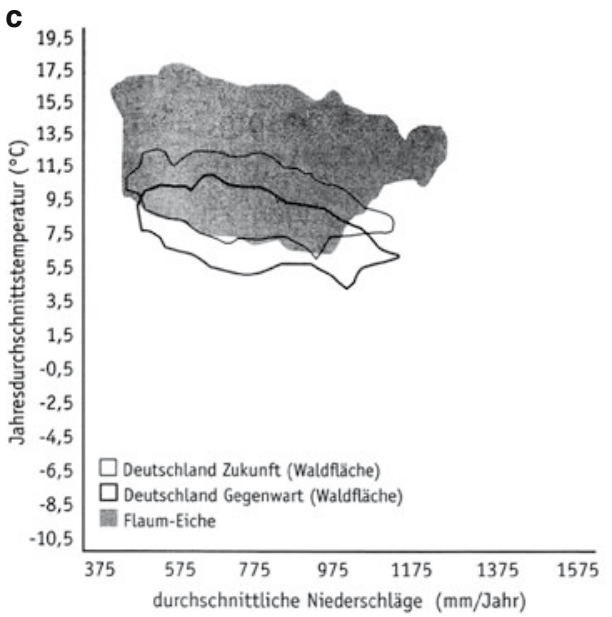

b

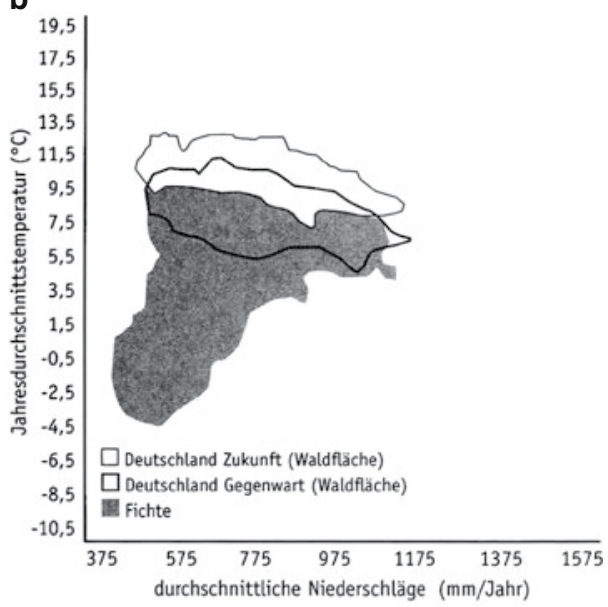

d

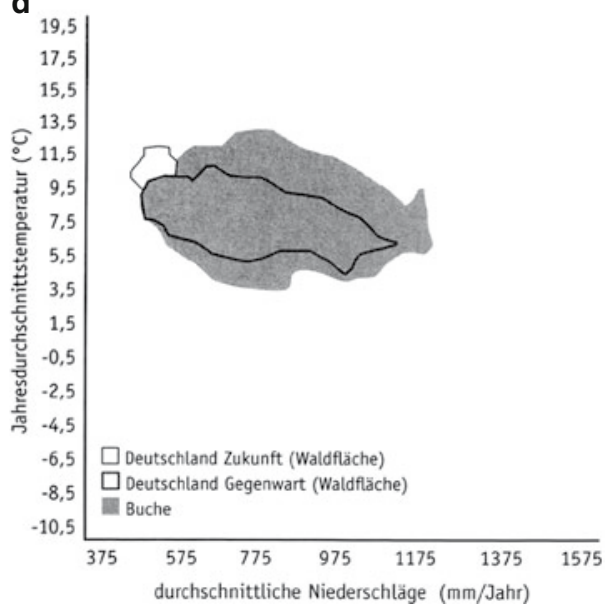

der Buche wird jedoch auf flachgründigen oder sandigen Standorten sowie an den westlichen und südlichen Arealrändern erwartet. Im Norddeutschen Tiefland könnten sich die Wachstumsbedingungen für die Buche bei geringeren Sommerniederschlägen und erhöhten Temperaturen so weit verschlechtern, dass Anbauflächen zukünftig von der Kiefer und den Eichenarten (Quercus robur, Quercus petraea, Quercus pubescens) eingenommen werden (Hickler et al. 2012). Die Forstwirtschaft strebt proaktiv eine Erhöhung der Trockenheitstoleranz der Buche über die Einmischung von Provenienzen aus randlichen Verbreitungsgebieten mit heute bereits trockenerem und wärmerem Klima an (Walentowski et al. 2009; Bolte und Degen 2010). Die höhere Toleranz der Eichen und der Kiefer gegenüber Sommertrockenheit könnte im Norden und Nordosten Deutschlands zu einer Ausbreitung dieser Arten führen, wenn sie eine ausreichende Resistenz gegenüber Schädlingen (Schadinsekten, Pilze) entwickeln (vgl. Walentowski et al. 2007; Bolte et al. 2009).

Nicht nur die Baumartenzusammensetzung der Wälder wird sich - in bisher noch unklarem Umfang - infolge des Klimawandels ändern, sondern das gesamte Artenspektrum wird betroffen sein (Jantsch et al. 2014). Mehr als die Hälfte der europäischen Pflanzenarten gilt als durch den Klimawandel gefährdet (Thuiller et al. 2005). Stickstoffeinträge, Ausbreitung von Neophyten, neu eingeschleppte Parasiten oder modifizierte Waldbewirtschaftung verstärken die Dynamik der Artenverschiebungen, sodass neue Lebensgemeinschaften entstehen werden (Essl et al. 2013b). Es ist zu erwarten, dass wärmeliebende nichteinheimische Gehölzarten wie Robinie (Robinia pseudacacia), Götterbaum (Ailanthus altissima), Douglasie (Pseudotsuga menziesii) oder Walnuss (Juglans regia) sowie immergrüne lorbeerblättrige Gehölze in diesen neuartigen Waldgesellschaften viel prominenter vertreten sein werden als bisher (Kowarik 2010; Kleinbauer et al. 2010).

\subsubsection{Moore}

Für die Entstehung von Mooren - Standorte mit Torfbildung oder oberflächlich anstehendem Torf - bestanden nach Ende der letzten Eiszeit in der MRH günstige geomorphologische, hydrogeologische und klimatische Voraussetzungen. Die Akkumulation von Torf setzt ein, wenn der Abbau organischer Substanz unter wassergesättigten Bedingungen aufgrund von Sauerstoffmangel gehemmt ist. Moore bilden sich bei der Versumpfung terrestrischer Lebensräume oder bei der Verlandung von Gewässern. Dabei wird unterschieden zwischen Niedermooren, die überwiegend von Grund- und Oberflächenwasser gespeist werden, und Hochmooren, die ihr Wasser und ihre Nährstoffe überwiegend aus der Atmosphäre erhalten (Succow und Joosten 
2001; Dierßen und Dierßen 2001). In den Kulturlandschaften Europas gibt es heute kaum noch ungestörte Moore. In Deutschland sind ca. $99 \%$ der einstigen Moorflächen von $15.000 \mathrm{~km}^{2}$ zerstört, d. h., sie sind entwässert bzw. weisen kein Torfwachstum mehr auf (vgl. Couwenberg und Joosten 2001). In Ländern wie Dänemark, den Niederlanden oder Belgien sind Moore als Landschaftstyp fast vollständig vernichtet worden (Joosten 2012).

Im Stadtgebiet Hamburgs entstanden Moore primär durch Überflutungen und Versumpfungen entlang der Flüsse Elbe und Alster, daneben auch in Senken saalezeitlicher Sanderflächen oder durch Verlandung von Eisstauseen der Jungmoränenlandschaft im Nordosten. Moorbildungen waren für die gesamte MRH charakteristische Landschaftselemente (Overbeck 1975; Behre 2008), etwa die großen Moorkomplexe im Wirkungsbereich tidebeeinflusster Flüsse, die Küstenüberflutungsmoore an Nord- und Ostsee, die Versumpfungsmoore in den Niederungen der Geest und in den Marschen, die Hochmoorkomplexe in den Niederungen der Tieflandflüsse oder die Verlandungsmoore im östlichen Hügelland Schleswig-Holsteins. Die Moorflächen mit Hochmooren, Niedermooren und verschiedenen Ausprägungen von Zwischenmooren hatten in Nordwestdeutschland einst eine beträchtliche Ausdehnung. Hier sind durch großflächige Umwandlung von Mooren und intensive Torfnutzung seit 1950 Hochmoorflächen in der Größenordnung von etwa 50.000 ha verschwunden (Jeschke und Joosten 2003), in Schleswig-Holstein sind lediglich $11 \%$ der ursprünglichen Moorflächen mit einem naturnahen Wasserstand erhalten (Drews et al. 2000). Im Hamburger Stadtgebiet beträgt die heute von naturnahen Mooren mit moortypischer Vegetation bedeckte Fläche bestenfalls noch $3 \mathrm{~km}^{2}$ - ein Rückgang von über $90 \%$ in den letzten 200 Jahren (vgl. Engelschall 2010). Die verbliebenen Restmoore liegen in der Regel am Stadtrand und sind sämtlich als Naturschutzgebiete geschützt.

Mit dem massiven Rückgang der Moorflächen sind wesentliche Funktionen im Wasser- und Stoffhaushalt der Landschaft verloren gegangen. Degradierung und Zerstörung von Mooren wirken sich insbesondere negativ auf die Funktion im globalen Kohlenstoffhaushalt aus. Moore speichern doppelt so viel Kohlenstoff in ihrem Torf wie die Wälder der Erde in ihrer Biomasse und sind somit die wichtigsten und raumeffektivsten terrestrischen Kohlenstoffspeicher (Joosten und Couwenberg 2008; Joosten et al. 2013). Mit 400-550 Gigatonnen speichern sie 20-30\% des weltweit in Böden festgelegten Vorrats an Kohlenstoff, obwohl sie nur 3 \% der Landoberfläche bedecken (Frolking et al. 2011). Wachsende Moore beeinflussen die Kohlenstoffbilanz jedoch auch durch die Emission von Methan $\left(\mathrm{CH}_{4}\right)$, da unter wassergesättigten Bedingungen ein Teil des Pflanzenmaterials anaerob umgesetzt wird. Der klimatische Effekt der $\mathrm{CO}_{2}$-Aufnahme ist langfristig indes viel bedeutender als jener der $\mathrm{CH}_{4}$-Emission, da Methan in der Atmosphäre vergleichsweise schnell abgebaut wird (Ciais et al. 2013; Joosten et al. 2013). Anthropogene Eingriffe haben die Moore von wichtigen Kohlenstoffsenken zu bedeutenden Quellen von Kohlenstoffemissionen umfunktioniert. Vor allem durch großflächige Entwässerung und Landnutzung wird der Kohlenstoff infolge des oxidativen Torfabbaus als $\mathrm{CO}_{2}$ und $\mathrm{N}_{2} \mathrm{O}$ (Lachgas) wieder freigesetzt (Drösler et al. 2012). Etwa $6 \%$ der globalen anthropogenen $\mathrm{CO}_{2}$-Emissionen gehen von entwässerten Moorflächen aus (Frolking et al. 2011; Joosten et al.
2013); in Deutschland ist die landwirtschaftliche Moornutzung für etwa 5 \% der Emissionen verantwortlich (Drösler et al. 2012).

Moore zählen als nährstoffarme Feuchtlebensräume zu den im Zuge globaler Umweltveränderungen außerordentlich gefährdeten Lebensräumen und sind dem Klimawandel unmittelbar ausgesetzt. Erhöhte Temperaturen und zurückgehende Sommerniederschläge führen insbesondere in Hochmooren zu sinkenden Moorwasserspiegeln. Wachstum und physiologische Leistungen der für die Torfbildung so wichtigen Sphagnum-Torfmoose werden viel stärker vom Wasserstand in den Mooren als direkt von der Menge des Niederschlags beeinflusst (Schmidt 2014; Jensen und Schoenberg 2015). Zunehmende sommerliche Trockenphasen und sinkende Moorwasserstände werden nicht nur die $\mathrm{CO}_{2}$-Aufnahme der Torfmoose durch Photosynthese vermindern, sondern auch die Konkurrenzbedingungen hin zu einer Förderung von Gefäßpflanzen verändern, deren Deckungsgrade bei vermindertem Sommerniederschlag auf Kosten der Torfmoose zunehmen (Schmidt 2014). Der Klimawandel wird in einer Verschiebung der Vegetationsgürtel in Mooren von außen nach innen resultieren. Sinkende Moorwasserspiegel und Mineralisierung bewirken eine Verbuschung zentraler offener Moorbereiche und eine zunehmende Gehölzsukzession in Richtung Bewaldung, welche die Austrocknung der Moore weiter forciert. In der Schweiz sind über einen Zeitraum von nur 5 Jahren Austrocknung und Verbuschung bei über einem Viertel der Moore festgestellt worden (Klaus 2007). In den Hochmooren Bayerns ist in den letzten Jahrzehnten die Umwandlung von natürlicherweise gehölzfreien Hochmoorkernen in bewaldungsfähige Standorte beobachtet worden; Fichtenbestände haben sich zunehmend vom Randgehänge in Richtung Moorzentrum ausgebreitet (Walentowski et al. 2008). Mit fortschreitendem Klimawandel wird das klimatische Risiko für alle Moorlebensräume weiter ansteigen, häufige und lang andauernde Trockenperioden werden die Sukzession von Hochmooren in Richtung trockenere Vegetationstypen (vor allem Moorwälder) vorantreiben (Essl et al. 2012). Neben den negativen Konsequenzen für das Kohlenstoffspeicherpotenzial ist damit auch der Rückgang der moortypischen Artenausstattung (viele Reliktarten und Endemiten) und der spezifischen Biodiversität verbunden. Ombrotrophe Hochmoore sind weitaus stärker gefährdet, insbesondere an ihrer südlichen Arealgrenze, als die von durchsickerndem Grundwasser geprägten Niedermoore.

\subsection{3 Ästuare und Küstenökosysteme}

Hohe Bevölkerungsdichten und hohe Nutzungsintensität bedrohen die Küstenregionen und deren Biodiversität weltweit, insbesondere in den gemäßigten Breiten, wo Einflüsse wie Küstenschutzmaßnahmen, Fischerei, die Einleitung toxischer Substanzen, Verschmutzung und Eutrophierung, Offshore-Windparks sowie Tourismus und Bebauung zu großen Veränderungen geführt haben. Im Zuge des Klimawandels kommen gravierende Auswirkungen der Erwärmung selbst, des Meeresspiegelanstiegs und der Versauerung der Meere hinzu (Wiltshire und Kraberg 2013). Aufgrund des sich beschleunigenden Meeresspiegelanstiegs von derzeit 3-4 mm pro Jahr (Church et al. 2013) werden 
charakteristische Lebensräume der Flachküsten wie Watt, Salzmarschen, ästuarine Marschen und Dünen beeinträchtigt. Falls die Akkretionsraten nicht ausreichen, um den Meeresspiegelanstieg zu kompensieren, werden sie infolge zunehmender Überstauung teilweise verloren gehen (s. u.). Die Reduzierung von Wattflächen und terrestrischen Habitaten hat schwerwiegende Konsequenzen für Lebensgemeinschaften und Arten, insbesondere für Vogelarten (Kröncke et al. 2012). Die Verschiebung der Küstenlinie in Richtung Inland wird sich langfristig nur durch aufwendige Küstenschutzmaßnahmen verhindern lassen.

In der MRH sind Küstenökosysteme im Vergleich zu anderen Ökosystemen noch häufig naturnah erhalten, was insbesondere für die heute auf Vordeichflächen der Nordsee sowie auf das Elbe- und Weserästuar beschränkten Küstenmarschen und ästuarinen Marschen gilt. Sie liegen meist in Naturschutzgebieten bzw. in den Wattenmeer-Nationalparks und sind daher nur geringen Nutzungseinflüssen ausgesetzt. Im tidebeeinflussten Wechselwasserbereich der Ästuare werden bis in den oligohalinen Bereich vordringende Süßwassermarschen (Salinität bis $5 \mathrm{ppt}$ ), mesohaline Brackwassermarschen (5-18 ppt) und Salzmarschen im euhalinen Bereich (18-30 ppt) unterschieden, deren Vegetationszusammensetzung sowohl durch den Salinitätsgradienten als auch durch den Überflutungsgradienten geprägt wird (Jensen et al. 2011). Untersuchungen von Baldwin et al. (2014) deuten darauf hin, dass die Artenvielfalt der Marschenvegetation durch eine Temperaturerhöhung zurückgehen wird. Demnach würde die Erwärmung zwar zu einer Erhöhung der Biomasseproduktion führen, aber gleichzeitig die Artenzahl der Pflanzen aufgrund zunehmender Konkurrenz verringern (• Abb. 6.9). Die erhöhte Biomasseproduktion steht in Zusammenhang mit erwärmungsbedingt höheren Streuabbauraten und StickstoffMineralisationsraten, die von Dahl (2001) sowie Blume und Müller-Thomsen (2007) für Salzmarschen der deutschen Nordseeküste aufgezeigt wurden. Es ist zu erwarten, dass erheblich ansteigende jährliche N-Mineralisationsraten die Konkurrenzkraft von Arten mit hohem N-Aufnahme- und -Speichervermögen (z. B. Elymus athericus, Atriplex portulacoides) fördern und als Folge konkurrenzschwache kleinwüchsige und annuelle Arten verdrängt werden. Veränderte Konkurrenzbeziehungen durch Verbesserung von Wuchsleistungen werden sich auch auf das Verhältnis zwischen C3- und C4-Pflanzen auswirken, die in unterschiedlichem Maße von Temperaturerhöhung und erhöhter $\mathrm{CO}_{2}$-Konzentration profitieren ( Abschn. 6.2). Experimentell konnte gezeigt werden, dass das verbreitete C3-Gras Puccinellia maritima gegenüber dem in Ausbreitung begriffenen C4-Gras Spartina anglica unter entsprechenden Bedingungen konkurrenzüberlegen ist (Gray und Mogg 2001). Die gegenwärtig starke Expansion von Spartina anglica in den Salzmarschen der Nordseeküste (Nehring und Hesse 2008; Roberts 2012) könnte somit zukünftig eingeschränkt werden. Andererseits sind bis 2050 erwärmungsbedingte Arealverluste von Puccinellia maritima und anderen Schlüsselarten der deutschen Küste, z. B. der Krähenbeere (Empetrum nigrum) in Dünenökosystemen, zu erwarten (Metzing 2005).

Substanzielle Einflüsse auf die Biodiversität der ästuarinen Marschen sind darüber hinaus durch eine Stromaufverschiebung der Brackwassergrenze zu erwarten - eine unausweichliche Folge
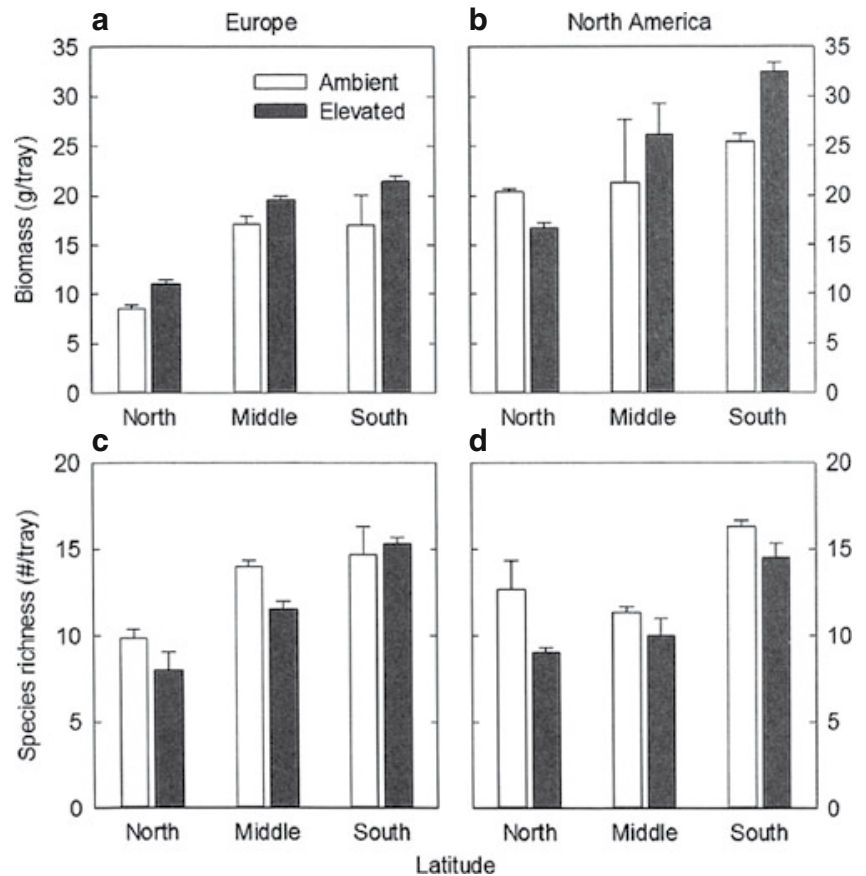

- Abb. 6.9 a-d Biomasseproduktion und Artenzahl experimenteller Lebensgemeinschaften tidebeeinflusster Süßwassermarschen aus Ästuaren in Europa und den USA bei zwei Temperaturregimen (ambient, erhöht). Der Nord-Süd-Gradient wird durch das Elbe-, Loire- und Minho-Ästuar (Europa) bzw. durch das Connecticut-, Pamunkey- und Waccamaw-Ästuar (USA) repräsentiert. (Jensen und Schoenberg 2015)

des Meeresspiegelanstiegs (Neubauer und Craft 2009). Die ohnehin bereits durch Strombaumaßnahmen um etwa $25 \mathrm{~km}$ stromauf verschobene Brackwassergrenze an der Tideelbe (Bergemann 1995) würde sich infolge des Meeresspiegelanstiegs sowie durch verminderten Oberwasserzustrom weiter stromaufwärts verschieben (Schoenberg et al. 2014). Die Konsequenz wäre eine Habitateinengung der tidebeeinflussten Süßwassermarschen, da diese an einem stromaufwärtigen Ausweichen durch das Wehr Geesthacht gehindert werden. Davon wären insbesondere die an der Tideelbe vorkommenden Endemiten Oenanthe conioides und Deschampsia wibeliana betroffen, deren Areal weitgehend auf den Bereich der tidebeeinflussten Süßwassermarschen beschränkt ist und für die ein beträchtlicher Verlust des Lebensraumes prognostiziert wird (Jensen und Schoenberg 2015).

Voraussetzung für die langfristige Erhaltung von ästuarinen Marschen und Salzmarschen der Nordseeküste ist, dass die Sedimentakkretionsraten mit dem Meeresspiegelanstieg Schritt halten (Jensen und Schoenberg 2015). Aktuelle Untersuchungen, die auch in den ästuarinen Marschen der Tideelbe sowie in den Salzmarschen der Wattenmeerküste durchgeführt wurden, deuten darauf hin, dass in der MRH die Akkretionsraten mit Werten zwischen 0,6 und 1,0 cm/Jahr bis hin $\mathrm{zu} 2,0 \mathrm{~cm} / \mathrm{Jahr}$ in der Brackwassermarsch bei Neufeld ausreichend sind, um einen moderaten Anstieg des Meeresspiegels zu kompensieren (Suchrow et al. 2012, Nolte et al. 2013, Butzeck et al. 2014). Obere Salzmarschen könnten jedoch durch unzureichende Sedimentzufuhr gefährdet sein (Butzeck 2015). Da Ausmaß und Geschwindigkeit des zukünftigen Meeresspiegelanstiegs noch ungewiss sind und bereits mehrfach nach oben revidiert werden mussten, könnten 
sich die vertikalen Zuwachsraten der Sedimentoberflächen für viele Marschen der Nordseeküste mittel- bis langfristig als unzureichend erweisen (vgl. Gönnert et al. 2009).

\subsubsection{Heiden}

Heiden des Binnenlandes sind in Mitteleuropa überwiegend durch Weidenutzung ursprünglicher Waldstandorte, d. h. anthropogen, entstanden, und stellen einen auch in der MRH vorkommenden Lebensraumtyp der Kulturlandschaft dar. Natürlicherweise waren Heiden auf den Randbereich von Mooren, auf saure Anmoor- und Torfböden mit stagnierendem Grundwasser sowie auf den Bereich von Küstendünen beschränkt (Hüppe 1993; Wilmanns 1993). In der MRH sind sie heute als Küstenheiden, Feuchtheiden und trockene Tieflandheiden verbreitet, mit je nach klimatischen und edaphischen Bedingungen unterschiedlicher Artenzusammensetzung (Dierßen 1996). Charakteristisch für die MRH sind die ausgedehnten Sandheiden mit von Ericaceen dominierter Zwergstrauchvegetation auf podsolierten Böden im Naturschutzgebiet Lüneburger Heide, die dort eine Gesamtfläche von etwa 5000 ha einnehmen (Pott 1999; Härdtle et al. 2009).

Auswirkungen des Klimawandels sind insbesondere direkt bei zunehmender sommerlicher Trockenheit und indirekt über erhöhte Nährstoffverfügbarkeit zu erwarten. Eine Erhöhung des Stickstoffangebots führt in den stickstofflimitierten Heideökosystemen zu Artenverschiebungen, wobei die in den Sandheiden vorherrschende Besenheide (Calluna vulgaris) von unter nährstoffreicheren Verhältnissen konkurrenzkräftigeren Arten wie Drahtschmiele (Deschampsia flexuosa) oder Pfeifengras (Molinia caerulea) verdrängt werden könnte (vgl. Britton et al. 2003). In Gewächshausexperimenten mit Calluna vulgaris zeigte sich bei einer Erhöhung der N-Verfügbarkeit ein starker Anstieg der Biomasseproduktion, Trockenphasen riefen dagegen keine Effekte hervor (Gordon et al. 1999; MeyerGrünefeldt et al. 2015a). Es ist dennoch von einer erhöhten Empfindlichkeit gegenüber Trockenheit auszugehen, da sich der Wasserverbrauch der Calluna-Individuen bei erhöhter NVerfügbarkeit erhöhte. Vor allem für junge Individuen wird die Gewährleistung der Wasserversorgung in trockenen Jahren wegen des größeren Verhältnisses von oberirdischer zu unterirdischer Biomasse und noch relativ geringer Wurzelmasse zukünftig ein Problem (Meyer-Grünefeldt et al. 2015b). Insbesondere die Keimlinge der Besenheide reagieren empfindlich auf Trockenheit, und vermehrt zu erwartende Trockenperioden im Sommer dürften die Keimlingsetablierung gefährden (Gordon et al. 1999; Britton et al. 2003). Untersuchungen in verschiedenen $\mathrm{N}$-limitierten Ökosystemen haben gezeigt, dass fortgesetzte Stickstoffdeposition in der Mehrzahl der Fälle zu einem Wechsel hin zu einer Phosphorlimitierung führt (Menge und Field 2007). Dieser Effekt könnte auch in Sandheiden eintreten, in denen die überwiegend in der organischen Auflage wurzelnde Besenheide dann gegenüber Arten mit tiefer reichendem Wurzelsystem, die größere Phosphorvorräte im Mineralboden erschließen können, Konkurrenznachteile erleiden würde (Jensen et al. 2011).

\subsubsection{Grünland}

Wiesen und Weiden, d. h. landwirtschaftliches Grünland, sind in Mitteleuropa aufgrund des großen Flächenanteils von erheblicher landschaftlicher, ökologischer und ökonomischer Bedeutung. Etwa ein Drittel der landwirtschaftlichen Nutzfläche in Deutschland wird als Grünland genutzt (Eitzinger et al. 2009; Schaller et al. 2012). In Hamburg wird mehr als die Hälfte der landwirtschaftlichen Nutzfläche von Grünland eingenommen, was etwa $13 \%$ der Landesfläche entspricht (Poppendieck und Brandt 2010). Dauergrünland leistet bei extensiver Nutzung einen besonderen Beitrag zum Erhalt von Biodiversität (Stoate et al. 2009). Der Begriff des Grünlandes umfasst eine Vielzahl unterschiedlicher Ökosysteme, wobei das in starkem Rückgang begriffene Extensivgrünland die gesamte Bandbreite von extrem trockenen bis zu ganzjährig nassen Standorten umspannt, während das stark gedüngte, ertragreiche Intensivgrünland inzwischen zum dominierenden Grünlandtyp in Mitteleuropa geworden ist (Essl 2013). Die Umwandlung von Grünland in Ackerland hat zu einem deutlichen Verlust an Grünlandfläche geführt (Schaller und Weigel 2007). Auf den verbliebenen Flächen hält der Trend zu Nutzungsintensivierung und Düngung weiter an, viele Flächen sind andererseits von Nutzungsaufgabe betroffen. Beides hat dazu geführt, dass nährstoffarmes, artenreiches Grünland zu den am stärksten gefährdeten Lebensräumen in Mitteleuropa gehört und viele Pflanzen- und Tierarten des Grünlandes auf den Roten Listen gefährdeter Arten geführt werden (Ellenberg und Leuschner 2010; Essl 2013). In Norddeutschland sind insbesondere artenreiche Auwiesen in den letzten Jahrzehnten stark zurückgegangen, und mit ihnen viele typische Arten des Feuchtgrünlandes (Krause et al. 2011; Wesche et al. 2012).

Auch in der MRH ist es zu einem massiven Flächenrückgang des artenreichen Feuchtgrünlandes gekommen. Während im südwestlichen Niedersachsen und im westlichen Schleswig-Holstein vor allem die Umwandlung in Acker- und Grasackerland dafür verantwortlich ist, sind die Feuchtwiesen am Oberlauf der Flüsse der Geestgebiete und des Östlichen Hügellandes in SchleswigHolstein überwiegend brach gefallen (Rosenthal et al. 1998; Jensen et al. 2011). Für die heutigen isolierten kleinflächigen Vorkommen wie die noch etwas ausgedehnteren Feuchtwiesen im Duvenstedter Brook, im Biosphärenreservat Niedersächsische Elbtalaue und in der Wümme-Niederung im westlichen Niedersachsen ist mit negativen Auswirkungen des Klimawandels zu rechnen, die allerdings gegenüber den Effekten der Landnutzung zurücktreten. Neben erhöhten Temperaturen werden vor allem Veränderungen des Wasserhaushaltes deutliche Verschiebungen im Arteninventar hervorrufen. Voraussichtlich wird der Rückgang winterlicher Schneeniederschläge und die Zunahme sommerlicher Trockenperioden in Kombination mit erhöhten Transpirationsleistungen der Pflanzen auf vielen Standorten zu geringeren Wassergehalten im Boden und zu niedrigeren Grundwasserständen führen, wodurch sich die Wuchsbedingungen für charakteristische Arten des Feuchtgrünlandes verschlechtern und auftretender Trockenstress ihre Wettbewerbsfähigkeit reduziert (Geißler 2007; Jensen et al. 2011). Modellierungen des zukünftigen Grundwasserstandes im Feuchtgrünland (z. B. Thompson et al. 2008) lassen auch für die $\mathrm{MRH}, \mathrm{z}$. B. für die Brenndoldenwiesen in den niedersächsischen 
Elbtalauen, vermehrt kritische Phasen der Wasserversorgung erwarten (Jensen et al. 2011).

Dass insbesondere die Artenzusammensetzung des Feuchtgrünlandes entlang der Elbe sensitiv auf klimatische Veränderungen reagiert, konnten Ludewig et al. (2014a) mit Vegetationsanalysen entlang eines klimatischen Gradienten von eher ozeanischen zu eher kontinentalen Bedingungen im Bereich der Mittelelbe zeigen. Im Vergleich zu frischen Auwiesen gab es deutliche Veränderungen in der Artenzusammensetzung der feuchten Auwiesen, die zudem eine starke Korrelation mit klimatischen Parametern wie Jahresniederschlag und Jahrestemperaturen zeigten. Dies lässt ebenso auf substanzielle Artenverschiebungen im Klimawandel der nächsten Jahrzehnte schließen wie die Ergebnisse eines Niederschlagsreduktionsexperiments in den Auwiesen der Sude und der Havel (Ludewig et al. 2014b), die eine Verringerung der Biomasseproduktion bei typischen Auwiesenarten wie der Brenndolde (Cnidium dubium) ergaben und auf eine deutliche Beeinflussung des Konkurrenzgefüges der Arten hindeuten. Artenverluste würden die Leistungsfähigkeit extensiv genutzten Grünlandes vermindern. Wie die Ergebnisse der Experimente zur funktionellen Bedeutung der Artenvielfalt im Grünland gezeigt haben, bedingt die funktionelle Unterschiedlichkeit der Pflanzenarten die Vielfalt zahlreicher weiterer Gruppen von Lebewesen (Scherber et al. 2010). Eine höhere Biodiversität erhöht die ökosystemare Leistung über komplementäre Ressourcennutzung und positive Interaktionen zwischen Arten (Beierkuhnlein und Jentsch 2005), wobei die funktionelle Rolle der Artenvielfalt erst im Zuge des Klimawandels deutlich zum Tragen kommen könnte (Yachi und Loreau 1999).

\subsubsection{Urbane Ökosysteme}

Urbane Ökosysteme weisen im Vergleich zum Umland große Struktur- und Klimaunterschiede auf, die u. a. in starker Bebauung und Oberflächenversiegelung, eingeschränkter Verdunstung, erhöhtem Abfluss, geringerer Wasserverfügbarkeit, veränderter Strahlungsbilanz, höherer Lufttemperatur, veränderten Niederschlagsmustern, geringerer Luftfeuchtigkeit, erhöhter $\mathrm{CO}_{2}$-Konzentration sowie erhöhter Luftverunreinigung und Bodenverschmutzung zum Ausdruck kommen (Kuttler 2010; Endlicher 2012; Mathey et al. 2012). Daraus ergeben sich für das Pflanzenwachstum in der Stadt und für die städtische Biodiversität stark modifizierte Standortbedingungen. Anpassungen sind insbesondere an die höheren Temperaturen der städtischen Wärmeinseln, die Trockenheit der Standorte und die Bodenalkalinität erforderlich. In Hamburg beträgt der urbane Wärmeinseleffekt z. B. im Mittel $1,1^{\circ} \mathrm{C}$, in Sommernächten sogar bis zu $3^{\circ} \mathrm{C}$ (Schlünzen et al. 2010). Zudem unterliegen städtische Ökosysteme aufgrund des hohen Grades an anthropogener Störung ständigen Veränderungen durch permanente Zerstörung und Neuschaffung von Lebensräumen, an die sich die Vegetation ebenfalls anpassen muss (Wittig 1991, 2002). Die räumliche Verzahnung von anthropogenen Lebensräumen wie Gärten, Grünanlagen sowie Bahn- und Industriebrachen mit landwirtschaftlich geprägter Kulturlandschaft am
Stadtrand und naturnahen Resthabitaten (Wälder, Feuchtwiesen, Fließ- und Stillgewässer) schafft in Kombination mit der hohen Störungsfrequenz die Voraussetzung für eine hohe Artenvielfalt. Tier- und Pflanzenwelt weisen in Städten in der Regel einen höheren Artenreichtum auf als im Umland, obwohl die zunehmende Urbanisierung global zu den wesentlichen Ursachen für die Gefährdung von biologischer Vielfalt zählt (Kühn et al. 2004; Kowarik 2011; Herberg und Kube 2013). Allerdings unterscheidet sich die Artenzusammensetzung in Städten sehr deutlich vom Umland. Die Mehrzahl der Arten sind Generalisten und weltweit verbreitete Arten (Kosmopoliten). Daneben sind Neobiota stark vertreten, die hier gute Entwicklungsmöglichkeiten vorfinden und deren Anteil in Richtung der städtischen Zentren zunimmt (Kowarik 2010; Wittig et al. 2012). Stadttypische Lebensräume sind inzwischen im Hinblick auf das Arteninventar weltweit sehr stark homogenisiert (Wittig und Becker 2010). Der regionale oder nationale Artenpool ist jedoch auch mit etwa $50 \%$ in den Städten der Nordhemisphäre vertreten (Werner und Zahner 2009).

Eine vergleichsweise hohe Artenvielfalt von Stadtgebieten ist beispielsweise für Städte wie Frankfurt am Main (Wittig et al. 2008) oder Hamburg (Poppendieck 2010) sehr gut dokumentiert. Die mehr als 1500 Arten umfassende rezente Flora Hamburgs besiedelt zu etwa einem Viertel die urban-industriellen Habitate der Stadt und bildet hier eine überwiegend krautige Vegetation oft gestörter Flächen, die sich halbmondförmig von Billwerder über den Hafen nach Harburg erstrecken (Jensen et al. 2011). Der Hafen ist für die Einführung und Ausbreitung von Neophyten immer noch von besonderer Bedeutung, während die hohe Störungsfrequenz durch Substrataufspülung und -aufschüttung insbesondere in den letzten Jahrzehnten zur Diversität stadttypischer Arten beigetragen hat (Ringenberg und von Prondzinski 2010). Eine Auswertung der floristischen Kartierung Hamburgs zeigte, dass der Urbanisierungsgrad im Stadtgebiet die Gesamtartenzahl nur unwesentlich beeinflusst, dass jedoch mit zunehmender Urbanisierung der Anteil gebietsfremder Arten zunimmt und der Anteil gefährdeter Arten abnimmt (Schmidt et al. 2014). Die städtische Wärmeinsel über Hamburg wird durch das vermehrte Vorkommen von thermophilen Arten in zentrumsnahen Bereichen widergespiegelt (Bechtel und Schmidt 2011).

Im Zuge des Klimawandels werden sich städtische Gebiete stärker erwärmen als das Umland, wodurch die städtischen Wärmeinseln noch deutlicher hervortreten werden als bisher (Wittig et al. 2012). Die stadttypische Flora und Vegetation wird davon in unterschiedlicher Weise beeinträchtigt. Die Habitatbedingungen für viele der als Stadtbäume gepflanzten einheimischen Baumarten werden sich deutlich verschlechtern (- Abb. 6.10), während sich gut an Trockenheit angepasste neophytische Baumarten wie der Götterbaum (Ailanthus altissima) oder der Blauglockenbaum (Paulownia tomentosa) weiter ausbreiten dürften. Letzteres gilt ebenfalls für häufig gepflanzte gebietsfremde Straucharten wie Forsythie (Forsythia spp.), Flieder (Syringa emodi) oder Liguster (Ligustrum vulgare), die aufgrund ihrer südlichen Herkunft relativ unempfindlich gegenüber trockenen und warmen Sommern sind. Auch die einheimischen, an relativ kühle und niederschlagsreiche Sommer angepassten krautigen Zierpflanzen der Gärten und Parkanlagen und die entsprechenden Grasarten der Nutz-, 


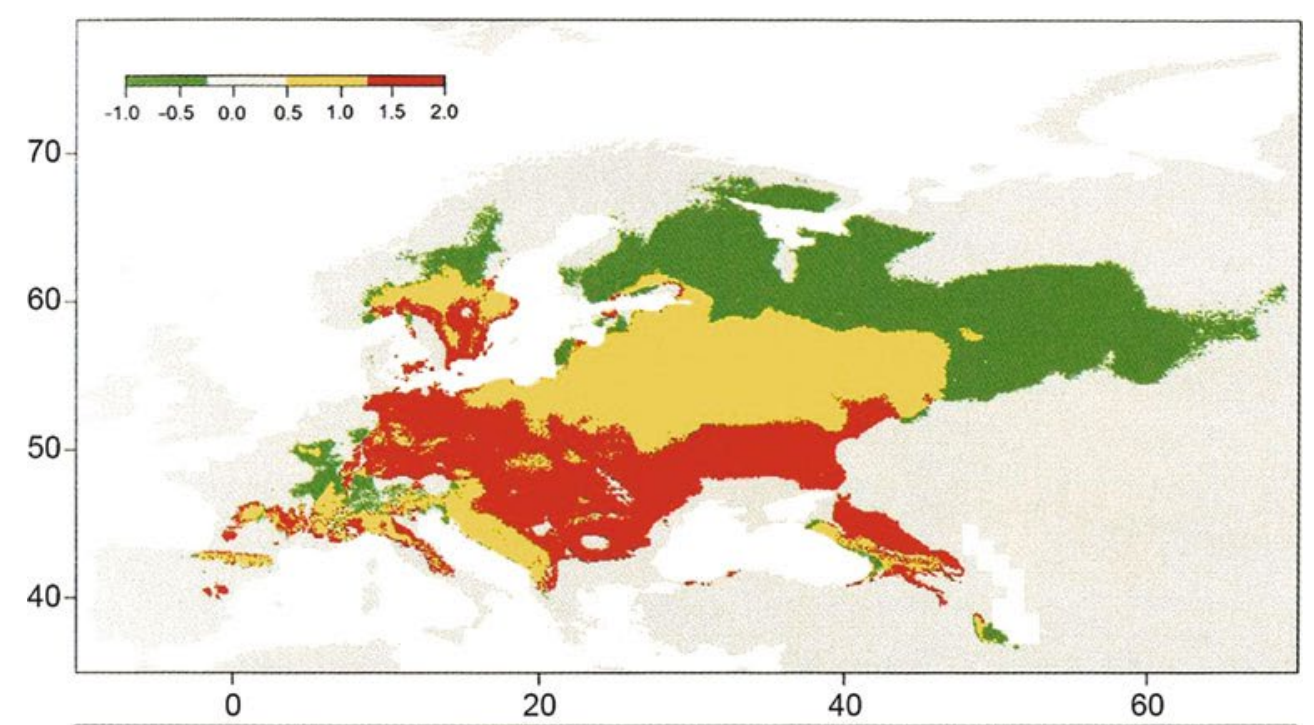

- Abb. 6.10 Veränderung der Habitateignung im Jahr 2050 gegenüber heute für drei in Städten häufig gepflanzte Baumarten: Spitzahorn (Acer platanoides) (oben); Winterlinde (Tilia cordata) (Mitte); Sommerlinde (Tilia platyphyllos) (unten). Grundlage: A2A-Klimaszenario mit dem Zirkulationsmodell HadCM3. Rot: deutliche Abnahme der Habitateignung; grün: deutliche Zunahme der Habitateignung; gelb: Gebiete ohne deutliche Veränderung der Habitateignung. (Wittig et al. 2012)
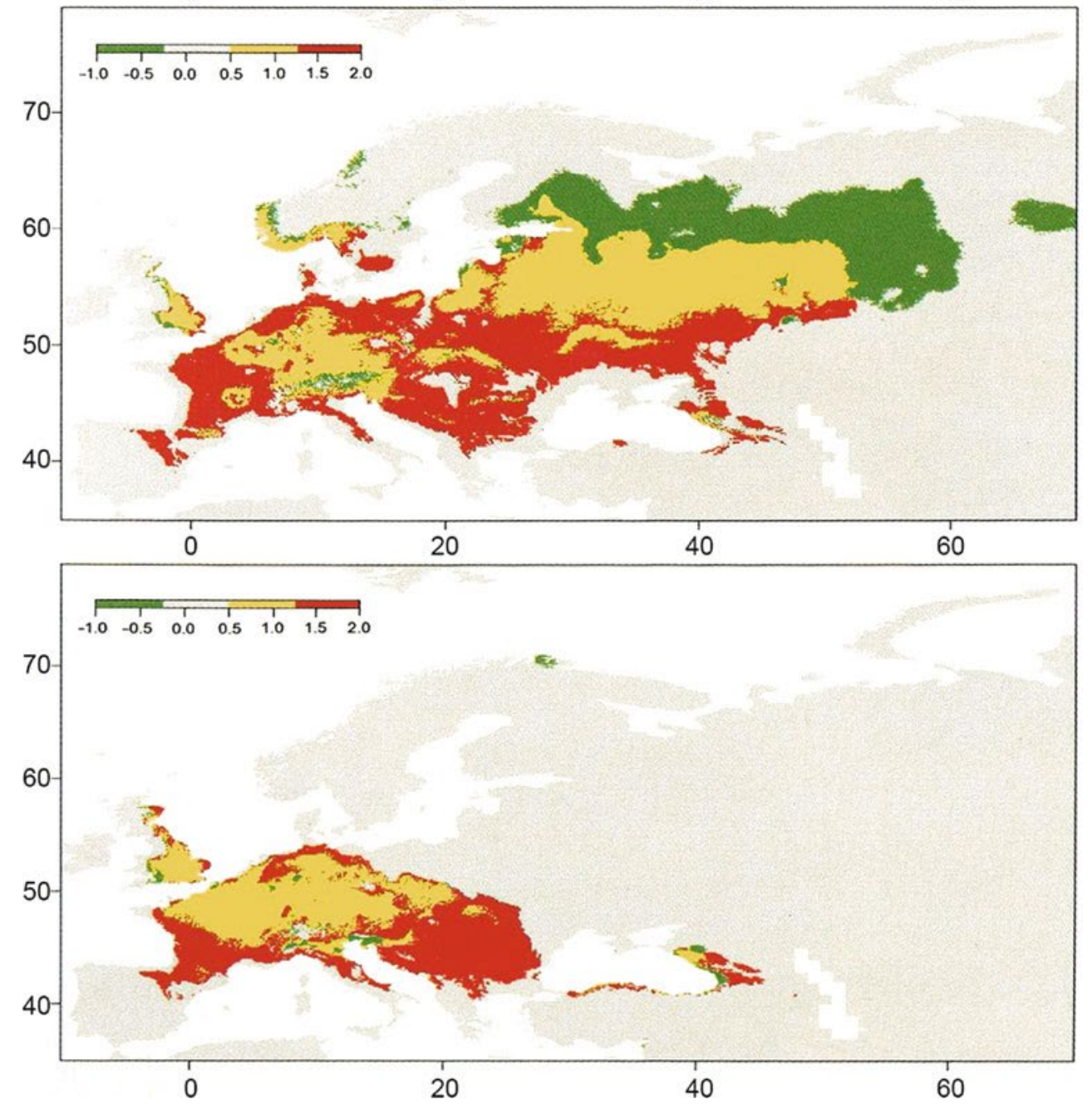

Park- und Zierrasen (z. B. Lolium perenne, Festuca rubra) werden gegenüber den aus wärmeren Gebieten stammenden oder an Trockenstandorte adaptierten Arten weniger gut verwendet werden können (Wittig et al. 2012). Im Vergleich zu den gepflanzten Arten enthält die spontane Stadtflora, insbesondere jene in stark urbanen Bereichen, als Folge des Wärmeinseleffektes bereits heute viele an Trockenheit angepasste Arten, die weiter zunehmen und sich teilweise bis ins Umland ausbreiten werden (Wittig 2008). Invasionsprozesse werden bei erhöhten Temperaturen begünstigt (Kowarik 2010). Darüber hinaus ist zu erwarten, dass die spontane, aus urbanophilen Arten aufgebaute Vegetation, die z. B. lokalklimatisch extreme Industrie- und Verkehrsbrachen großflächig besiedelt, in Zukunft auch auf eher mittleren Standorten städtischer Agglomerationen konkurrenzfähig sein wird. 


\subsection{Zusammenfassung: Auswirkungen des Klimawandels auf terrestrische und semiterrestrische ökosysteme in der MRH}

Es bestehen nach wie vor beträchtliche Wissensdefizite bzgl. der konkreten Reaktion von Ökosystemen auf den Klimawandel. Dennoch lassen sich auf der Grundlage bisher gewonnener Erkenntnisse Konsequenzen für Böden, Arten, Lebensgemeinschaften und Ökosysteme klar erkennen und Entwicklungstendenzen darstellen.

Einzelne Auswirkungen von sich ändernden Klimabedingungen auf Bodeneigenschaften wurden in den vergangenen Jahren intensiv untersucht. Relativ differenzierte Aussagen sind heute zu den direkt wirkenden Klimaänderungen von Niederschlagsverteilung und Temperaturerhöhung auf den Wasser- und Wärmehaushalt der Böden möglich. Die zu erwartenden Veränderungen des Bodenwasserregimes können beispielsweise in Abhängigkeit der regional projizierten Klimaänderungen und der heute ausgeprägten Bodeneigenschaften für die wichtigsten Böden der MRH (• Abb. 6.2) abgeleitet werden, wenn auch mit Unsicherheiten behaftet. Die hohe Diversität der Böden in der MRH und ihre sehr unterschiedlich ausgeprägten Eigenschaften und Funktionen führen allerdings dazu, dass die Auswirkungen des Klimawandels auf die Böden sogar innerhalb eines Naturraumes unterschiedlich und teilweise sogar gegenläufig sein können.

Bei den indirekt wirkenden Effekten gibt es derzeit noch eine Vielzahl offener Fragen aufgrund der Komplexität der Interaktionen im System Boden. Zu den Risiken und Auswirkungen des Klimawandels auf Böden, deren Resilienz oder Empfindlichkeit gegenüber den projizierten Änderungen des Klimas besteht ein beträchtlicher Diskussions- und Forschungsbedarf. Dies betrifft sowohl die Böden mit natürlicher Entwicklung als auch die stark vom Menschen ge- und überprägten Böden in den Ballungsräumen. Bei einzelnen Parametern und Funktionen, wie z. B. beim Humushaushalt und bei der Kohlenstofffestlegung, sind die indirekten Folgen, Interaktionen und Feedbackprozesse noch nicht in ihrer ganzen Komplexität erfasst und verstanden, sodass trotz hohen Forschungsaufwands z. T. keine gesicherten Aussagen möglich sind.

Um den geschilderten komplexen Wirkungszusammenhängen des Klimawandels auf Bodeneigenschaften, Funktionen und Gefährdungen, aber auch Interaktionen wichtiger Bodeneigenschaften untereinander und nicht zuletzt dem Mitigations- und Anpassungspotenzial der Böden gegenüber dem Klimawandel gerecht zu werden, ist eine sehr differenzierte Betrachtung erforderlich. Erschwert wird die Analyse der Folgen des Klimawandels durch die langen Zeiträume, die erforderlich sind, bzw. durch die zeitliche Verzögerung, die auftritt, bis Effekte und Rückkopplungsmöglichkeiten erfassbar und quantitativ messbar sind. Die Simulation und Modellierung der Auswirkungen des Klimawandels auf Böden ist in den letzten Jahren immer weiter vorangeschritten. Allerdings sind die Ergebnisse bisher noch mit großen Unsicherheiten behaftet (Asseng et al. 2013).

Grundlagen zur Anpassung an den Klimawandel aus Sicht des Bodenschutzes wurden von Willand et al. (2014) erarbeitet, die Maßnahmen zum Schutz, zur Erhaltung und (Wieder-)Herstellung der Kohlenstoffspeicherfunktion des Bodens, der Kühl- funktion des Bodens und des Schutzes des Bodens vor negativen Folgen des Klimawandels empfehlen. Die Autoren halten fest, dass ein genereller Schutz des Bodens vor den Wirkungen des Klimawandels nicht erfolgen kann. Möglich sind aber (Willand et al. 2014; Umweltbundesamt (2011)):

- die Wiederherstellung der Kohlenstoffspeicherfunktion der Böden durch Vermeidung von großflächigen Grundwasserabsenkungen, Abtorfungen und/oder landwirtschaftlicher Nutzung in Gebieten mit Mooren und hydromorphen Böden, durch Überbauungsschutz besonders speicherfähiger Böden, durch Vermeidung des Grünlandumbruchs sowie durch Regeneration und Schutz von Hoch- und Niedermooren,

- die Konkretisierung und Weiterentwicklung der guten fachlichen Praxis der landwirtschaftlichen Bodennutzung im Sinne des Klimaschutzes und möglicher Klimafolgen,

- ein besserer Schutz von wind- und wassererosionsempfindlichen Böden gegen die zunehmende Erosionsgefährdung durch Anpassung der Landnutzung, Vermeidung von Flurbereinigung und nicht fachgerechter Landwirtschaft,

- die Reduktion der Flächeninanspruchnahme und der Schutz klimafunktionsstarker Böden zur Kühlung der unteren Atmosphäre der Stadt durch Vermeidung von Überbauung sowie durch Flächenentsiegelung,

- die Sicherstellung und Weiterentwicklung der betriebenen Mess- und Erhebungsprogramme für Bodendaten im Hinblick auf die Erfordernisse eines auf den Klimawandel bezogenen Bodenmonitorings.

In der Pflanzen- und Tierwelt wird es aufgrund artspezifischer Reaktionen auf klimatische Veränderungen zu einem Wandel der Konkurrenzverhältnisse und zur Entwicklung neuartiger Lebensgemeinschaften mit veränderten Artabundanzen, Artdominanzen und veränderter ökologischer Funktionalität kommen, was eine potenzielle Beeinträchtigung ökologischer Serviceleistungen bedeutet.

In den letzten Jahrzehnten sind deutliche phänologische Änderungen bei zahlreichen Pflanzen- und Tierarten aufgetreten. In der Nordhemisphäre ist es zu einer Verschiebung phänologischer Ereignisse um einige Tage pro Dekade gekommen. In den mittleren Breiten hat sich die Vegetationsperiode um 14-24 Tage in den letzten 5-7 Jahrzehnten verlängert. Höhere Temperaturen und ein erhöhtes $\mathrm{CO}_{2}$-Angebot führen langfristig zu einer Steigerung der Primärproduktion; sie fällt jedoch geringer aus, als lange Zeit angenommen wurde. Die Nettoprimärproduktion ist in den letzten Dekaden global leicht angestiegen. Die Netto-Kohlenstoffaufnahme der terrestrischen Ökosysteme wird indes im Verlauf des 21. Jahrhunderts zurückgehen, falls intensivierte Störungsregime und/oder vermehrter Trockenstress in Sommermonaten die Kohlenstoffspeicherung einschränken sollten. Der Klimawandel wird sich ebenfalls zwangsläufig auf das auf verschiedensten biotischen Interaktionen wie Herbivorie, Bestäubung, Prädation, Parasitismus etc. basierende Beziehungsgeflecht in Ökosystemen auswirken, da neuartige Lebensgemeinschaften („novel communities") einstweilen durch das Fehlen von koevolvierten, d. h. lang etablierten biotischen Interaktionen charakterisiert sind. Die zeitliche Entkopplung von inter- 
agierenden Arten kann gravierende Änderungen in Nahrungsnetzen über verschiedene trophische Ebenen hinweg zur Folge haben. Globale Metaanalysen belegen zunehmende, durch den Klimawandel ausgelöste Arealerweiterungen zahlreicher Pflanzen- und Tierarten. Für verschiedene taxonomische Gruppen wurde rezent eine mittlere Arealverschiebung in höhere Breiten um 16,9 km/Dekade und in höhere Lagen in Gebirgen um $11 \mathrm{~m} /$ Dekade ermittelt. In den Gipfellagen der meisten europäischen Gebirge hat die Anzahl der Gefäßpflanzen deutlich zugenommen, mit erhöhter Abundanz thermophiler Arten auf Kosten kälteadaptierter Arten. Modelle der potenziellen zukünftigen Verbreitung deuten darauf hin, dass sich geeignete Lebensräume für viele Arten verkleinern werden, in Deutschland insbesondere im Nordosten und im Südwesten. Der Klimawandel begünstigt darüber hinaus die Etablierung bisher unbeständig auftretender Neophyten und Neozoen. Nichteinheimische thermophile Gehölze wie Lorbeerkirsche oder Walnussbaum zeigen im Bereich städtischer Wärmeinseln starke Ausbreitungstendenzen, so auch in Hamburg.

Bisher liegen erst wenige Untersuchungen zu den Auswirkungen des Klimawandels auf terrestrische und semiterrestrische Ökosysteme in der MRH vor. Das Artenspektrum der Wälder wird sich ändern, wobei die Rotbuche auf tiefgründigen Böden mittlerer bis guter Wasserspeicherkapazität die potenziell vorherrschende Baumart bleiben dürfte. Die Wachstumsbedingungen für die Buche könnten sich bei geringeren Sommerniederschlägen und erhöhten Temperaturen indes soweit verschlechtern, dass Anbauflächen zukünftig von der Kiefer und den Eichenarten eingenommen werden. Für die verbliebenen Moorlebensräume im Hamburger Stadtgebiet wird das klimatische Risiko weiter ansteigen, häufige und lang andauernde Trockenperioden werden die Sukzession in Richtung trockenerer Vegetationstypen (vor allem Moorwälder) vorantreiben. Bezüglich der Artenvielfalt der Marschenvegetation wird ein Rückgang infolge der Temperaturerhöhung erwartet, da konkurrenzschwache kleinwüchsige und annuelle Arten verdrängt werden. Voraussetzung für die langfristige Erhaltung von ästuarinen Marschen und Salzmarschen der Nordseeküste ist, dass die Sedimentakkretionsraten mit dem Meeresspiegelanstieg Schritt halten, was gegenwärtig der Fall ist. Artenverschiebungen in den ausgedehnten Sandheiden der MRH sind insbesondere bei zunehmender sommerlicher Trockenheit und über erhöhte Nährstoffverfügbarkeit zu erwarten. Die Keimlinge der Besenheide reagieren empfindlich auf Trockenheit, und vermehrt zu erwartende Trockenperioden im Sommer dürften die Keimlingsetablierung gefährden. Im artenreichen Feuchtgrünland werden neben erhöhten Temperaturen vor allem Veränderungen des Wasserhaushaltes deutliche Verschiebungen im Arteninventar hervorrufen. Modellierungen des zukünftigen Grundwasserstandes im Feuchtgrünland lassen für die MRH, z. B. für die Brenndoldenwiesen in den niedersächsischen Elbtalauen, vermehrt kritische Phasen der Wasserversorgung erwarten. Im Bereich urbaner Ökosysteme werden Invasionsprozesse bei erhöhten Temperaturen begünstigt. Die Habitatbedingungen für viele einheimische Arten werden sich deutlich verschlechtern, während sich gut an Trockenheit angepasste neophytische Arten weiter ausbreiten dürften.

\section{Literatur}

AG Boden (2005) Bodenkundliche Kartieranleitung, 5. Aufl. Schweizerbart, Hannover

Ainsworth EA, Long SP (2005) What have we learned from 15 years of freeair $\mathrm{CO}_{2}$ enrichment (FACE)? A meta-analytic review of the responses of photosynthesis, canopy properties and plant production to rising $\mathrm{CO}_{2}$. New Phytol 165(2):351-372

Ainsworth EA, Rogers A (2007) The response of photosynthesis and stomatal conductance to rising $\left[\mathrm{CO}_{2}\right]$ : mechanisms and environmental interactions. Plant Cell Environ 30(3):258-270

Amano T, Smithers RJ, Sparks TH, Sutherland WJ (2010) A 250-year index of first flowering dates and its response to temperature changes. P Roy Soc Lond B Bio 277:2451-2457

Anderson JT, Panetta AM, Mitchell-Olds T (2012) Evolutionary and ecological responses to anthropogenic climate change. Plant Physiol 160:1728-1740

Arbeitskreis Umweltökonomische Gesamtrechnungen der Länder (2015) Statistische Ämter der Länder. Webseiten der Statistischen Ämter der Länder

van Asch M, Visser ME (2007) Phenology of forest caterpillars and their host trees: the importance of synchrony. Annu Rev Entomol 52:37-55

Asseng S, Ewert F, Rosenzweig C, Jones JW, Hatfield JL, Ruane AC, Boote KJ, Thorburn PJ, Rötter RP, Cammarano D, Brisson N, Basso B, Martre P, Aggarwal PK, Angulo C, Bertuzzi P, Biernath C, Challinor AJ, Doltra J, Gayler S, Goldberg R, Grant R, Heng L, Hooker J, Hunt LA, Ingwersen J, Izaurralde RC, Kersebaum KC, Müller C, Naresh Kumar S, Nendel C, O'Leary G, Olesen JE, Osborne TM, Palosuo T, Priesack E, Ripoche D, Semenov MA, Shcherbak I, Steduto P, Stöckle C, Stratonovitch P, Streck T, Supit I, Tao F, Travasso M, Waha K, Wallach D, White JW, Williams JR, Wolf J (2013) Uncertainty in simulating wheat yields under climate change. Nat Clim Change 3:827-832

Bader MK-F, Leuzinger S, Keel SG, Siegwolf RTW, Hagedorn F, Schleppi P, Körner $\mathrm{C}$ (2013) Central European hardwood trees in a high- $\mathrm{CO}_{2}$ future: synthesis of an 8-year forest canopy $\mathrm{CO}_{2}$ enrichment project. J Ecol 101 (6):1509-1519

Baldwin AH, Jensen K, Schönfeldt M (2014) Warming increases plant biomass and reduces diversity across continents, latitudes, and species migration scenarios in experimental wetland communities. Glob Change Biol 20(3):835-850

BBodSchG (1998) Gesetz zum Schutz des Bodens. BGBI I, G 5702, Nr. 16 v. 24.3.1998, S 502-510

Bechtel B, Schmidt KJ (2011) Floristic mapping data as a proxy for the mean urban heat island. Clim Res 49:45-58

Beer C, Reichstein M, Tomelleri E, Ciais P, Jung M, Carvalhais N, Rödenbeck $C$, Altaf Arain M, Baldocchi D, Bonan GB, Bondeau A, Cescatti A, Lasslop G, Lindroth $\mathrm{A}$, Lomas $\mathrm{M}$, Luyssaert $\mathrm{S}$, Margolis $\mathrm{H}$, Oleson KW, Roupsard $\mathrm{O}$, Veenendaal E, Viovy N, Williams C, Woodward FI, Papale D (2010) Terrestrial gross carbon dioxide uptake: global distribution and covariation with climate. Science 329(5993):834-838

Behre KE (2008) Landschaftsgeschichte Norddeutschlands. Umwelt und Siedlung von der Steinzeit bis zur Gegenwart. Wachholtz, Neumünster

Beierkuhnlein C, Foken T (2008) Klimawandel in Bayern. Auswirkungen und Anpassungsmöglichkeiten. Bayreuther Forum Ökologie, Bd. 113

Beierkuhnlein C, Jentsch A (2005) Ecological importance of species diversity. A review on the ecological implications of species diversity in plant communities. In: Henry RJ (Hrsg) Plant diversity and evolution: genotypic and phenotypic variation in higher plants. CAB International, Wallingford, $S$ 249-285

Bellard C, Bertelsmeier C, Leadley P, Thuiller W, Courchamp F (2012) Impacts of climate change on the future of biodiversity. Ecol Lett 15(4):365-377

Benda L (Hrsg) (1995) Das Quartär Deutschlands. Gebr. Borntraeger, Berlin

Bergamini A, Ungricht S, Hofmann H (2009) An elevational shift of cryophilous bryophytes in the last century - an effect of climate warming? Divers Distrib 15(5):871-879

Bergemann M (1995) Die Lage der oberen Brackwassergrenze im Elbeästuar. Dtsch Gewässerkdl Mitt 39:134-137

Berger S, Söhlke G, Walther G-R, Pott R (2007) Bioclimatic limits and range shifts of cold-hardy evergreen broad-leaved species at their northern distributional limit in Europe. Phytocoenologia 37(3-4):523-539 
Bertram H, Poppendieck HH (2010) Wälder. In: Poppendieck HH, Bertram H, Brandt I, Engelschall B, von Prondzinski J (Hrsg) Der Hamburger Pflanzenatlas von A bis Z. Dölling \& Galitz, München, Hamburg, S 32-39

BGR - Bundesanstalt für Geowissenschaften und Rohstoffe (2013) Bodenübersichtskarte der Bundesrepublik Deutschland $1: 100.000$ (BÜK1000). Digit. Archiv FISBo BGR, Hannover, Berlin

Bittner T, Beierkuhnlein C (2014) Entwicklung von Szenarien zur Beeinflussung und Veränderung von Lebensräumen durch den Klimawandel. In: Beierkuhnkein C, Jentsch A, Reineking B, Schlumprecht H, Ellwanger G (Hrsg) Auswirkungen des Klimawandels auf Fauna, Flora, Lebensräume sowie Anpassungsstrategien des Naturschutzes. Naturschutz und Biologische Vielfalt 137., S 274-367

Blume HP, Müller-Thomsen U (2007) A field experiment on the influence of the postulated global climatic change on coastal marshland soils. J Plant Nutr Soil Sc 170(1):145-156

Böhm J (2008) Potentielle Auswirkungen des Klimawandels auf die Eigenschaften und Entwicklung der Böden Schleswig-Holsteins. Diplomarbeit am Institut für physische Geographie und Landschaftsökologie an der Leibniz Universität Hannover

Bolte A, Degen B (2010) Anpassung der Wälder an den Klimawandel: Optionen und Grenzen. Landbauforsch - Vti Agric For Res 60(3):111-118

Bolte A, Eisenhauer D-R, Ehrhart H-P, Groß J, Hanewinkel M, Kölling C, Profft I, Rohde M, Röhe P, Amereller K (2009) Klimawandel und Forstwirtschaft - Übereinstimmungen und Unterschiede bei der Einschätzung der Anpassungsnotwendigkeiten und Anpassungsstrategien der Bundesländer. Landbauforsch - Vti Agric For Res 59(4):269-278

Bolte A, Hilbrig L, Grundmann B, Kampf F, Brunet J, Roloff A (2010) Climate change impacts on stand structure and competitive interactions in a southern Swedish spruce-beech forest. Eur J Forest Res 129(3):261-276

Both C, van Asch M, Bijlsma RG, van den Burg AB, Visser ME (2009) Climate change and unequal phenological changes across four trophic levels: constraints or adaptations? J Anim Ecol 78(1):73-83

Bréda N, Huc R, Granier A, Dreyer E (2006) Temperate forest trees and stands under severe drought: a review of ecophysiological responses, adaptation processes and long-term consequences. Ann Sci 63(6):625-644

Briones MJI, Ostle NJ, McNamara NP, Poskitt J (2009) Functional shifts of grassland soil communities in response to soil warming. Soil Biol Biochem 41:315-322

Britton A, Marrs R, Pakeman R, Carey P (2003) The influence of soil-type, drought and nitrogen addition on interactions between Calluna vulgaris and Deschampsia flexuosa: implications for heathland regeneration. Plant Ecol 166(1):93-105

Bundesamt für Kartographie und Geodäsie (2011) Verwaltungsgrenzen Deutschland. Datensatz mit 4 Shape Dateien

Burkle LA, Marlin JC, Knight TM (2013) Plant-pollinator interactions over 120 years: loss of species, co-occurrence, and function. Science 339(6127):1611-1615

Butzeck C (2015) Tidal marshes of the Elbe estuary: spatial and temporal dynamics of sedimentation and vegetation. Dissertation. Universität Hamburg, Hamburg

Butzeck C, Eschenbach A, Gröngröft A, Hansen K, Nolte S, Jensen K (2014) Sediment deposition and accretion rates in tidal marshes are highly variable along estuarine salinity and flooding gradients. Estuaries Coasts 38:434-450

Carrera N, Barreal ME, Gallego PP, Briones MJ (2009) Soil invertebrates control peatland $C$ fluxes in response to warming. Funct Ecol 23:637-648

Charru M, Seynave I, Morneau F, Bontemps J-D (2010) Recent changes in forest productivity: an analysis of national forest inventory data for common beech (Fagus sylvatica L.) in north-eastern France. Ecol Manag 260(5):864874

Chen I-C, Hill JK, Ohlemüller R, Roy DB, Thomas CD (2011) Rapid range shifts of species associated with high levels of climate warming. Science 333(6045):1024-1026

Chmielewski FM (2007) Folgen des Klimawandels für die Land- und Forstwirtschaft. In: Endlicher W, Gerstengarbe FW (Hrsg) Der Klimawandel - Einblicke, Rückblicke und Ausblicke. Eigenverlag, Potsdam, S 75-85
Chmielewski FM (2016) Was bringt der Klimawandel dem Obstbau? Geogr Rdsch 68(3):12-19

Chmielewski FM, Rötzer T (2001) Response of tree phenology to climate change across Europe. Agr For Meteorol 108(2):101-112

Chmielewski FM, Müller A, Bruns E (2004) Climate changes and trends in phenology of fruit trees and field crops in Germany, 1961-2000. Agr For Meteorol 121(1):69-78

Church JA, Clark PU, Cazenave A, Gregory JM, Jevrejeva S, Levermann A, Merrifield MA, Milne GA, Nerem RS, Nunn PD, Payne AJ, Pfeffer WT, Stammer D, Unnikrishnan AS (2013) Sea level change. In: Stocker TF, Qin D, Plattner G-K, Tignor M, Allen SK, Boschung J, Nauels A, Xia Y, Bex V, Midgle PM (Hrsg) Climate change 2013: the physical science basis. Contribution of working group I to the fifth assessment report of the intergovernmental panel on climate change. Cambridge University Press, Cambridge, S 1137-1216

Ciais P, Sabine C, Bala G, Bopp L, Brovkin V, Canadell J, Chhabra A, DeFries R, Galloway J, Heimann M, Jones C, Le Quéré C, Myneni RB, Piao S, Thornton P (2013) Carbon and other biogeochemical cycles. In: Stocker TF, Qin D, Plattner G-K, Tignor M, Allen SK, Boschung J, Nauels A, Xia Y, Bex V, Midgle PM (Hrsg) Climate change 2013: the physical science basis. Contribution of working group I to the fifth assessment report of the intergovernmental panel on climate change. Cambridge University Press, Cambridge, $\mathrm{S}$ 465-570

Cook BI, Wolkovich EM, Davies TJ, Ault TR, Betancourt JL, Allen JM, Bolmgren K, Cleland EE, Crimmins TM, Kraft NJB, Lancaster LT, Mazer SJ, McCabe GJ, McGill BJ, Parmesan C, Pau S, Regetz J, Salamin N, Schwartz MD, Travers SE (2012) Sensitivity of spring phenology to warming across temporal and spatial climate gradients in two independent databases. Ecosystems 15(8):1283-1294

Coûteaux M-M, Bolger T (2000) Interactions between atmospheric $\mathrm{CO}_{2}$ enrichment and soil fauna. Plant Soil 224:123-134

Couwenberg J, Joosten H (2001) Bilanzen zum Moorverlust - das Beispiel Deutschland. In: Succow M, Joosten H (Hrsg) Landschaftsökologische Moorkunde, 2. Aufl. Schweizerbart, Stuttgart, S 409-411

Crimmins SM, Dobrowski SZ, Greenberg JA, Abatzoglou JT, Mynsberge AR (2011) Changes in climatic water balance drive downhill shifts in plant species' optimum elevations. Science 331(6015):324-327

Dahl M (2001) Mögliche Effekte eines Klimawandels auf die Stickstoffnettomineralisation in Vorlandsalzwiesen. Dissertation. Universität Kiel, Kiel

Damm E, Höke S, Doetsch P (2012) Erfassung und Optimierungspotential der Kühlleistung von Böden dargestellt an ausgewählten Beispielfächen der Stadt Bottrop. Bodenschutz Erhalt Nutz Wiederherstell Böden 3:94-98

Davidson EA, Janssens IA (2006) Temperature sensitivity of soil carbon decomposition and feedbacks to climate change. Nature 440:165-173

Dierßen K (1996) Vegetation Nordeuropas. Ulmer, Stuttgart

Dierßen K, Dierßen B (2001) Moore. Ulmer, Stuttgart

Dittmar C, Zech W, Elling W (2003) Growth variations of common beech (Fagus sylvatica $L$.) under different climatic and environmental conditions in Europe - a dendroecological study. For Ecol Manag 173(1):63-78

Doak DF, Morris WF (2010) Demographic compensation and tipping points in climate-induced range shifts. Nature 467(7318):959-962

Dorendorf J, Wilken A, Eschenbach A, Jensen K (2015) Urban-induced changes in tree leaf litter accelerate decomposition. Ecol Process 4:1

Drews H, Jacobsen J, Trepel M, Wolter K (2000) Moore in Schleswig-Holstein unter besonderer Berücksichtigung der Niedermoore - Verbreitung, Zustand und Bedeutung. Telma 30:241-278

Drösler M, Adelmann W, Augustin J, Bergmann L, Beyer M, Gibels M, Förster C, Freibauer A, Höper H, Petschow U, Hahn-Schöfl M, Kantelhardt J, Liebersbach H, Schägner JP, Schaller L, Sommer M, Thuille A, Wehrhan M (2009) Klimaschutz durch Moorschutz. In: Mahammadzadeh M, Biebeler $\mathrm{H}$, Hubertus B (Hrsg) Klimaschutz und Anpassung an die Klimafolgen. Institut der deutschen Wirtschaft Köln Medien GmbH, Köln, S 89-97

Drösler M, Schaller L, Kantelhardt J, Schweiger M, Fuchs D, Tiemeyer B, Augustin J, Wehrhan M, Förster C, Bergmann L, Kapfer A, Krüger GM (2012) Beitrag von Moorschutz- und -revitalisierungsmaßnahmen zum Klimaschutz am Beispiel von Naturschutzgroßprojekten. Nat Landsch 87:70-76

Dullinger S, Gattringer A, Thuiller W, Moser D, Zimmermann NE, Guisan A, Willner W, Plutzar C, Leitner M, Mang T, Caccianiga M, Dirnböck T, Ertl S, Fischer 
A, Lenoir J, Svenning J-C, Psomas A, Schmatz DR, Silc U, Vittoz P, Hülber K (2012) Extinction debt of high-mountain plants under twenty-first-century climate change. Nat Clim Change 2(8):619-622

Eggleton P, Inward K, Smith J, Jones DT, Sherlock E (2009) A six year study of earthworm (Lumbricidae) populations in pasture woodland in southern England shows their responses to soil temperature and soil moisture. Soil Biol Biochem 41:1857-1865

Eitzinger J, Kersebaum KC, Formayer H (2009) Landwirtschaft im Klimawandel. Auswirkungen und Anpassungsstrategien für die Land- und Forstwirtschaft in Mitteleuropa. Agrimedia, Clenze

Ellenberg H, Leuschner C (2010) Vegetation Mitteleuropas mit den Alpen in ökologischer, dynamischer und historischer Sicht, 6. Aufl. Ulmer, Stuttgart Endlicher W (2012) Einführung in die Stadtökologie. Ulmer, Stuttgart

Engel N, Müller U (2009) Auswirkungen des Klimawandels auf Böden in Niedersachsen. Landesamt für Bergbau, Energie und Geologie, LBEG, Hannover

Engelschall B (2010) Moore. In: Poppendieck HH, Bertram H, Brandt I, Engelschall B, von Prondzinski J (Hrsg) Der Hamburger Pflanzenatlas von A bis Z. Dölling \& Galitz, München, Hamburg, S 40-45

Erwin K (2009) Wetlands and global climate change: the role of wetland restoration in a changing world. Wetl Ecol Manag 17:71-84

Essl F (2013) Grünland - im Spannungsfeld von Klima- und Nutzungswandel. In: Essl F, Rabitsch W (Hrsg) Biodiversität und Klimawandel. Auswirkungen und Handlungsoptionen für den Naturschutz in Mitteleuropa. Springer, Berlin, Heidelberg, S 212-216

Essl F, Kobler J (2009) Spiny invaders - patterns and determinants of cacti invasion in Europe. Flora 204(7):485-494

Essl F, Dullinger S, Moser D, Rabitsch W, Kleinbauer I (2012) Vulnerability of mires under climate change: implications for nature conservation and climate change adaptation. Biodivers Conserv 21(3):655-669

Essl F, Knapp HD, Lexer MJ, Seidl R, Riecken U (2013a) Vegetation und Boden als Kohlenstoffsenken und -speicher. In: EssI F, Rabitsch W (Hrsg) Biodiversität und Klimawandel. Auswirkungen und Handlungsoptionen für den Naturschutz in Mitteleuropa. Springer, Berlin, Heidelberg, S 264-277

Essl F, Lexer MJ, Seidl R (2013b) Wälder: Anbaugrenzen, Klimaextreme, Parasiten und Störungen. In: Essl F, Rabitsch W (Hrsg) Biodiversität und Klimawandel. Auswirkungen und Handlungsoptionen für den Naturschutz in Mitteleuropa. Springer, Berlin, Heidelberg, S 179-192

Estrella N, Sparks TH, Menzel A (2007) Trends and temperature response in the phenology of crops in Germany. Glob Change Biol 13(8):1737-1747

Falk W, Hempelmann N (2013) Species favourability shift in Europe due to climate change: a case study for Fagus sylvatica L. and Picea abies (L.) Karst. Based on an ensemble of climate models. J Climatol 2013:787250

FHH - Freie und Hansestadt Hamburg, Behörde für Stadtentwicklung und Umwelt (2012) Bodenformengesellschaften in der FHH. FFH, Hamburg

Frolking S, Talbot J, Jones MC, Treat CC, Kauffman JB, Tuittila E-S, Roulet N (2011) Peatlands in the Earth's $21^{\text {st }}$ century climate system. Environ Rev 19(NA):371-396

Fu YH, Piao S, Op de Beeck M, Cong N, Zhao H, Zhang Y, Menzel A, Janssens IA (2014) Recent spring phenology shifts in Western Central Europe based on multiscale observations. Global Ecol Biogeogr 23(11):1255-1263

Geißler K (2007) Lebensstrategien seltener Stromtalpflanzen. Autökologische Untersuchung von Cnidium dubium, Gratiola officinalis und Juncus atratus unter besonderer Berücksichtigung ihrer Stressresistenz. Dissertation. Universität Potsdam, Potsdam

Giesecke T, Davis B, Brewer S, Finsinger W, Wolters S, Blaauw M, de Beaulieu JL, Binney H, Fyfe RM, Gaillard MJ, Gil-Romera G, van der Knaap WO, Kunes $P_{\text {, }}$ Kühl N, van Leeuwen JFN, Leydet M, Lotter AF, Ortu E, Semmle M, Bradshaw RHW (2014) Towards mapping the late Quaternary vegetation change of Europe. Veg Hist Archaeobot 23(1):75-86

Goldbach A, Kuttler W (2012) Quantification of turbulent heat fluxes for adaptation strategies within urban planning. Int J Climate 33:143-159

Gönnert G, von Storch H, Jensen J, Thumm S, Wahl T, Weise R (2009) Der Meeresspiegelanstieg. Ursachen, Tendenzen und Risikobewertung. Küste 76:225-256

Gordon C, Woodin SJ, Alexander IJ, Mullins CE (1999) Effects of increased temperature, drought and nitrogen supply on two upland perennials of contrasting functional type: Calluna vulgaris and Pteridium aquilinum. New Phytol 142(2):243-258
Gottfried M, Pauli H, Futschik A, Akhalkatsi M, Barančok P, Alonso BJL, Coldea G, Dick J, Erschbamer B, Fernandez Calzado MR, Kazakis G, Krajči J, Larsson P, Mallaun M, Michelsen O, Moiseev D, Moiseev P, Molau U, Merzouki A, Nagy L, Nakhutsrishvili G, Pedersen B, Pelino G, Puscas M, Rossi G, Stanisci A, Theurillat JP, Tomaselli M, Villar L, Vittoz P, Vogiatzakis I, Grabherr G (2012) Continent-wide response of mountain vegetation to climate change. Nat Clim Chang 2:111-115

Grabherr G (2003) Alpine vegetation dynamics and climate change - a synthesis of long-term studies and observations. In: Nagy L, Grabherr G, Körner C, Thompson DBA (Hrsg) Alpine biodiversity in Europe. Ecol Stud 167., S 399-409

Gray AJ, Mogg RJ (2001) Climate impacts on pioneer saltmarsh plants. Clim Res 18(1/2):105-112

Greinert A (2015) The heterogeneity of urban soils in the light of their properties. J Soil Sediment 15:1725-1737

Härdtle W, Assmann T, van Diggelen R, von Oheimb G (2009) Renaturierung und Management von Heiden. In: Zerbe S, Wiegleb G (Hrsg) Renaturierung von Ökosystemen in Mitteleuropa. Spektrum Akademischer Verlag, Heidelberg, S 317-347

Hasenauer H, Nemani RR, Schadauer K, Running SW (1999) Forest growth response to changing climate between 1961 and 1990 in Austria. Forest Ecol Manag 122(3):209-219

Hassenpflug W (2005) Winderosion. In: Blume H-P (Hrsg) Handbuch des Bodenschutzes. Bodenökologie und -belastung. Vorbeugende und abwehrende Schutzmaßnahmen, 3. Aufl. ecomed Medizin, Landsberg am Lech, S 231253

Hegland SJ, Nielsen A, Lázaro A, Bjerknes A-L, Totland Ø (2009) How does climate warming affect plant-pollinator interactions? Ecol Lett 12(2):184-195

Heidt $L$ (2009) Auswirkungen des Klimawandels auf die potenzielle Beregnungsbedürftigkeit Nordost-Niedersachsens. Geo Ber 13:1-109

Henninger S (Hrsg) (2011) Stadtökologie: Bausteine des Ökosystems Stadt. Schöningh, Paderborn

Herberg A, Kube A (2013) Klimawandel und Städte: Naturschutz und Lebensqualität. In: Essl F, Rabitsch W (Hrsg) Biodiversität und Klimawandel. Auswirkungen und Handlungsoptionen für den Naturschutz in Mitteleuropa. Springer, Berlin, Heidelberg, S 254-262

Hetzel I (2012) Ausbreitung klimasensitiver ergasiophygophytischer Gehölzsippen in urbanen Wäldern im Ruhrgebiet. Dissertationes Botanicae 411. Cramer, Stuttgart

Hickler T, Bolte A, Hartard B, Beierkuhnlein C, Blaschke M, Blick T, Brüggemann W, Dorow WHO, Fritze M-A, Gregor T, Ibisch P, Kölling C, Kühn I, Musche M, Pompe S, Petercord R, Schweiger O, Seidling W, Trautmann S, Waldenspuhl T, Walentowski H, Wellbrock N (2012) Folgen des Klimawandels für die Biodiversität in Wald und Forst. In: Mosbrugger V, Brasseur G, Schaller $M$, Stribrny B (Hrsg) Klimawandel und Biodiversität - Folgen für Deutschland. WBG, Darmstadt, S 164-221

Hickling R, Roy DB, Hill JK, Fox R, Thomas CD (2006) The distributions of a wide range of taxonomic groups are expanding polewards. Glob Change Biol 12(3):450-455

Hillebrand H, Fitter A (2012) Neue Erkenntnisse zu einem ökologischen Paradigma. In: Beck E (Hrsg) Die Vielfalt des Lebens: Wie hoch, wie komplex, warum?. Wiley-VCH, Weinheim, S 111-118

Hódar JA, Zamora R (2004) Herbivory and climatic warming: a Mediterranean outbreaking caterpillar attacks a relict, boreal pine species. Biodivers Conserv 13(3):493-500

Höper H, Schäfer W (2012) Die Bedeutung der organischen Substanz von Mineralböden für den Klimaschutz. Bodenschutz 17:72-79

Huang S, Hattermann FF, Krysanova V, Bronstert A (2013) Projections of climate change impacts on river flood conditions in Germany by combining three different RCMs with a regional eco-hydrological model. Clim Change $116: 631-663$

Hüppe J (1993) Entwicklung der Tieflands-Heidelandschaften Mitteleuropas in geobotanisch-vegetationsgeschichtlicher Sicht. Ber Reinhold Tüxen Ges 5:49-75

Hüttl RF, Russel DJ, Sticht C, Schrader S, Weigel H-J, Bens O, Lorenz K, Schneider BU (2012) Auswirkungen auf Bodenökosysteme. In: Mosbrugger V, Brasseur G, Schaller M, Stribrny B (Hrsg) Klimawandel und Biodiversität: Folgen für Deutschland. WBG, Darmstadt, S 128-163 
IPCC (2014) Climate Change 2014: Synthesis Report. Contribution of Working Groups I, II and III to the Fifth Assessment Report of the Intergovernmental Panel on Climate Change [Core Writing Team, Pachauri RK und Meyer LA (Hrsg). IPCC, Geneva, Switzerland

Jackson ST, Blois JL (2015) Community ecology in a changing environment: perspectives from the quaternary. Proc Nat Acad Sci 112(16):4915-4921

Jansson C, Jansson P-E, Gustafsson D (2007) Near surface climate in an urban vegetated park and its surroundings. Theor Appl Climatol 89:185-193

Jantsch MC, Fischer HS, Winter S, Fischer A (2014) How are plant species in central European beech (Fagus sylvatica L.) forests affected by temperature changes? Shift of potential suitable habitats under global warming. Ann Di Bot 4:97-113

Jensen K, Schoenberg W (2015) Mögliche Effekte des Klimawandels auf Vegetation und Funktionen ausgewählter Ökosysteme der Metropolregion Hamburg. Abh Naturwiss Verein Hambg 45:107-132

Jensen K, Härdtle W, Meyer-Grünefeldt M, Pfeiffer EM, Reisdorff C, Schmidt K, Schmidt S, Schrautzer J, von Oheimb G (2011) Klimabedingte Änderungen in terrestrischen und semi-terrestrischen Ökosystemen. In: von Storch $\mathrm{H}$, Claussen M (Hrsg) Klimabericht für die Metropolregion Hamburg. Springer, Berlin, Heidelberg, S 143-176

Jensen K, Knieling J, Rechid D (2014) Charakteristika der Metropolregion Hamburg. In: KLIMZUG-NORD Verbund (Hrsg) Kursbuch Klimaanpassung. Handlungsoptionen für die Metropolregion Hamburg. TuTech, Hamburg, S4-7

Jeschke L, Joosten H (2003) Moore - gefährdete Ökosysteme. In: Leibniz-Institut für Länderkunde (Hrsg) Nationalatlas Bundesrepublik Deutschland - Klima, Pflanzen- und Tierwelt. Spektrum Akad. Verlag, Heidelberg, Berlin, S 112-115

Jochner SC, Sparks TH, Estrella N, Menzel A (2012) The influence of altitude and urbanisation on trends and mean dates in phenology (1980-2009). Int J Biometeorol 56(2):387-394

Jones AD, Stolbovoy V, Rusco E, Gentile AR, Gardi C, Marechal B, Montanarella L (2009) Climate change in Europe. 2. Impact on soil. A review. Agron Sustain Dev 29:423-432

Joosten H (2012) Zustand und Perspektiven der Moore weltweit. Nat Landsch 87:50-55

Joosten H, Couwenberg J (2008) Peatlands and carbon. In: Parish F, Sirin A, Charman D, Joosten H, Minayeva T, Silvius M, Stringer L (Hrsg) Assessment on peatlands, Biodiversity and climate change. Global Environment Centre, Wetlands International, Kuala Lumpur, Wageningen, S 99-117

Joosten H, Brust K, Couwenberg J, Gerner A, Holsten B, Permien T, Schäfer A, Tanneberger F, Trepel M, Wahren A (2013) MoorFutures. Integration von weiteren Ökosystemdienstleistungen einschließlich Biodiversität in Kohlenstoffzertifikate - Standard, Methodologie und Übertragbarkeit in andere Regionen. BfN-Skripten 350. BfN, Bonn

Kardol P, Reynolds WN, Norby RJ, Classen AT (2011) Climate change effects on soil microarthropod abundance and community structure. Appl Soil Ecol 47:37-44

Karnosky DF, Tallis M, Darbah J, Taylor G (2007) Direct effects of elevated carbon dioxide on forest tree productivity. In: Freer-Smith P, Broadmeadow $M$, Lynch J (Hrsg) Forestry and climate change. CABI Publishing, Cambridge, S 136-142

Kearns CA, Inouye DW, Waser NM (1998) Endangered mutualisms: the conservation of plant-pollinator interactions. Annu Rev Ecol Syst 29:83-112

Keller F, Körner C (2003) The role of photoperiodism in alpine plant development. Arctic Antarct Alp Res 35(3):361-368

Kersebaum KC, Nendel C (2014) Site-specific impacts of climate change on wheat production across regions of Germany using different $\mathrm{CO}_{2}$ response functions. Eur J Agronom 52:22-32

Kimble JM, Lal R, Grossmann RB (1998) Alteration of soil properties caused by climate change. Adv Geoecol 31:175-184

Kint V, Aertsen W, Campioli M, Vansteenkiste D, Delcloo A, Muys B (2012) Radial growth change of temperate tree species in response to altered regional climate and air quality in the period 1901-2008. Clim Change 115(2):343-363

Kjøhl M, Nielsen A, Stenseth NC (2011) Potential effects of climate change on crop pollination. Food and Agriculture Organization of the United Nations (FAO), Rom
Klaus G (2007) Zustand und Entwicklung der Moore in der Schweiz. Ergebnisse der Erfolgskontrolle Moorschutz. Umwelt-Zustand Nr. 0730. BAFU, Bern

Kleinbauer I, Dullinger S, Klingenstein F, May R, Nehring S, EssI F (2010) Ausbreitungspotenzial ausgewählter neophytischer Gefäßpflanzen unter Klimawandel in Deutschland und Österreich. BfN-Skripten 275., S 1-74

Knorr W, Prentice LC, House Jl, Holland EA (2005) Long-term sensitivity of soil carbon turnover to warming. Nature 433:298-301

Kolářová E, Nekovář J, Adamík P (2014) Long-term temporal changes in central European tree phenology (1946-2010) confirm the recent extension of growing seasons. Int J Biometeorol 58(8):1739-1748

Kölling C, Zimmermann L (2014) Klimawandel gestern und morgen. Neue Argumente können die Motivation zum Waldumbau erhöhen. LWF Aktuell 99:27-31

Kölling C, Zimmermann L, Walentowski H (2007) Klimawandel: Was geschieht mit Buche und Fichte? AFZ Wald 11:584-588

Körner C, Basler D (2010) Phenology under global warming. Science 327(5972):1461-1462

Kovats RS, Valentini R, Bouwer LM, Georgopoulou E, Jacob D, Martin E, Rounsevell M, Soussana JF (2014) Europe. In: IPCC (Hrsg) Climate change 2014: impacts, adaptation and vulnerability. Part B: regional aspects. Contribution of working group II to the fifth assessment report of the intergovernmental panel on climate change. Cambridge University Press, Cambridge, New York, S 1267-1326

Kowarik I (2010) Biologische Invasionen. Neophyten und Neozoen in Mitteleuropa, 2. Aufl. Ulmer, Stuttgart

Kowarik I (2011) Novel urban ecosystems, biodiversity, and conservation. Environ Pollut 159(8):1974-1983

Krause A (2010) Auswertung der Vegetationsperiode in der Metropolregion Hannover-Braunschweig-Göttingen(-Wolfsburg). Werkstattbericht, Institut für Meteorologie und Klimatologie, Universität Hannover (unveröff.)

Krause B, Culmsee H, Wesche K, Bergmeier E, Leuschner C (2011) Habitat loss of floodplain meadows in North Germany since the 1950s. Biodivers Conserv 20:2347-2364

Kröncke I, Boersma M, Czeck R, Dippner JW, Ehrich S, Exo KM, Hüppop O, Malzahn A, Marencic H, Markert A, Millat G, Neumann H, Reiss H, Sell AF, Sobottka M, Wehrmann A, Wiltshire KH, Wirtz K (2012) Auswirkungen auf marine Lebensräume. In: Mosbrugger V, Brasseur G, Schaller M, Stribrny B (Hrsg) Klimawandel und Biodiversität - Folgen für Deutschland. WBG, Darmstadt, S 106-127

Krüger F, Urban B (2014) Schadstoffregime in Auenböden der Elbe. In: Prüter J, Keienburg T, Schreck C (Hrsg) Klimafolgenanpassung im Biosphärenreservat Niedersächsische Elbtalaue - Modellregion für nachhaltige Entwicklung. Berichte aus den KLIMZUG-NORD Modellgebieten, Bd. 5. TuTech Verlag, Hamburg

Kühn I, Brandl R, Klotz S (2004) The flora of German cities is naturally species rich. Evol Ecol Res 6(5):749-764

Kühn I, Pompe S, Trautmann S, Böhning-Gaese K, Essl F, Rabitsch W (2013) Arealänderungen in der Zukunft. In: Essl F, Rabitsch W (Hrsg) Biodiversität und Klimawandel. Auswirkungen und Handlungsoptionen für den Naturschutz in Mitteleuropa. Springer, Berlin, Heidelberg, S 86-101

Kuttler W (2010) Urbanes Klima. In: Gefahrstoffe - Reinhaltung der Luft. Umweltmeteorologie 70:329-340 (S. 378-382)

LABO (2010) LABO-Positionspapier - Klimawandel - Betroffenheit und Handlungsempfehlungen des Bodenschutzes. Stand 9.6.2010

Lal R (2010) Managing soils for a warming earth in a food-insecure and energystarved world. J Plant Nutr Soil Sci 173:4-15

Lal R (2014) Principles and practices of soil resource conservation. eLS. Wiley, Chichester

LANU - Landesamt für Natur und Umwelt Schleswig-Holstein (2006) Die Böden Schleswig-Holsteins - Entstehung, Verbreitung, Nutzung, Eigenschaften und Gefährdung. In: Schriftenreihe LANU SH. Geologie und Boden 11. LANU, Flintbek

LANUV - Landesamt für Natur, Umwelt und Verbraucherschutz NordrheinWestfalen (2015) Kühlleistung von Böden. Leitfaden zur Einbindung in stadtklimatische Konzepte in NRW. LANUV-Arbeitsblatt 29.

Le Conte Y, Navajas M (2008) Climate change: impact on honey bee populations and diseases. Rev Sci Tech 27(2):499-510 
Le Quéré C, Raupach MR, Canadell JG, Marland G, Bopp L, Ciais P, Conway TJ, Doney SC, Feely RA, Foster P, Friedlingstein P, Gurney K, Houghton RA, House Jl, Huntingford C, Levy PE, Lomas MR, Majkut J, Metzl N, Ometto JP, Peters GP, Prentice IC, Randerson JT, Running SW, Sarmiento JL, Schuster U, Sitch S, Takahashi T, Viovy N, van der Werf GR, Woodward FI (2009) Trends in the sources and sinks of carbon dioxide. Nat Geosci 2(12):831-836

Leakey AD, Ainsworth EA, Bernacchi CJ, Rogers A, Long SP, Ort DR (2009) Elevated $\mathrm{CO}_{2}$ effects on plant carbon, nitrogen, and water relations: six important lessons from FACE. J Exp Bot 60:2859-2876

Lenoir J, Gégout JC, Marquet PA, De Ruffray P, Brisse H (2008) A significant upward shift in plant species optimum elevation during the $20^{\text {th }}$ century. Science 320(5884):1768-1771

Lexer MJ, Rabitsch W, Grabherr G, Dokulil MT, Dullinger S, Eitzinger J, Englisch M, EssI F, Gollmann G, Gottfried M, Graf W, Hoch G, Jandl R, Kahrer A, Kainz M Kirisits T, Netherer S, Pauli H, Rott E, Schleper C, Schmidt-Kloiber A, Schmutz S, Schopf A, Seidl R, Vogl W, Winkler H, Zechmeister HG (2014) Der Einfluss des Klimawandels auf die Biosphäre und Ökosystemleistungen. In: APCC (Hrsg) Österreichischer Sachstandsbericht Klimawandel 2014 (AAR14) Austrian Panel on Climate Change (APCC), Verlag der Österreichischen Akademie der Wissenschaften, Wien, S 467-556

Lu P, Yu Q, Liu J, Lee X (2006) Advance of tree-flowering dates in response to urban climate change. Agr For Meteorol 138(1):120-131

Ludewig K, Korell L, Löffler F, Scholz M, Mosner E, Jensen K (2014a) Vegetation patterns of floodplain meadows along the climatic gradient at the middle Elbe river. Flora 209:446-455

Ludewig K, Hanke JM, Korell L, Jensen K (2014b) Mögliche Auswirkungen des Klimawandels auf die Vegetation von Auenwiesen entlang der mittleren Elbe. In: Prüter J, Keienburg T, Schreck C (Hrsg) Klimafolgenanpassung im Biosphärenreservat Niedersächsische Elbtalaue - Modellregion für nachhaltige Entwicklung. Berichte aus den KLIMZUG-NORD Modellgebieten, Bd. 5. TuTech Verlag, Hamburg

Luo Y, Melillo J, Niu S, Beier C, Clark JS, Classen AT, Davidson E, Dukes JS, Evans RD, Field CB, Czimczik Cl, Keller M, Kimball BA, Kueppers LM, Norby RJ, Pelini SL, Pendall E, Rastetter E, Six J, Smith M, Tjoelker MG, Torn MS (2011) Coordinated approaches to quantify long-term ecosystem dynamics in response to global change. Glob Change Biol 17(2):843-854

Lurgi M, López BC, Montoya JM (2012) Novel communities from climate change. P Roy Soc Lond B Bio 367(1605):2913-2922

Manthey M, Leuschner C, Härdtle W (2007) Buchenwälder und Klimawandel. Nat Landsch 82(9/10):441-445

Marhan S, Rempt F, Högy P, Fangmeier A, Kandeler E (2010) Effects of Aporrectodea caliginosa (Savigny) on nitrogen mobilization and decomposition of elevated- $\mathrm{CO}_{2}$ Charlock mustard litter. J Plant Nutr Soil Sci 173:861-868

Mathey J, Rößler S, Lehmann I, Bräuer A, Goldberg V, Kurbjuhn C, Westheld A (2012) Noch wärmer, noch trockener? Stadtnatur und Freiraumstrukturen im Klimawandel. Naturschutz Biol Vielfalt 111:1-220

Maxwell RM, Kollet SJ (2008) Interdependence of groundwater dynamics and land energy feedbacks under climate change. Nat Geosci 1:665-669

McCain CM, Colwell RK (2011) Assessing the threat to montane biodiversity from discordant shifts in temperature and precipitation in a changing climate. Ecol Lett 14(12):1236-1245

Menge DNL, Field CB (2007) Simulated global changes alter phosphorus demand in annual grassland. Glob Change Biol 13(12):2582-2591

Menzel A (2013) Plant phenological "fingerprints". In: Schwartz MD (Hrsg) Phenology: an integrative environmental science. Springer, Dordrecht, $\mathrm{S}$ 335-350

Menzel A, Fabian P (1999) Growing season extended in Europe. Nature 397(6721):659-659

Menzel A, Sparks TH, Estrella N, Koch E, Aasa A, Ahas R, Alm-Kübler K, Bissolli P, Braslavská O, Briede A, Chmielewski FM, Crepinsek Z, Curnel Y, Dahl Å, Defila C, Donnelly A, Filella Y, Jatczak K, Måge F, Mestre A, Nordli Ø, Peñuelas J, Pirinen $P$, Remišová V, Scheifinger $H$, Striz M, Susnik A, van Vliet AJH, Wielgolaski F-E, Zach S, Zust A (2006a) European phenological response to climate change matches the warming pattern. Glob Change Biol 12(10):1969-1976

Menzel A, Sparks TH, Estrella N, Roy DB (2006b) Altered geographic and temporal variability in phenology in response to climate change. Global Ecol Biogeogr 15(5):498-504
Metropolregion Hamburg (o. J.) Flächennutzung: Siedlungs- und Verkehrsfläche nach Art der tatsächlichen Nutzung

Metzing D (2005) Küstenflora und Klimawandel: Der Einfluss der globalen Erwärmung auf die Gefäßpflanzenflora des deutschen Küstengebietes von Nord- und Ostsee. Dissertation. Universität Oldenburg, Oldenburg

Meyer-Grünefeldt M, Friedrich U, Klotz M, Von Oheimb G, Härdtle W (2015a) Nitrogen deposition and drought events have non-additive effects on plant growth - Evidence from greenhouse experiments. Plant Biosyst 149(2):424-432

Meyer-Grünefeldt M, Calvo L, Marcos E, Oheimb G, Härdtle W (2015b) Impacts of drought and nitrogen addition on Calluna heathlands differ with plant life-history stage. J Ecol 103(5):1141-1152

Miehlich G (2010) Die Böden Hamburgs. In: Poppendieck H-H, Bertram H, Brandt I, Engelschall B, v PJ (Hrsg) Der Hamburger Pflanzenatlas. Dölling \& Galitz, München, Hamburg, S 18-27

Miehlich G (2015) Böden der Stadt - Plädoyer für einen direkten Draht zum Boden. architekt 1(15):27-35

Montoya JM, Raffaelli D (2010) Climate change, biotic interactions and ecosystem services. P Roy Soc Lond B Bio 365(1549):2013-2018

Morales P, Hickler T, Rowell DP, Smith B, Sykes MT (2007) Changes in European ecosystem productivity and carbon balance driven by regional climate model output. Glob Change Biol 13:108-122

Moritz C, Agudo R (2013) The future of species under climate change: resilience or decline? Science 341(6145):504-508

Morris JT, Sundareshwar PV, Nietch CT, Kjerfve B, Cahoon DR (2002) Responses of coastal wetlands to rising sea level. Ecology 83:2869-2877

Müller-Kroehling S, Walentowski H, Bußler H, Kölling C (2009) Natürliche Fichtenwälder im Klimawandel - hochgradig gefährdete Ökosysteme. LWF Wissen 63:70-85

Myneni RB, Keeling CD, Tucker CJ, Asrar G, Nemani RR (1997) Increased plant growth in the northern high latitudes from 1981 to 1991. Nature 386:698702

Nehring S, Hesse KJ (2008) Invasive alien plants in marine protected areas: the Spartina anglica affair in the European Wadden Sea. Biol Invasions 10(6):937-950

Nehring S, Kowarik I, Rabitsch W, Essl F (2013) Naturschutzfachliche Invasivitätsbewertungen für in Deutschland wild lebende gebietsfremde Gefäßpflanzen. BfN-Skripten 352. BfN, Bonn Bad Godesberg

Nemani RR, Keeling CD, Hashimoto H, Jolly WM, Piper SC, Tucker CJ, Myneni RB, Running SW (2003) Climate-driven increases in global terrestrial net primary production from 1982 to 1999 . Science 300(5625):1560-1563

Nentwig W (2010) Invasive Arten. Haupt, Bern

Neubauer SC, Craft CB (2009) Global change and tidal freshwater wetlands: scenarios and impacts. In: Barendregt A, Whigham DF, Baldwin AH (Hrsg) Tidal freshwater wetlands. Backhuys, Leiden, S 253-266

Nolte S, Müller F, Schuerch M, Wanner A, Esselink P, Bakker JP, Jensen K (2013) Does livestock grazing affect sediment deposition and accretion rates in salt marshes? Estuar Coast Shelf Sci 135:296-305

Ovaskainen O, Skorokhodova S, Yakovleva M, Sukhov A, Kutenkov A, Kutenkova N, Shcherbakov A, Meyke E, del Mar Delgado M (2013) Community-level phenological response to climate change. P Natl Acad Sci Usa 110(33):13434-13439

Overbeck F (1975) Botanisch-geologische Moorkunde: unter besonderer Berücksichtigung der Moore Nordwestdeutschlands als Quellen zur Vegetations-, Klima- und Siedlungsgeschichte. Wachholtz, Neumünster

Pan Y, Birdsey RA, Fang J, Houghton R, Kauppi PE, Kurz WA, Phillips OL, Shvidenko A, Lewis SL, Canadell JG, Ciais P, Jackson RB, Pacala SW, McGuire AD, Piao S, Rautiainen A, Sitch S, Hayes D (2011) A large and persistent carbon sink in the world's forests. Science 333(6045):988-993

Parmesan C (2007) Influences of species, latitudes and methodologies on estimates of phenological response to global warming. Glob Change Biol 13(9):1860-1872

Parmesan C, Yohe G (2003) A globally coherent fingerprint of climate change impacts across natural systems. Nature 421(6918):37-42

Pauchard A, Kueffer C, Dietz H, Daehler CC, Alexander J, Edwards PJ, Arevalo JR, Cavieres LA, Guisan A, Haider S, Jakobs G, McDougall K, Millar Cl, Naylor BJ, Parks CG, Rew LJ, Seipel T (2009) Ain't no mountain high enough: plant invasions reaching new elevations. Front Ecol Environ 7(9):479-486 
Pauli H, Gottfried M, Reiter K, Klettner C, Grabherr G (2007) Signals of range expansions and contractions of vascular plants in the high Alps: observations (1994-2004) at the GLORIA master site Schrankogel, Tyrol, Austria. Glob Change Biol 13:147-156

Pauli H, Gottfried M, Dullinger S, Abdaladze O, Akhalkatsi M, Alonso JLB, Coldea G, Dick J, Erschbamer B, Calzado RF, Ghosn D, Holten JI, Kanka R, Kazakis G, Kollar J, Larsson P, Moiseev P, Moiseev D, Molau U, Mesa JM, Nagy L, Pelino G, Puscas M, Rossi G, Stanisci A, Syverhuset AO, Theurillat JP, Tomaselli M, Unterluggauer P, Villar L, Vittoz P, Grabherr G (2012) Recent plant diversity changes on Europe's mountain summits. Science 336(6079):353-355

Peñuelas J, Sardans J, Estiarte M, Ogaya R, Carnicer J, Coll M, Barbeta A, RivasUbach A, Llusia J, Garbulsky M, Filella I, Jump AS (2013) Evidence of current impact of climate change on life: a walk from genes to the biosphere. Glob Change Biol 19(8):2303-2338

Pfeiffer E-M (1998) Methanfreisetzung aus hydromorphen Böden verschiedener naturnaher und genutzter Feuchtgebiete (Marsch, Moor, Tundra, Reisanbau). Hambg Bodenkd Arb 37:207

Poll C, Marhan S, Back F, Niklaus PA, Kandeler E (2013) Field-scale manipulation of soil temperature and precipition change soil $\mathrm{CO}_{2}$ flux in a temperate agricultural ecosystem. Agricult Ecosyst Environ 165:88-97

Pompe S, Hanspach J, Badeck F, Klotz S, Thuiller W, Kühn I (2008) Climate and land use change impacts on plant distributions in Germany. Biol Lett 4(5):564-567

Pompe S, Berger S, Bergmann J, Badeck F-W, Lübbert J, Klotz S, Rehse A-K, Söhlke G, Sattler S, Walther G-R, Kühn I (2011) Modellierung der Auswirkungen des Klimawandels auf die Flora und Vegetation in Deutschland. BfN-Skripten 304., S 1-193

Poppendieck HH (2010) Hamburger Artenvielfalt. In: Poppendieck HH, Bertram H, Brandt I, Engelschall B, von Prondzinski J (Hrsg) Der Hamburger Pflanzenatlas von A bis Z. Dölling \& Galitz, München, Hamburg, S 99-111

Poppendieck HH, Brandt I (2010) Grünland. In: Poppendieck HH, Bertram H, Brandt I, Engelschall B, von Prondzinski J (Hrsg) Der Hamburger Pflanzenatlas von A bis Z. Dölling \& Galitz, München, Hamburg, S 61-67

Poppendieck HH, Bertram H, Brandt I, Engelschall B, von Prondzinski J (Hrsg) (2010) Der Hamburger Pflanzenatlas von A bis Z. Dölling \& Galitz, München, Hamburg

Pott R (1999) Lüneburger Heide. Ulmer, Stuttgart

Potts SG, Biesmeijer JC, Kremen C, Neumann P, Schweiger O, Kunin WE (2010) Global pollinator declines: trends, impacts and drivers. Trends Ecol Evol 25(6):345-353

Pretzsch H (1999) Waldwachstum im Wandel. Forstwiss Cbl 118:228-250

Prochnow A, Risius H, Hoffmann T, Chmielewski FM (2015) Does climate change affect period, available field time and required capacities for grain harvesting in Brandenburg, Germany? Agr For Meteorol 203:43-53

van der Putten WH, de Ruiter PC, Bezemer TM, Harvey JA, Wassen M, Wolters V (2004) Trophic interactions in a changing world. Basic Appl Ecol 5(6):487494

Rabitsch W, Herren T (2013) Phänologie. In: Essl F, Rabitsch W (Hrsg) Biodiversität und Klimawandel. Auswirkungen und Handlungsoptionen für den Naturschutz in Mitteleuropa. Springer, Berlin, Heidelberg, S 52-58

Rabitsch W, Essl F, Kühn I, Nehring S, Zangger A, Bühler C (2013a) Arealänderungen. In: Essl F, Rabitsch W (Hrsg) Biodiversität und Klimawandel. Auswirkungen und Handlungsoptionen für den Naturschutz in Mitteleuropa. Springer, Berlin, Heidelberg, S 59-66

Rabitsch W, EssI F, Kruess A, Nehring S, Nowack C, Walther GR (2013b) Biologische Invasionen und Klimawandel. In: Essl F, Rabitsch W (Hrsg) Biodiversität und Klimawandel. Auswirkungen und Handlungsoptionen für den Naturschutz in Mitteleuropa. Springer, Berlin, Heidelberg, S 66-74

Raupach MR, Canadell JG, Le Quéré C (2008) Anthropogenic and biophysical contributions to increasing atmospheric $\mathrm{CO}_{2}$ growth rate and airborne fraction. Biogeosciences 5(6):1601-1613

Ringenberg J, von Prondzinski J (2010) Hafen, Industrie und Verkehr. In: Poppendieck HH, Bertram H, Brandt I, Engelschall B, von Prondzinski J (Hrsg) Der Hamburger Pflanzenatlas von A bis Z. Dölling \& Galitz, München, Hamburg, S 93-97

Roberts PD (2012) Spartina anglica C.E. Hubbard (English cord-grass). In: Francis RA (Hrsg) A handbook of global freshwater invasive species. Earthscan, New York, S 113-123
Rötzer T, Wittenzeller M, Haeckel H, Nekovar J (2000) Phenology in central Europe - differences and trends of spring phenophases in urban and rural areas. Int J Biometeorol 44(2):60-66

Root TL, Price JT, Hall KR, Schneider SH, Rosenzweig C, Pounds JA (2003) Fingerprints of global warming on wild animals and plants. Nature 421(6918):5760

Rosenthal G, Hildebrandt J, Zöckler C, Hengstenberg M, Mossakowski D, Lakomy W, Burfeindt I (1998) Feuchtgrünland in Norddeutschland. Ökologie, Zustand, Schutzkonzepte. Angewandte Landschaftsökologie 15.

Russell DJ, Sticht C, Schrader S, Wegel H-J (2014) Vielfalt und Funktion der Bodenfauna. In: Hüttl RF, Russell DJ, Sticht C, Schrader S, Weigel H-J, Bens O, Lorenz K, Schneider B, Schneider BU: Auswirkungen auf Bodenökosysteme. In: Mosbrugger V, Brasseur G, Schaller M, Stirbrny B (Hrsg) Klimawandel und Biodiversität - Folgen für Deutschland. 2. Aufl. WBG, Darmstadt

Schaller M, Weigel HJ (2007) Analyse des Sachstands zu Auswirkungen von Klimaveränderungen auf die deutsche Landwirtschaft und Maßnahmen zur Anpassung. Landbauforschung Völkenrode, Sonderheft 316.

Schaller M, Beierkuhnlein C, Rajmis S, Schmidt T, Nitsch H, Liess M, Kattwinkel $M$, Settele J (2012) Auswirkungen auf landwirtschaftlich genutzte Lebensräume. In: Mosbrugger V, Brasseur G, Schaller M, Stribrny B (Hrsg) Klimawandel und Biodiversität - Folgen für Deutschland. WBG, Darmstadt, $S$ 222-259

Scharnke M, Krüger F, Urban B, Schneider W (2014) Modellierung von klimainduzierten Veränderungen des Bodenwasserhaushalts von Auenböden an der unteren Mittelelbe. In: Prüter J, Keienburg T, Schreck C (Hrsg) Klimafolgenanpassung im Biosphärenreservat Niedersächsische Elbtalaue - Modellregion für nachhaltige Entwicklung. Berichte aus den KLIMZUG-NORD Modellgebieten, Bd. 5. TuTech, Hamburg

Scheffer F, Schachtschabel P (2010) Lehrbuch der Bodenkunde, 16. Aufl. Springer, Heidelberg

Scherber C, Eisenhauer N, Weisser WW, Schmid B, Voigt W, Fischer M, Schulze ED, Roscher C, Weigelt A, Allan E, Beßler H, Bonkowski M, Buchmann N, Buscot F, Clement LW, Ebeling A, Engels C, Halle S, Kertscher I, Klein AM, Koller R, König S, Kowalski E, Kummer V, Kuu A, Lange M, Lauterbach D, Middelhoff C, Migunova VD, Milcu A, Müller R, Partsch S, Petermann JS, Renker C, Rottstock T, Sabais A, Scheu S, Schumacher J, Temperton VM, Tscharntke T (2010) Bottom-up effects of plant diversity on multitrophic interactions in a biodiversity experiment. Nature 468:553-556

Schils R, Kuikman P, Liski J, Van Oijen M, Smith P, Webb J, Alm J, Somogyi Z, Van den Akker J, Billett M, Emmett B, Evans C, Lindner M, Palosuo T, Bellamy $P$, Alm J, Jandl R, Hiederer R (2008) Final report: review of existing information on the interrelations between soil and climate change. ClimSoil. Alterra, Wageningen

Schipull K (1999) Die Naturlandschaften im Großraum Hamburg - kurze Erläuterungen zu einer Übersichtskarte. Hambg Geogr Stud 48:1-7

Schlichting E (1960) Typische Böden Schleswig-Holsteins. Schriftenreihe der landwirtschaftlichen Fakultät der Universität Kiel, Bd. 26. Universität Kiel, Kiel

Schlünzen KH, Linde M (Hrsg) (2014) Wilhelmsburg im Klimawandel - Ist-Situation und mögliche Veränderungen. Berichte aus den KLIMZUG-NORD Modellgebieten, Bd. 4. TuTech, Hamburg

Schlünzen KH, Hoffmann P, Rosenhagen G, Riecke W (2010) Long-term changes and regional differences in temperature and precipitation in the metropolitan area of Hamburg. Int J Climatol 30(8):1121-1136

Schmelmer K, Urban B (2014) Auswirkungen von Klimaänderungen auf den Bodenwasserhaushalt sandiger Ackerböden; Modellierungen im lokalen Maßstab. In: Urban B, Becker J, Mersch I, Meyer W, Rechid D, Rottgardt E (Hrsg) Klimawandel in der Lüneburger Heide - Kulturlandschaften zukunftsfähig gestalten. Berichte aus den KLIMZUG-NORD Modellgebieten, Bd. 6. TuTech, Hamburg

Schmid B, Balvanera P, Cardinale BJ, Godbold J, Pfisterer AB, Raffaelli D, Solan $M$, Srivastava DS (2009) Consequences of species loss for ecosystem functioning: meta-analyses of data from biodiversity experiments. In: Naeem S, Bunker DE, Hector A, Loreau M, Perrings C (Hrsg) Biodiversity, ecosystem functioning, and human wellbeing: an ecological and economic perspective. Oxford University Press, Oxford, S 14-29 
Schmidt KJ, Poppendieck HH, Jensen K (2014) Effects of urban structure on plant species richness in a large European city. Urban Ecosyst 17(2):427444

Schmidt SR (2014) Sphagnum in a changing world - from the landscape to the isotope scale. Dissertation. Universität Hamburg, Hamburg

Schoenberg W, Butzeck C, Eick D, Jensen K, Magath V, Thiel R, Rottgardt E, Runge K, Heise S, Hsu PC (2014) Lebensraum Elbe-Ästuar - auch 2050 alles im Fluss? In: KLIMZUG-NORD Verbund (Hrsg) Kursbuch Klimaanpassung Handlungsoptionen für die Metropolregion Hamburg. TuTech, Hamburg, S 96-97

Scholes MC, Scholes RJ (2013) Dust unto dust. Science 342:565-566

Schuster C, Estrella N, Menzel A (2014) Shifting and extension of phenological periods with increasing temperature along elevational transects in southern Bavaria. Plant Biol 16(2):332-344

Schwartz R, Gröngröft A, Miehlich G (2000) Charakterisierung und Wasserhaushalt typischer Böden im Überschwemmungsbereich der unteren Mittelelbe. In: Friese K, Witter B, Rode M, Miehlich G (Hrsg) Stoffhaushalt von Auenökosystemen. Böden und Hydrologie, Schadstoffe, Bewertungen. Springer, Berlin, Heidelberg, S 65-78

Schweiger O, Biesmeijer JC, Bommarco R, Hickler T, Hulme PE, Klotz S, Kuehn I, Moora M, Nielsen A, Ohlemüller R, Petanidou T, Potts SG, Pysek P, Stout JC, Sykes MT, Tscheulin T, Vila M, Walther G-R, Westphal C, Winter M, Zobe M, Settele J (2010) Multiple stressors on biotic interactions: how climate change and alien species interact to affect pollination. Biol Rev 85(4):777795

Schweiger O, Essl F, Kruess A, Rabitsch W, Winter M (2013) Erste Änderungen in ökologischen Beziehungen. In: Essl F, Rabitsch W (Hrsg) Biodiversität und Klimawandel. Auswirkungen und Handlungsoptionen für den Naturschutz in Mitteleuropa. Springer, Berlin, Heidelberg, S 75-83

Selsted MB, Van der Linden L, Ibrom A, Michelsen A, Larsen KS, Pedersen JK Mikkelsen TN, Pilegaard K, Beier C, Ambus P (2012) Soil respiration is stimulated by elevated $\mathrm{CO}_{2}$ and reduced by summer drought: three years of measurements in a multifactor ecosystem manipulation experiment in a temperate heathland (CLIMAITE). Glob Change Biol 18:1216-1230

Settele J, Scholes R, Betts R, Bunn S, Leadley P, Nepstad D, Overpeck JT, Taboada MA (2014) Terrestrial and inland water systems. In: IPCC (Hrsg) Climate change 2014: impacts, adaptation and vulnerability. Part A: global and sectoral aspects. Contribution of working group II to the fifth assessment report of the intergovernmental panel on climate change. Cambridge University Press, Cambridge, New York, S 271-359

Simberloff D, Martin J-L, Genovesi P, Maris V, Wardle DA, Aronson J, Courchamp F, Galil B, Garcia-Berthou E, Pascal M, Pyšek P, Sousa R, Tabacchi E, Vila M (2013) Impacts of biological invasions: What's what and the way forward. Trends Ecol Evol 28(1):58-66

Sparks TH, Menzel A, Peñuelas J, Tryjanowski P (2011) Species response to contemporary climate change. In: Millington A, Blumler M, Schickhoff U (Hrsg) Handbook of biogeography. SAGE, London, S 231-242

Spiecker H, Mielikäinen K, Köhl M, Skovsgaard JP (Hrsg) (1996) Growth trends in European forests - studies from 12 countries. Springer, Berlin, Heidelberg

Stoate C, Baldi A, Beja P, Boatman ND, Herzon I, von Doorn A, de Snoo GR, Rakosy L, Ramwell C (2009) Ecological impacts of early 21st century agricultural change in Europe - a review. J Environ Manag 91:22-46

Subke J-A, Bahn M (2010) On the 'temperature sensitivity' of soil respiration: Can we use the immeasurable to predict the unknown? Soil Biol Biochem 42:1653-1656

Succow M, Joosten H (Hrsg) (2001) Landschaftsökologische Moorkunde, 2. Aufl. Schweizerbart, Stuttgart

Suchrow S, Pohlmann N, Stock M, Jensen K (2012) Long-term surface elevation changes in German North Sea salt marshes. Estuar Coast Shelf Sci 98:71-83

Sutmöller J, Spellmann H, Fiebiger C, Albert M (2008) Der Klimawandel und seine Auswirkungen auf die Buchenwälder in Deutschland. Beitr NW FVA 3:135-158

Tang J, Riley WJ (2014) Weaker soil carbon-climate feedbacks resulting from microbial and abiotic interactions. Nat Clim Change 5:56-60

Taylor AR, Schröter D, Pflug A, Wolters V (2004) Response of different decomposer communities to the manipulation of moisture availability: potential effects of changing precipitation patterns. Glob Change Biol 10:1313-1324
Theuerl S, Buscot F (2010) Laccases: toward disentangling their diversity and functions in relation to soil organic matter cycling. Biol Fertil Soils 46:215225

Thompson JR, Gavin H, Refsgaard A, Refstrup Sörensen H, Gowing DJ (2008) Modelling the hydrological impacts of climate change on UK lowland wet grassland. Wetl Ecol Manag 17:503-523

Thuiller W, Lavorel S, Araújo MB, Sykes MT, Prentice IC (2005) Climate change threats to plant diversity in Europe. Proc Natl Acad Sci USA 102:8245-8250

Trnka M, Kersebaum KC, Eitzinger J, Hayes M, Hlavinka P, Svoboda M, Dubrovsky M, Smeradova D, Wardlow B, Pokorny E, Mozny M, Wilhite D, Zalud Z (2013) Consequences of climate change for the soil climate in Central Europe and the central plains of the United States. Clim Change 120:405-418

Trumbore SE, Czimczik CI (2008) An uncertain future for soil carbon. Science 321:1455-1456

Trusilova K, Riecke W (2015) Klimauntersuchung für die Metropolregion Hamburg zur Entwicklung verschiedener meteorologischer Parameter bis zum Jahr 2050. Berichte des Deutschen Wetterdienstes, Bd. 247

Tucker CJ, Slayback DA, Pinzon JE, Los SO, Myneni RB, Taylor MG (2001) Higher northern latitude normalized difference vegetation index and growing season trends from 1982 to 1999. Int J Biometeorol 45(4):184-190

Tylianakis JM, Didham RK, Bascompte J, Wardle DA (2008) Global change and species interactions in terrestrial ecosystems. Ecol Lett 11(12):1351-1363

Umweltbundesamt (Hrsg) (2011) Themenblatt Anpassung an den Klimawandel. Boden. Umweltbundesamt, Dessau-Roßlau

Umweltbundesamt (Hrsg) (2015) Monitoringbericht 2015 zur Deutschen Anpassungsstrategie an den Klimawandel. Bericht der Interministeriellen Arbeitsgruppe der Bundesregierung. Umweltbundesamt, Dessau-Roßlau

Uvarov AV, Tiunov AV, Scheu S (2011) Effects of seasonal and diurnal temperature fluctuations on population dynamics of two epigeic earthworm species in forest soil. Soil Biol Biochem 43:559-570

Vanselow-Algan M (2014) Impact of summer drought on greenhouse gas fluxes and nitrogen availability in a restored bog ecosystem with differing plant communities. Dissertation. Fachbereich Geowissenschaften, Universität Hamburg, Hamburg

Vanselow-Algan M, Schmidt SR, Greven M, Fiencke C, Kutzbach L, Pfeiffer E-M (2015) High methane emissions dominate annual greenhouse gas balances 30 years after bog rewetting. Biogeosci Discuss 12:2809-2842

Varallyay GY (1990) Influence of climatic change on soil moisture regime, texture, structure and erosion. In: Scharpenseel HW, Schomaker M, Ayoub A (Hrsg) Soils on a warmer earth. Dev Soil Sci 20., S 39-49

Varallyay GY (2010) The impact of climate change on soils and their water management. Agron Res 8:385-396

Venterink OH, Davidsson TE, Kiehl K, Leonardson L (2002) Impact of drying and re-wetting on N, P and K dynamics in a wetland soil. Plant Soil 243:119-130

Walentowski H, Kölling C, Ewald J (2007) Die Waldkiefer - bereit für den Klimawandel? LWF Wiss 57:37-46

Walentowski H, Lotsch H, Meier-Uhlherr R (2008) Moore und Klimawandel. LWF Aktuell 67:44-47

Walentowski H, Bolte A, Ibisch PL, Glogner K, Reif A (2009) AFSV-Konzeptpapier Wald im Klimawandel - Möglichkeiten der Risikominderung. Forst Holz 64(9):10-13

Wall DH, Virginia RA (2000) The world beneath our feet: soil biodiversity and ecosystem functioning. In: Raven PH (Hrsg) Nature and human society: the quest for a sustainable world. National Academy of Sciences Press, Washington, S 225-241

Wall DH, Bradford MA, St John MG, Trofymow JA, Behan-Pelletier VI, Bignell DE, Dangerfield JM, Parton WJ, Rusek J, Voigt W, Wolters V, Gardel HZ, Ayuke FO, Bashford R, Beljakova OI, Bohlen PJ, Brauman A, Flemming S, Henschel JR, Johnson DL, Jones TH, Kovarova M, Kranabetter JM, Kutny L, Lin K-C, Maryati M, Masse D, Pokarzhevskii A, Rahman H, Sabara MG, Salamon J-A, Swift MJ, Varela A, Vasconcelos HL, White D, Zou X (2008) Global decomposition experiment shows soil animal impacts on decomposition are climate-dependent. Glob Change Biol 14:2661-2677

Walther G-R, Post E, Convey P, Menzel A, Parmesan C, Beebee TJC, Fromentin J-M, Hoegh-Guldberg O, Bairlein F (2002) Ecological responses to recent climate change. Nature 416(6879):389-395

Walther G-R, Berger S, Sykes MT (2005) An ecological 'footprint' of climate change. P Roy Soc Lond B Bio 272(1571):1427-1432 
Walther G-R, Gritti ES, Berger S, Hickler T, Tang Z, Sykes MT (2007) Palms tracking climate change. Glob Ecol Biogeogr 16(6):801-809

Walther G-R, Roques A, Hulme PE, Sykes MT, Pyšek P, Kühn I, Zobel M et al (2009) Alien species in a warmer world: risks and opportunities. Trends Ecol Evol 24(12):686-693

Wan S, Norby RJ, Ledford J, Weltzin JF (2007) Responses of soil respiration to elevated $\mathrm{CO}_{2}$, air warming, and changing soils availability in a model oldfield grassland. Glob Change Biol 13:2411-2424

Wang D, Heckathorn SA, Wang X, Philpott SM (2012) A meta-analysis of plant physiological and growth responses to temperature and elevated $\mathrm{CO}_{2}$. Oecologia 169(1):1-13

Warren R, van der Wal J, Price J, Welbergen JA, Atkinson I, Ramirez-Villegas J, Osborn TJ, Jarvis A, Shoo LP, Williams SE, Lowe J (2013) Quantifying the benefit of early climate change mitigation in avoiding biodiversity loss. Nat Clim Change 3(7):678-682

Werner P, Zahner R (2009) Biologische Vielfalt und Städte. Eine Übersicht und Bibliographie. BfN-Skripten 245., S 1-129

Wesche K, Krause B, Culmsee H, Leuschner C (2012) Fifty years of change in central European grassland vegetation: large losses in species richness and animal-pollinated plants. Biol Conserv 150:76-85

Wessolek G, Lorenz M, Schwärzel K, Kayser M (2003) Auswirkungen von Klimaänderungen auf bodenhydrologische Zustandsgrößen: Veränderungen des Bodenwasserhaushaltes, der Biomasseproduktion und der Degradierung der Niedermoore als Folgen des globalen Wandels. Endbericht GLOWA-Elbe, Teilthema „Spreewald“. Kennzeichen: 203015. TU Berlin, Berlin

Wessolek G, Nehls T, Kluge B (2010) Bodenüberformung und Versiegelung. In: Blume H-P, Horn R, Thiele-Bruhn S (Hrsg) Handbuch des Bodenschutzes, 4. Aufl. Wiley-VCH, Weinheim, S 155-169

Wiesner S, Eschenbach A, Ament F (2014) Urban air temperature anomalies and their relation to soil moisture observed in the city of Hamburg. Meteorol Z 23:143-157

Willand A, Buchsteiner D, Höke S, Kaufmann-Boll C (2014) Erarbeitung fachlicher, rechtlicher und organisatorischer Grundlagen zur Anpassung an den Klimawandel aus Sicht des Bodenschutzes - Teilvorhaben 1: Erarbeitung der fachlichen und rechtlichen Grundlagen zur Integration von Klimaschutzaspekten ins Bodenschutzrecht. Texte 57/2014. Umwelt Bundesamt, Dessau-Roßlau

Wilmanns O (1993) Ericaceen-Zwergsträucher als Schlüsselarten. Ber Reinhold Tüxen Ges 5:91-112

Wiltshire KH, Kraberg A (2013) Meere und Küsten: Klimawandel und Biodiversität. In: Essl F, Rabitsch W (Hrsg) Biodiversität und Klimawandel. Auswirkungen und Handlungsoptionen für den Naturschutz in Mitteleuropa. Springer, Berlin, Heidelberg, S 217-223

Wittich KP, Liedtke M (2015) Shifts in plant phenology: a look at the sensitivity of seasonal phenophases to temperature in Germany. Int J Climatol 35(13):3991-4000

Wittig R (1991) Ökologie der Großstadtflora. Flora und Vegetation der Städte des nordwestlichen Mitteleuropas. Fischer, Stuttgart

Wittig R (2002) Siedlungsvegetation. Ulmer, Stuttgart

Wittig R (2008) Gartenflüchtlinge als neue Mitglieder der Dorfflora in Nordrhein-Westfalen. Braunschweiger Geobot Arb 9:481-490

Wittig R, Becker U (2010) The spontaneous flora around street trees in cities - a striking example for the worldwide homogenization of the flora of urban habitats. Flora 205(10):704-709

Wittig R, Uebeler M, Ehmke W (Hrsg) (2008) Die Flora des Hohen Taunus. Geobotanische Kolloquien 21

Wittig R, Kuttler W, Tackenberg O (2012) Urban-industrielle Lebensräume. In: Mosbrugger V, Brasseur G, Schaller M, Stribrny B (Hrsg) Klimawandel und Biodiversität - Folgen für Deutschland. WBG, Darmstadt, S 290-307

Wohlgemuth T, Brang P, Bugmann H, Rigling A, Zimmermann NE (2014) Forschung zu Wald und Klimawandel in Mitteleuropa: eine Werkschau. Schweiz Z Forstwes 165(2):27-36

Working Group (2006) World reference base for soil resources, 2. Aufl. World Soil Resources Reports No. 103. FAO, Rome

Xu Z, Shimizu H, Yagasaki Y, Ito S, Zheng Y, Zhou G (2013) Interactive effects of elevated $\mathrm{CO}_{2}$, drought, and warming on plants. J Plant Growth Regul 32:692-707
Yachi S, Loreau M (1999) Biodiversity and ecosystem productivity in a fluctuating environment: the insurance hypothesis. Proc Natl Acad Sci USA 96:1463-1468

Zaehle S, Bondeau A, Carter TR, Cramer W, Erhard M, Prentice IC, Reginster I, Rounsevell MDA, Sitch S, Smith B, Smith PC, Sykes M (2007) Projected changes in terrestrial carbon storage in Europe under climate and land-use change, 1990-2100. Ecosystems 10(3):380-401

Zarnetske PL, Skelly DK, Urban MC (2012) Biotic multipliers of climate change. Science 336(6088):1516-1518

Zhou L, Tucker CJ, Kaufmann RK, Slayback D, Shabanov NV, Myneni RB (2001) Variations in northern vegetation activity inferred from satellite data of vegetation index during 1981 to 1999. J Geophys R Atmos 106(D17):2006920083

Open Access Dieses Kapitel wird unter der Creative Commons Namensnennung - Nicht kommerziell 4.0 International Lizenz (http://creativecommons.org/licenses/by-nc/4.0/deed.de) veröffentlicht, welche die nicht-kommerzielle Nutzung, Vervielfältigung, Bearbeitung, Verbreitung und Wiedergabe in jeglichem Medium und Format erlaubt, sofern Sie den/die ursprünglichen Autor(en) und die Quelle ordnungsgemäß nennen, einen Link zur Creative Commons Lizenz beifügen und angeben, ob Änderungen vorgenommen wurden.

Die in diesem Kapitel enthaltenen Bilder und sonstiges Drittmaterial unterliegen ebenfalls der genannten Creative Commons Lizenz, sofern sich aus der Abbildungslegende nichts anderes ergibt. Sofern das betreffende Material nicht unter der genannten Creative Commons Lizenz steht und die betreffende Handlung nicht nach gesetzlichen Vorschriften erlaubt ist, ist auch für die oben aufgeführten nicht-kommerziellen Weiterverwendungen des Materials die Einwilligung des jeweiligen Rechteinhabers einzuholen.

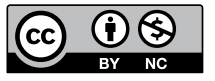

